\title{
DESIGN OF GLOBAL SUSTAINABLE SUPPLY CHAINS
}

A Dissertation

presented to

the Faculty of the Graduate School

at the University of Missouri-Columbia

In Partial Fulfillment

of the Requirements for the Degree

Doctor of Philosophy

by

DIAN TRIHASTUTI

Dr. James Noble, Dissertation Supervisor

December 2019 
The undersigned, appointed by the dean of the Graduate School, have examined the dissertation entitled

\section{DESIGN OF GLOBAL SUSTAINABLE SUPPLY CHAINS}

presented by Dian Trihastuti, a candidate for the degree of Doctor of Philosophy, and hereby certify that, in their opinion, it is worthy of acceptance.

Professor James S. Noble

Professor Luis G. Occena

Professor Ronald McGarvey

Professor Christine Costello 
Dedicated with love and gratitude to my parents, my brothers, and sisters, and everyone who always pray for me, to Jesus my Lord and my Savior who makes all this happen All praises of glory and honor only for Him.

THANK YOU! 


\section{Acknowledgments}

First and foremost, praises and thanks to the Lord God Almighty, for His showers of blessings and providence throughout my $\mathrm{PhD}$ study and research work.

I would like to express my deep and sincere gratitude to my research supervisor Dr. James S. Noble for giving me the opportunity to conduct the research and providing me invaluable insights and guidance throughout the research. His patience, sincerity, support, and motivation have deeply inspired me. He taught me the methodology to carry out the research and to present the research works as clearly as possible. It was both a great honor and a privilege to work and study under his guidance. I am deeply grateful for his friendship, empathy, prayers, and belief in me. All these motivated me to keep challenging myself and to continue moving forward in the endeavor to complete the degree. Dr. Noble is the best advisor I could ever ask for.

I also would like to thank my committee members: Dr. Luis G. Occena, Dr. Ronald McGarvey, and Dr. Christine Costello, for their committed and relentless support during my doctoral study. Our conversations have been insightful and full of valuable advice. They always knew when to encourage me. Dr. Costello particularly spent a great deal of time helping me through the intellectual processes, and we soon became close friends. Along with them, the entire Department of IMSE at the University of Missouri has been my second home for more than five years. All the faculty, staff, and fellow graduate students have provided me with a secure and dynamic place to study and to conduct research. 
I am forever grateful to my parents for their love, prayers, care, and sacrifices for my future education. I also express my thanks to my sisters, brothers, sister-in-law and brothers-in-law, and nephews for their support and fervent prayers. My special thanks go to fellow Indonesian students and families in Columbia, Missouri, who have become my families and companions in good and bad times while I was studying in a foreign land. Your loves and cares help me feel at home.

Last but not least, I would like to thank my funders for their support. It takes money to get a higher degree and conduct research, especially in a foreign country. Thanks to the U.S. Fulbright Student Fellowship for granting me the scholarship that opens the door for me to pursue what has become one of the most challenging, enlightening, and rewarding endeavors I have ever undertaken. I would also like to thank the Center for Excellence in Logistics and Distribution (CELDi), IMSE department and the GIA Scholarship for their financial support of my PhD study, especially this dissertation research.

Finally, my thanks go to all friends, family and everyone who have supported and prayed for me in completing this PhD journey. May God bless you all abundantly. 


\section{Table of Contents}

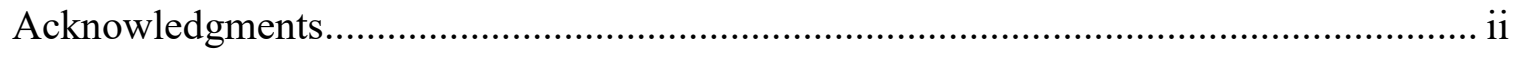

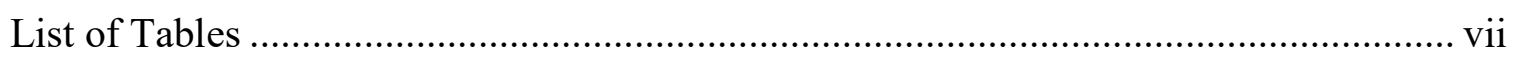

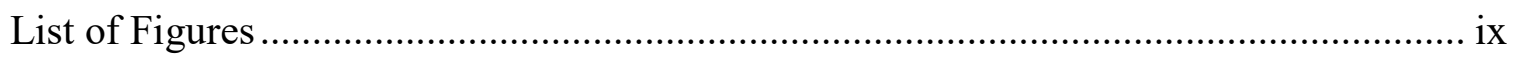

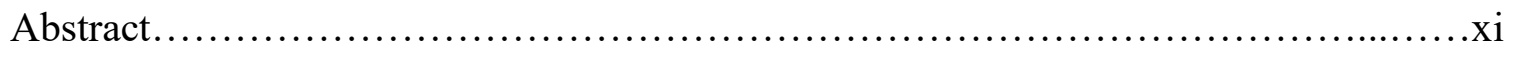

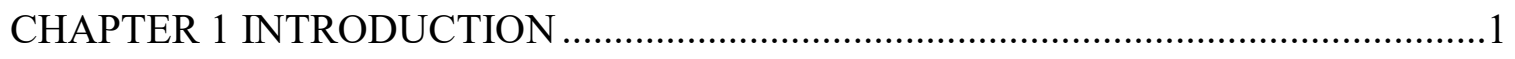

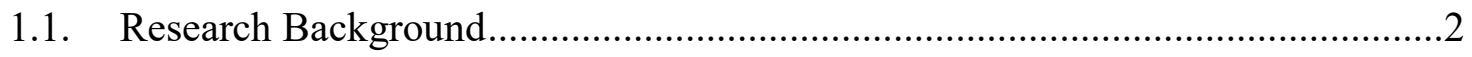

1.2. Research Motivation .............................................................................

1.3. Overview of the Research Problem..................................................................

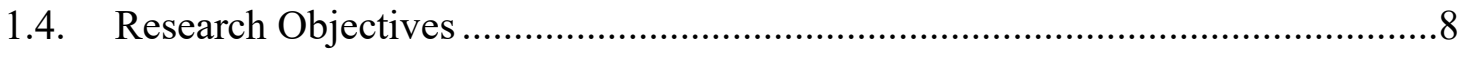

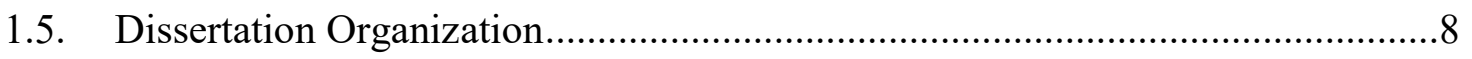

CHAPTER 2 LITERATURE REVIEW ….......................................................... 10

2.1 Sustainable Supply Chain Management .........................................................11

2.2 Sustainable SCM Dimensions....................................................................13

2.3 Methodology to Assess Environmental and Social Impact ................................16

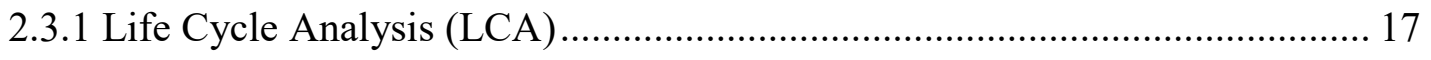

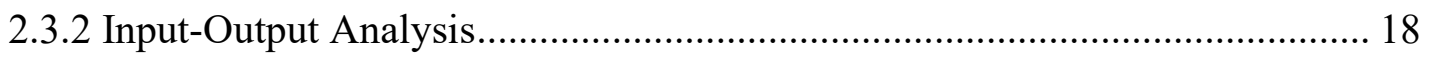

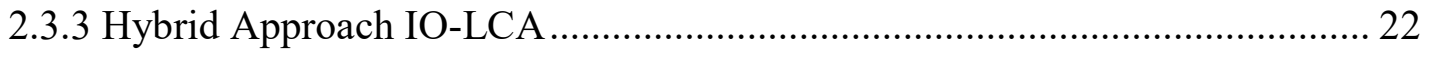


2.4 Integrated Approaches to Sustainable Supply Chain.....

2.4.1 Multi-Criteria Decision Making ................................................................ 24

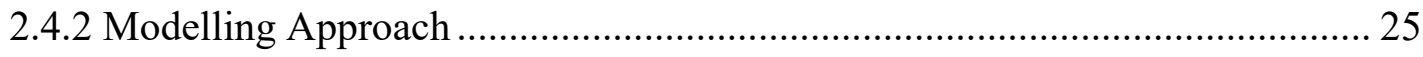

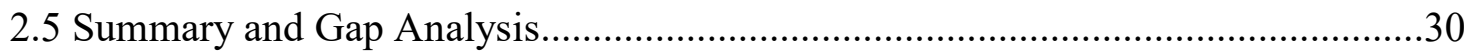

CHAPTER 3 MEASURING SUSTAINABILITY IMPACTS IN TRANSPORT AND

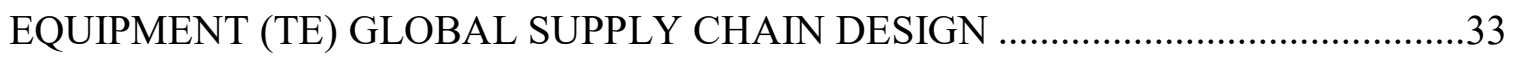

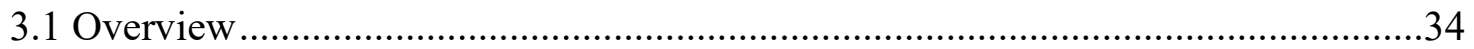

3.2 Literature Review of Sustainability in Global Supply Chain Design .....................35

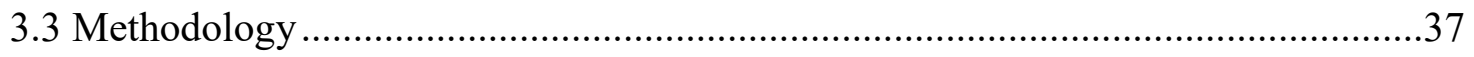

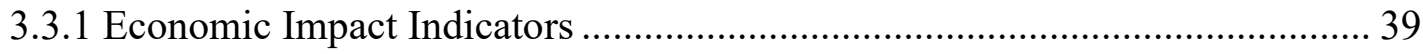

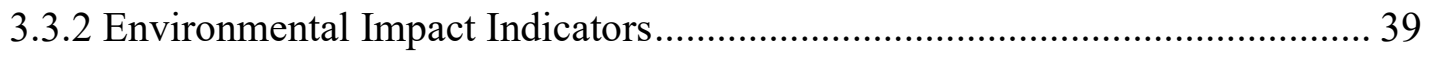

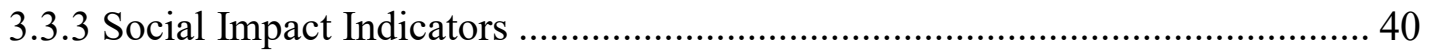

3.3.3 Calculation of environmental and social impact...................................... 44

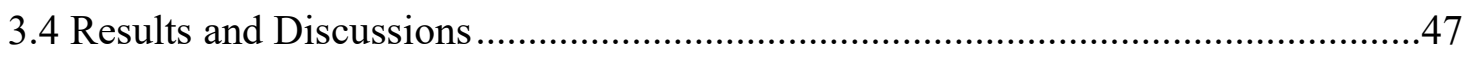

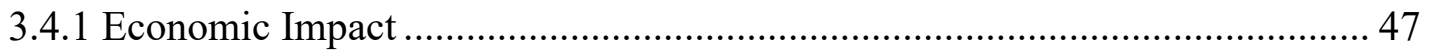

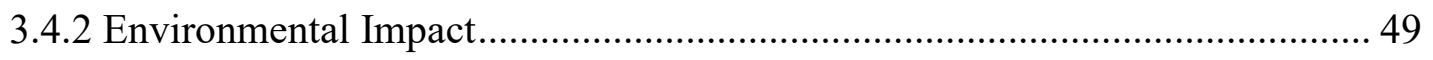

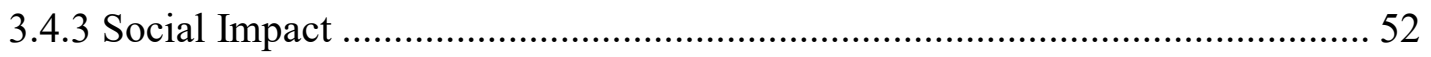

CHAPTER 4 INTEGRATED SUPPLY CHAIN AND INPUT-OUTPUT MODEL........61

4.1 Mathematical Formulation of the Integrated SC-IO Model ...............................63

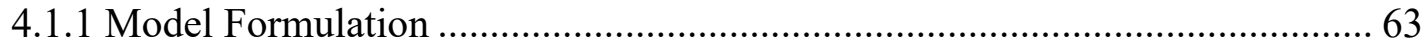


4.2.1 Single Objective Optimization.

4.2.2 The Epsilon Constraint ( $\varepsilon$-constraint) Method. 83

4.3 Summary .86

CHAPTER 5 OPTIMAL PLANNING IN THE GLOBAL SUSTAINABLE SUPPLY CHAIN (GSSC): AN INTEGRATED MULTIOBJECTIVE INPUT-OUTPUT

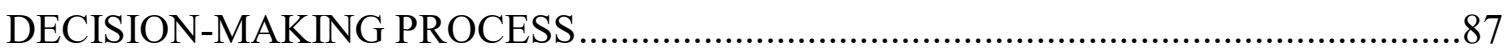

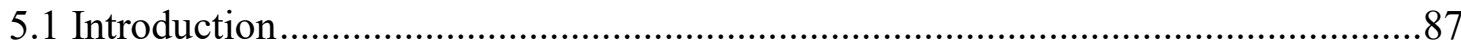

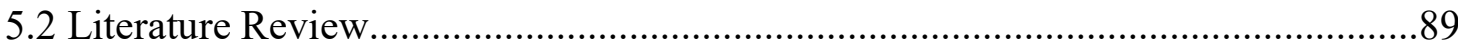

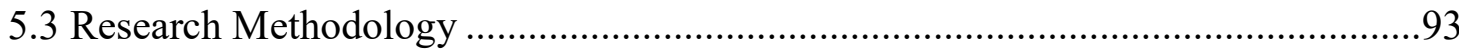

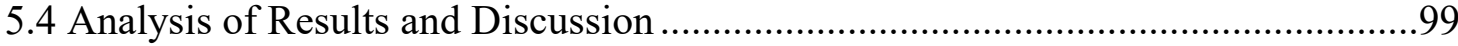

5.5 Conclusion

CHAPTER 6 SUMMARY, CONTRIBUTION, AND FUTURE WORK .....................112

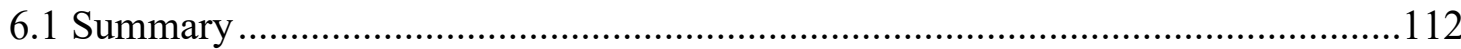

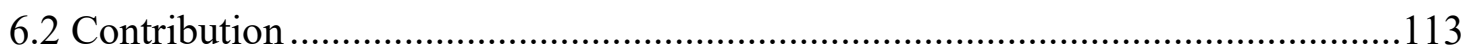

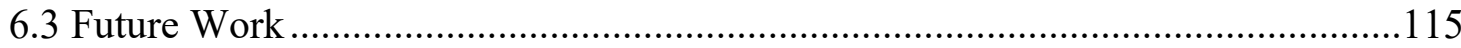

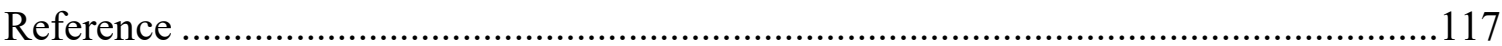

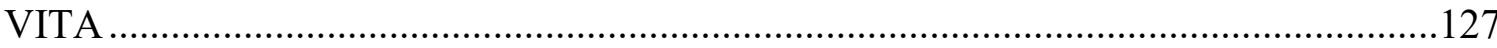




\section{List of Tables}

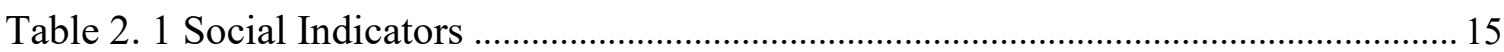

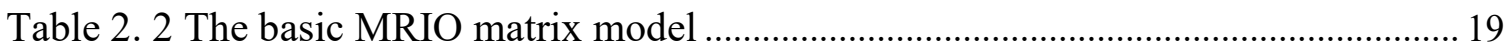

Table 2. 3 Literature of sustainability in the supply chain using IO approach .................. 22

Table 2. 4 Integrated Sustainability in the Supply Chain Literature ................................28

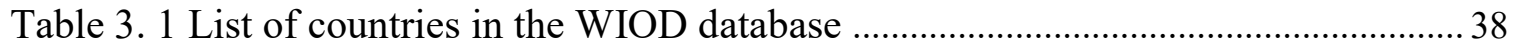

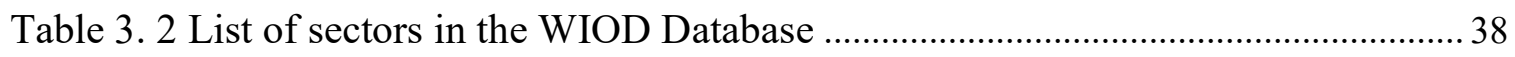

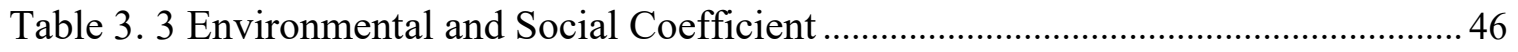

Table 3. 4 Value-Added and Productivity of China and the USA ....................................... 48

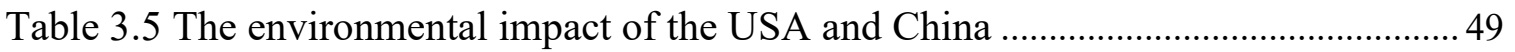

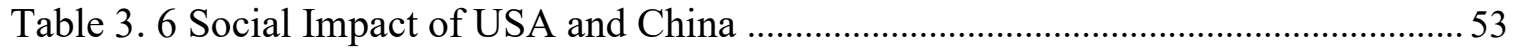

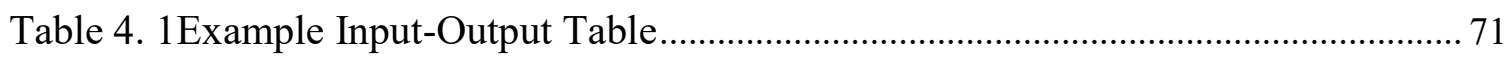

Table 4. 2 The quantity required in the supply chain by country .................................... 71

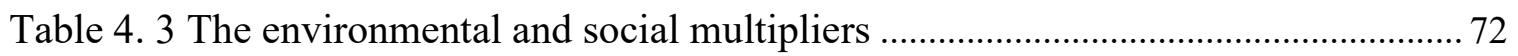

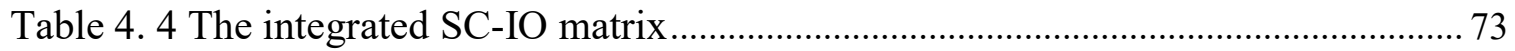

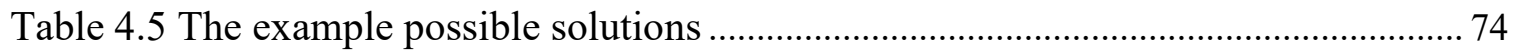

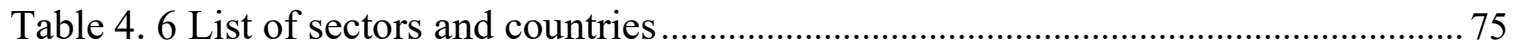

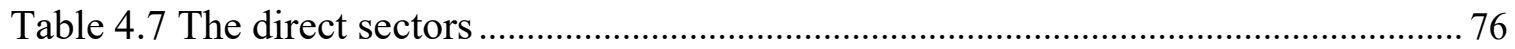

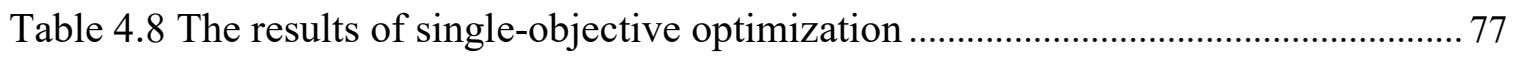

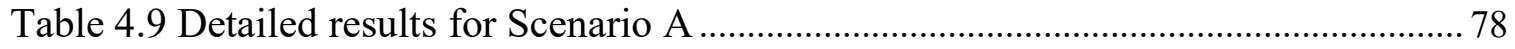

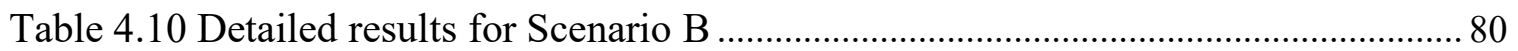

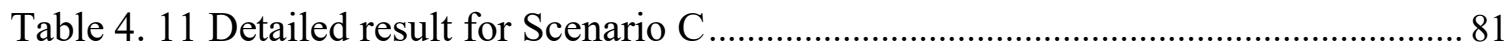


Table 4.12 Solutions obtained by AUGMECON method, where the economic OF is the

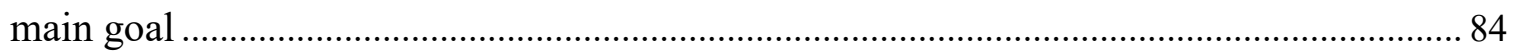

Table 5. 1 Literature in Sustainable Supply Chain Design ................................................. 92

Table 5. 2 Cost Parameter Definitions and Data Sources .................................................... 94

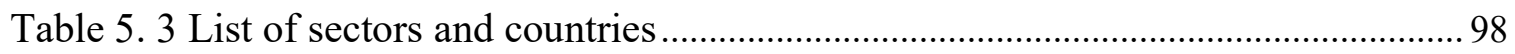

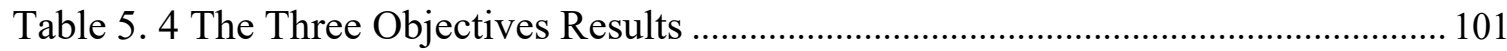

Table 5. 5 Supply Chain Configuration - Three Objectives ........................................... 101

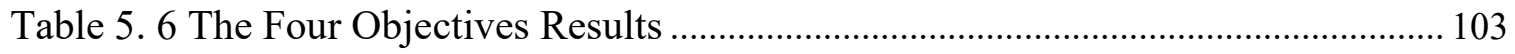

Table 5. 7 Supply Chain Configuration - Four Objectives ............................................ 105

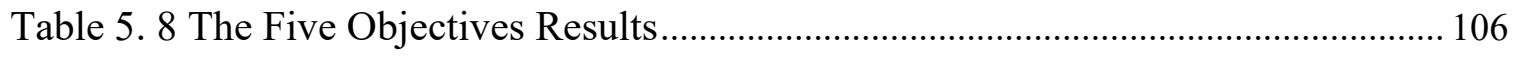

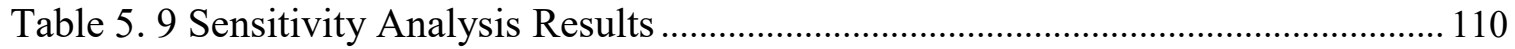




\section{List of Figures}

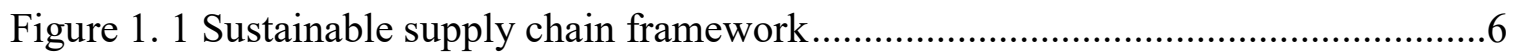

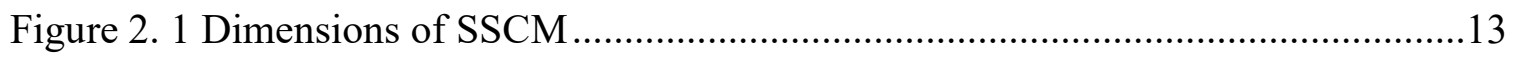

Figure 3. 1 Calculation steps of social impact coefficient ...............................................43

Figure 3. 2 The Calculation Steps for Social Impact....................................................4

Figure 3.3 Production share for 1B USD Demand of sector TE ………………….........47

Figure 3. 4 Domestic production share by sectors .........................................................49

Figure 3. 5 Comparison of $\mathrm{CO}_{2}$ and Energy use emissions in the USA and China...........50

Figure 3. 6 Comparison of Energy Use for sector TE in USA and China .........................50

Figure 3. 7 Comparison of Energy Use for Electricity Industry in the USA and China ...51

Figure 3. 8 Comparison of environmental impact in China and USA by sectors..............52

Figure 3. 9 Proportion of social impacts of sector TE China and the USA ……................53

Figure 3. 10 Distribution of employment intensity in the USA and China ………….......54

Figure 3. 11Distribution of wages intensity in USA and China ......................................55

Figure 3. 12 The working hour impacts by skills ………….........................................5

Figure 3. 13 Number of Vulnerable employment ..........................................................57

Figure 3.14 The proportion of fatal incident in the US and China TE supply chain by

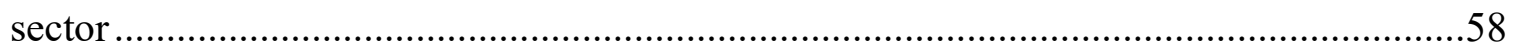

Figure 3. 15 Non-fatal cases by sector in USA and China TE supply chain ......................58

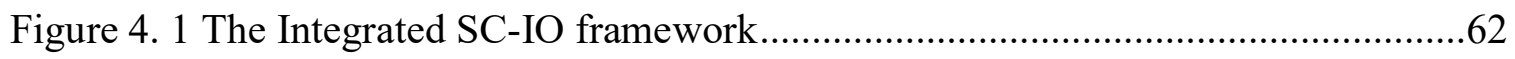

Figure 4. 2 Superstructure of the illustrative example ......................................................69

Figure 4. 3 The Transport and Equipment Supply Chain …………………………........76 
Figure 4. 4 Direct and indirect CO2 emission impact of Scenario A ..............................78

Figure 4. 5 Direct and Indirect Vulnerable Hour of Scenario A....................................79

Figure 4. 6 Direct and indirect $\mathrm{CO}_{2}$ impact of Scenario B ...................................... 80

Figure 4. 7Direct and indirect vulnerable hour impact of Scenario B ............................81

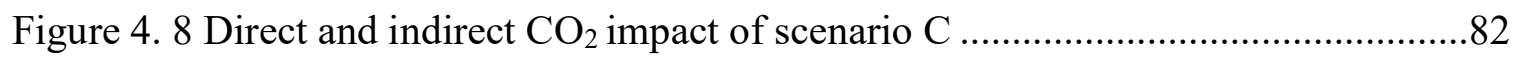

Figure 4. 9 Direct and Indirect vulnerable hour in Scenario C ....................................82

Figure 4. 8 Pareto solution when the economic objective is the main optimization .........85

Figure 5. 1 The Sustainable Supply Chain Design Framework ......................................89

Figure 5. 2 The Transport and Equipment Supply Chain ..........................................98

Figure 5. 3 Pareto Curve Showing the Tradeoff between the Three Objectives .............100

Figure 5. 4 Normalized Pareto Curve Showing Tradeoff between the Four

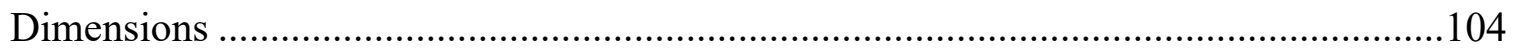

Figure 5. 6 Normalized Pareto Curve Showing Tradeoff between the Five Dimension 107 


\title{
DESIGN OF GLOBAL SUSTAINABLE SUPPLY CHAINS
}

\author{
Dian Trihastuti
}

\author{
Dr. James Noble, Dissertation Supervisor
}

\begin{abstract}
Increasing concern about the sustainability of supply chain operations is motivating companies and organizations to pursue strategies to reduce their contribution to global environmental and social negative impacts. While most papers in the field of sustainable supply chains have focused on economic and environmental performance at the firm level, recently some studies have considered the problem at the national level. However, there still exists a gap in quantitatively modeling social impacts, together with environmental and economic impacts, at the global level.
\end{abstract}

To fill this gap, this research presents a multi-objective mathematical model for the design and planning of a supply chain, integrating the three dimensions of sustainability (economic, environmental, and social). In this research, the economic dimension of sustainability is addressed by considering the costs of the supply chain. Then MRIO, a national input-output table that describes the interdependencies between countries and economic sectors, is integrated with national environmental and social impacts to construct a triple bottom line (3BL) approach by industrial sectors.

This model supports decision making by including both direct impacts, as well as indirect impacts, associated with upstream supply chain paths. This expands the range of impact considered in sustainable performance measurement both within and beyond the supply chain boundary. The integrated model can improve a company's ability to select 
supply chain partners based on a wider range of criteria, rather than being based on economics alone.

A case study is conducted that considers three tiers of the transportation and equipment supply chain, which consists of six industrial sectors that are part of a larger system of fourteen industrial sectors operating across seventeen of the largest manufacturing countries in the world. The model is solved using a $\varepsilon$-constraint method; and the resulting Pareto optimal curves show the tradeoffs between the economic, environmental and social dimensions.

The results reveal that indirect economic activities dominate when contributing to the environmental and social impact of the whole system. Expanding the scope of sustainability changes supply chain configuration decisions. Therefore, the primary result from this research is that firms and industry sectors need to change their focus from solely on economic aspects and include environmental and social aspects in supply chain decision making at operational and/or strategic levels of decisions. 


\section{CHAPTER 1 INTRODUCTION}

There is a growing concern about managing supply chains across a wide range of industries in a sustainable manner. Due to pressure from various stakeholders, such as customers, government regulators, community activists, NGOs; firms cannot ignore environmental and social issues within the supply chain (Gupta and Palsule-Desai, 2011; Hassini et al., 2012; Hutchins and Sutherland, 2008). Firms are being forced to adopt a certain level of commitment to sustainability practices to maintain a competitive advantage. The definition of a sustainable supply chain is the integration of all three dimensions of sustainability development (economic, environmental and social) in managing the supply chain among companies (Seuring and Müller, 2008a).

However, this sustainable management interest has not been followed by a standard approach to evaluate a sustainability initiative's impact on the supply chain. Especially the social aspects of the supply chain are often neglected during the development of a sustainable supply chain model. There is no agreement between how to measure supply chain sustainable performance, nor is there a common model to link sustainability to the supply chain (Hutchins and Sutherland, 2008; Seuring, 2013). Therefore, it is the goal of this research to develop a framework that connects sustainable metrics and performance into strategic supply chain design and to create a model for global sustainable supply chain decision making.

This chapter will describe the background, motivation, and objectives of this research. The chapter begins by providing the research background of sustainability in 
supply chain management. Then it briefly introduces the issues related to sustainable supply chain management which provide the motivation for this research. Next, the research objectives and approaches are described. Finally, the overall research organization is presented.

\subsection{Research Background}

Recently, supply chain management has considered sustainability aspects, such as environmental and social factors, in addition to economics, and included them in decisionmaking. There are some cases, which have illustrated the positive benefit of sustainable supply chain practices on companies, such as Walmart, IKEA, Nike, etc. (Dubey et al., 2015). These cases show that the use of sustainable performance, which integrates three bottom-line issues; economic, environmental and social, is relevant to improve overall supply chain performance.

The concept of triple-bottom-line (3BL) was first coined by John Elkington. He suggested that companies include environmental and social dimensions to measure a company's performance (Savitz and Weber, 2006). The rationale provided is that in a company's operations, they do not solely use financial resources, but also environmental resources, such as energy and water, and social resources, such as community and infrastructure provided by government (Gladwin et al., 1995; Jennings and Zandbergen, 2002; Pagell and Wu, 2009; Savitz and Weber, 2006).

A common practice is that the economic dimension is the first aspect that is addressed in supply chain design. In fact, economic factors have been used as the main 
determinate of company performance. Total cost-based or decisions related to cost and revenue remain the leading performance measures used as the objective in the majority of research (Seuring, 2013). Typical economic indicators include sales, profit, ROI, taxes paid, etc.

The addition of an environmental dimension into the decision process has been reviewed extensively in the published research. Life cycle assessment (LCA) is one of the tools used to assess environmental impacts in the supply chain. Its ability to capture cradle to grave analyses makes LCA a popular method for environmental supply chain research. Typical measures for environmental dimensions are carbon emissions, air, and water quality, energy usage, and waste produced (Savitz and Weber, 2006; Seuring, 2013).

Though there has been considerable effort put into the economic and environmental impacts in the supply chain, little work had been done on the social impacts in supply chains. The main obstacle is that social factors can range from quantitative to qualitative measures that require a comprehensive method for data collection. The availability of data is the main problem for researchers in this area. Existing research that attempts to focus on social factors in the supply chain mainly includes labor practice issues, such as the number of jobs created and labor safety (Alsamawi et al., 2017; Chen et al., 2014; Mota et al., 2015). Other important social issues such as community impact and human rights have seen less investigation (Seuring and Müller, 2008b). Finally, the integration of all three dimensions has received far less consideration in the research literature.

This research will address the social aspects of sustainable supply chain design and develop an integrated model to incorporate 3BL dimensions in global supply chain design decisions. Similar to environmental issues, social issues can be the source of significant 
operational risks in the supply chain (Klassen and Vereecke, 2012). For example, problems related to discrimination litigation, product safety, and labor welfare have resulted in negative publicity (Carter and Jennings, 2002; Maloni and Brown, 2006). Moreover, collaborative practices in supply chain management between a firm with its suppliers, customers, and stakeholders can improve social outcomes.

\subsection{Research Motivation}

There are two factors that motivate the research undertaken in this study. First, the research focuses on social factors in the supply chain which is still very limited due to being a difficult multi-disciplinary and multi-stakeholder issue (Pishvaee et al., 2012). The challenge that has been discussed in the literature is that there is no agreement yet between researchers and practitioners of the supply chain about the social indicators needed to assess sustainable supply chain performance. Although there have been several attempts to provide frameworks and metrics for social factor analysis, the social factor data is rarely available or hard to obtain (Benoit-Norris et al., 2012; Benoît-Norris et al., 2011; Dreyer et al., 2005). Since the data collection process requires significant cost and time, this results in ignoring social factors in the SSCM analysis.

Considering the importance of sustainable supply chains, a wider perspective that covers macroeconomic social aspects is necessary. Several organizations, such as the United Nation and World Bank, have posted national data to depict country-based social performance. Although the data is aggregated by industry sectors, it can be used as the 
preliminary data to analyze the social aspects in the supply chain design decision-making process.

The second motivation for this study is to fill the gap in the integration of three sustainability dimensions in supply chain management decision making. As mentioned previously, the research in this area is still very limit, while there is a need for an integrated model for the development of sustainable supply chains. Most of the literature only provides theoretical concepts for the integration of the three dimensions in the supply chain, without an applicable method or model to put it into practice. Existing research often focuses on the tradeoffs among economic and environmental aspects to build an integrated model. Thus, this leaves plenty of opportunities for research in this area.

Finally, for organizations operating at an international level, economic, environmental, and social aspects are without borders (Foran et al., 2005). Therefore, a model that integrates at the macro-level economic, environment and social factors is necessary to ensure that companies are able to optimize economic objectives, as well as not harm the environment and community worldwide. To the best of our knowledge, there is no literature considering the $3 \mathrm{BL}$ of the sustainable dimensions to design the supply chain network from a global perspective (Seuring, 2013). As a result of all these issues, the research problem being addressed is unique compared to the existing research.

\subsection{Overview of the Research Problem}

As mentioned previously, sustainable supply chains include complex multidisciplinary and multi-stakeholder issues. Typically, different stakeholders become the 
drivers that lead a supply chain to apply sustainability (3BL) initiatives. The research focused on sustainable supply chain analysis usually measures the impact of each sustainability dimension individually. The number of research works on the integration between the economic dimension in the supply chain with environmental aspects have recently increased, but not so much on the integration of the three dimensions. In practice, the three dimensions are interdependent on each other, thus change in one dimension may impact other dimensions. Sustainability performance indicators are grouped under three sections covering the economic, environmental, and social dimensions of sustainability. Figure 1.1 illustrates the framework of a sustainable supply chain.

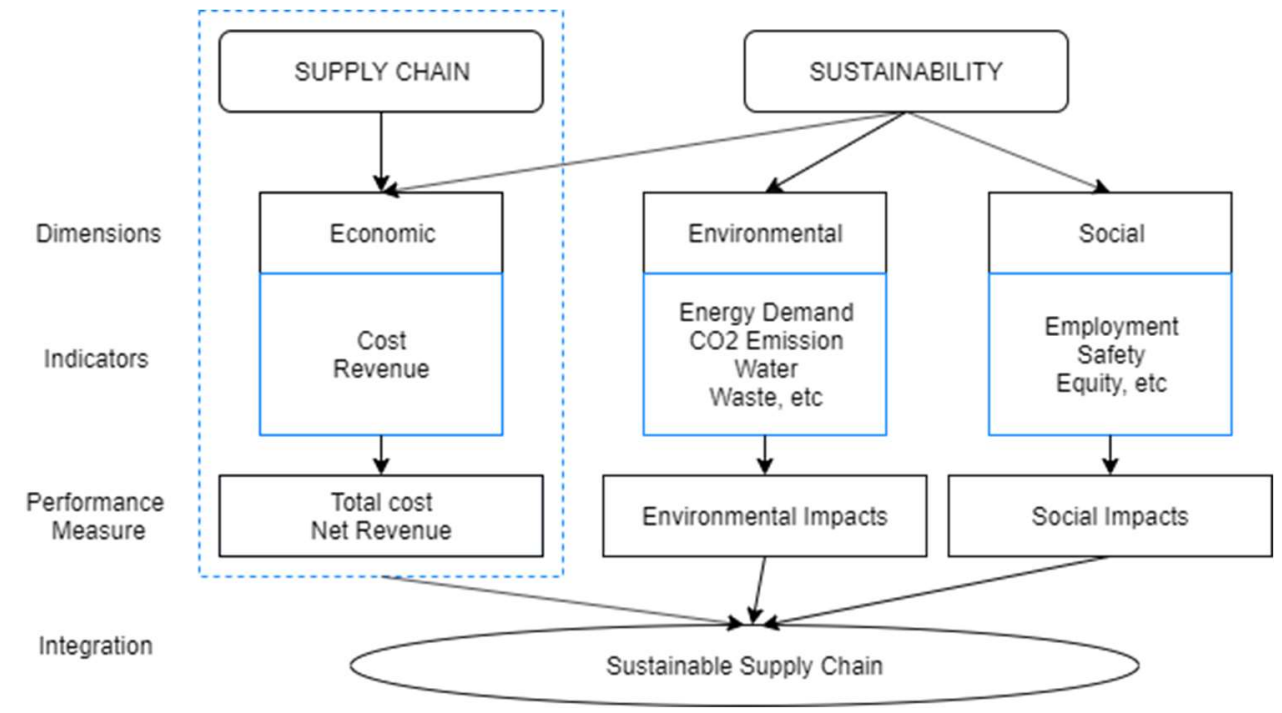

Figure 1. 1 Sustainable supply chain framework

According to Foran et al. (2005), supply chain impacts can be beyond country borders for firms operating in a global context. As an example, the direct fuel combustion of a factory may affect local, regional and global emissions. Moreover, the effort of an organization to reduce undesirable social impacts, such as reduce the level of accidents in 
the workplace, may result in improved global social risk. The three dimensions of sustainability have become an essential element of competitive advantage and something firms can no longer ignore (Bassiouny, 2007)

The integration of the 3BL dimensions to achieve a global sustainable supply chain system is important. Therefore, a model that emphasizes national economic issues (macroeconomic level) and considers the interrelationship between countries is a starting place to investigate the sustainability impact on a global supply chain. To achieve this purpose, it is important to define global performance indicators that are acceptable by most of the stakeholders in the global supply chain. This would include determining the indicators of 3BL impacts, which represent the national impacts of each 3BL dimension.

In existing supply chain analysis, the social dimension is omitted from the integration, unless the supply chain only focuses on the microeconomic level analysis (Bamufleh et al., 2013; El-Halwagi et al., 2013; Chen and Andresen, 2014). Moreover, the majority of research only investigates the impact of social issues in a single-objective model. Finally, unlike a traditional supply chain, where the nodes of the network are the processes in the system, this research will cover the global supply chain where the system would include examining the interrelationship not only between process but also between countries. 


\subsection{Research Objectives}

The objective of this research is to develop a model that investigates sustainable supply chain performance that includes economic, environmental and social dimensions for decision making support. The research questions that define this research are:

1. How to integrate a broader definition of sustainability into supply chain design and planning?

2. How can the IO framework be used to determine which countries and economic sectors contribute to the social impact intensities associated with fulfilling a given level of demand (i.e. sector demand for Transport and Equipment in the USA and China)?

3. How does the integration of the three pillars of sustainable SC influence the design of a global supply chain when applying IO analysis?

4. What is the impact of the price change on the global sustainable supply chain configuration?

\subsection{Dissertation Organization}

The first chapter of this proposal has described the research background, motivation, and objectives. Chapter Two reviews the literature on the sustainable supply chain, global supply chain, and current modeling methodologies and issues. Chapter Three defines and measures the three-supply chain sustainability dimension impact indicators. Chapter Four develops a mathematical model that integrates the 3BL dimensions into the 
supply chain analysis. The application of the model is included in Chapter Four by using the results from Chapter Three as input data. Chapter Five presents the application of the model in Chapter Four in conducting a multi-objective analysis. This chapter also discusses a sensitivity analysis and how the inclusion of environmental cost and social cost influence decision making. Finally, Chapter Six presents conclusions, contributions and future work for the research. 


\section{CHAPTER 2 LITERATURE REVIEW}

This research examines the integration of three dimensions of sustainability within the context of Sustainable Supply Chain Management (SSCM). The literature relating to this research addresses the importance of sustainability in the SCM, the dimensions, metrics, and models for decision making. Over the past two decades, researchers have studied various aspects of SSCM. Studies include the implications of environmental and social concerns on a firm's supply chain activities, managerial decision making, and a value chain perspective (Gupta and Palsule-Desai, 2011; Seuring and Müller, 2008c)

The literature covering sustainability in the supply chain (Boukherroub et al., 2015; Brandenburg et al., 2014; Cambero and Sowlati, 2016; Kannegiesser and Günther, 2014) shows that studies and data related to social dimension metrics are rather few and limited in scope. Initial research on the sustainable supply chain provided approaches to include social aspects in supply chain management, but they are mainly theoretical and have included the development of frameworks (Foran et al., 2005; Matos and Hall, 2007; Seuring, 2004). Following this, research on measuring the sustainability performance of a supply chain was started, especially in determining social indicators and methodologies (Agbonkhese, 2010; Benoit-Norris et al., 2012; Hutchins and Sutherland, 2008).

The purpose of this chapter is to review papers about sustainable supply chain management. This chapter starts by explaining the importance of including sustainable dimensions in supply chain performance analysis. Then, sustainable dimensions and 
current methods are reviewed and discussed. Finally, the gaps in the literature are discussed.

\subsection{Sustainable Supply Chain Management}

In recent years sustainable supply chain management and practices have attracted a significant amount of interest among academia and practitioners. This can be seen from the growing number of literature reviews stating that companies have now included sustainability in their company strategy and goals due to rapid changes in climate and increased customer awareness. Sustainable supply chain management (SSCM) is defined as the management of flows in the supply chain by considering the three dimensions of sustainable development, which are economic, environmental and social (Seuring and Müller, 2008a). In the other words, the emphasis is on multiple objectives, in which sustainability can only be achieved by finding the optimal balance between the three objectives (Boukherroub et al., 2015; Carter and Rogers, 2008).

The three dimensions of sustainability are taken from the triple-bottom-line (3BL) concept. It emphasizes the interrelationship of different aspects of human existence, which includes people, planet and profit (Savitz and Weber, 2006). From a business point of view, it is a common practice that economic growth and financial success is the first dimension that is addressed by organizations as they provide significant benefit to them. The research has focused on the economic side of sustainability includes total cost-based or decision-related cost and revenue approaches (Seuring, 2013; Seuring and Müller, 2008a). 
Yet, human existence also values other aspects, such as health, moral and social development, which drive organizations to include the benefit back to the environment and social communities outside the business. The addition of environmental aspects, together with economic aspects, in SCM, has been reviewed in the published research. Studies have been conducted where the objectives used for the optimization are the minimization of carbon emissions, environmental footprint, or overall environmental indicators based on available various Life Cycle Impacts Assessment methods, such as Eco Indicator and ReCiPe (Cambero and Sowlati, 2016; Eskandarpour et al., 2015). Typical metrics used for environmental dimensions are carbon emissions, air quality, water quality, energy usage and waste produced (Savitz and Weber, 2006; Seuring, 2013).

In contrast, the literature that focuses on the incorporation of social factors in the supply chain is still limited, though the number is growing. Research on social dimensions mostly emphasized the development of paradigms, frameworks, and regulative issues, rather than the influence of social concerns in managerial decisions across supply chain functions.

There are cases which have indicated how a company has earned more benefit by practicing SSCM, such as Walmart, Nike, IKEA. According to Savits \& Weber (2006), companies that embrace environmental and social issues can increase shareholder value by properly managing risks, anticipating regulatory action and exploiting new opportunities in the marketplace (Gimenez et al., 2012; Székely and Knirsch, 2005). 


\subsection{Sustainable SCM Dimensions}

In this section, the SSCM dimensions will be presented. The indicators commonly used interchangeably in sustainable supply chain research will be described. Figure 1.2, adapted from (Cetinkaya et al., 2011), shows the dimensions of sustainability. As already mentioned, the 3BL, economic, environmental and social dimensions are the pillars of sustainability. In this diagram, input and output factors for the environmental dimension and internal and external factors for the social dimension are provided.

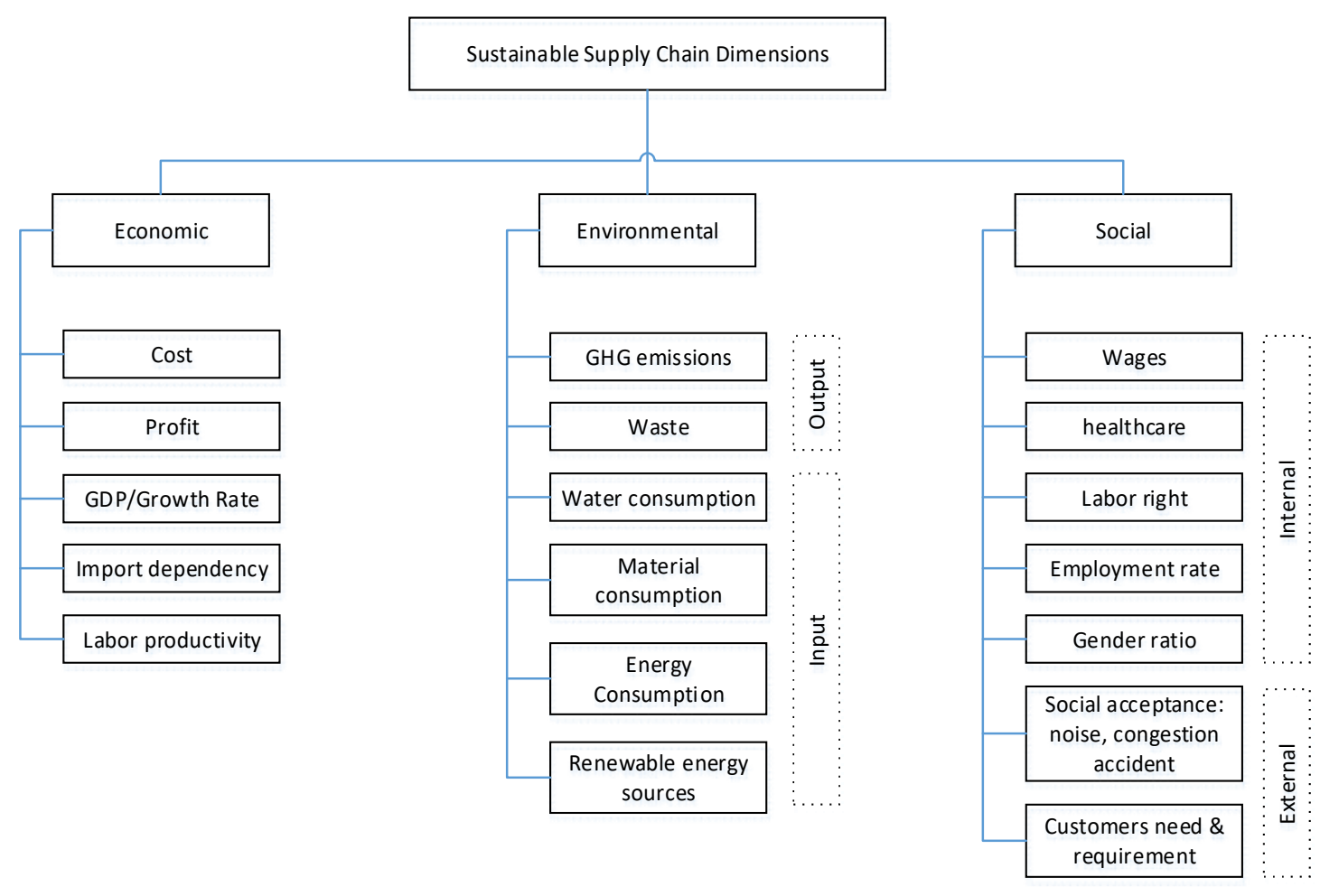

Figure 2. 1 Dimensions of SSCM (adapted from Cetinkaya et al., 2011)

\section{Economic Dimension}

The economic pillar is the first dimension that is typically addressed in SSCM. The most frequent metrics used as an economic indicator are total cost and net revenue 
(Cambero and Sowlati, 2016; El-Halwagi et al., 2013; Woolley, 2010). In the SSCM literature, economic and environmental issues are the most commonly integrated. The analysis typically focuses on comparing economic benefits between different alternatives with respect to environmental performance. Decision making then depends on which alternative gives the maximum profit or minimum cost for all stakeholders while maintaining certain environmental performance (Seuring, 2013). Other economic metrics found in the SSCM literature are a capital investment, capital expenditure, sales, GDP, economic growth, export, and import rate.

\section{Environmental Dimension}

Studies addressing environmental impacts in the supply chain performance are usually called "green-supply chain." The main objective of a green supply chain is to eliminate the negative effect of environmental impact within the supply chain. Thus, metrics for green supply chains involve various indicators such as resource waste and GHG emissions (Ahi and Searcy, 2015; Seuring and Müller, 2008a). Regarding the impact on climate change, carbon emission $\left(\mathrm{CO}_{2}\right)$ is the most common indicator used to measure environmental impact (Matthews et al., 2008; Sundarakani et al., 2010). Many local and international organizations have integrated the standard carbon emission level in the production process. Thus, companies nowadays need to adjust their processes to meet environmental standards.

It has been noted that the total environmental impact should be measured throughout each stage in the supply chain (Vachon and Mao, 2008). The optimization of environmental impact involves the environmental footprints of multiple tiers in the supply chain (Benjaafar et al., 2013; Čuček et al., 2012a). 


\section{Social Dimension}

Social sustainability in supply chains addressed moral issues, such as social justice and human rights, as well as social conditions that define work conditions (Eskandarpour et al., 2015). Even though social indicators are informative, they are usually hard to quantify and are thus hard to incorporate into the decision-making tools required by businesses (Hutchins and Sutherland, 2008). Due to limited literature on this subject, research needs to include stages in social factors analysis, starting from establishing metrics, prioritizing issues, identifying and tracking issues in the supply chain and developing strategies.

Various social metrics have been discussed in the literature. Until recently, due to the availability of data, there has not been an agreement between researchers or industry practitioners on either social metrics or analysis framework. Benoît-Norris et al. (2011) classify five different groups of social indicators that are based on the guidelines of the Social Life Cycle Analysis (SLCA) framework developed by UNEP/SETAC life cycle initiative project (Table 2.1).

Table 2. 1 Social Indicators

\begin{tabular}{|l|l|}
\hline \multicolumn{1}{|c|}{ Category } & \multicolumn{1}{c|}{ Possible Data Indicators } \\
\hline Labor right \& decent works & $\begin{array}{l}\text { Minimum wages, percentage of child labor and forced labor, } \\
\text { excessive working time, the unemployment rate }\end{array}$ \\
\hline Governance & Human rights index, law enforcement \\
\hline Health and safety & Number of accidents at work (fatal and nonfatal) \\
\hline Human rights & Life expectancy, mortality rates \\
\hline Community infrastructure & Access to improved sanitation, children out of school rate \\
\hline
\end{tabular}

In their research, all the risks related to these five categories are assessed. They also created a database called Social Hotspot database (SHDB) that stores the level of social risk for 
countries and sector-specific that could be used to identify hotspots, the countries and sectors of concern, in supply chains based on potential social impacts.

One common indicator to measure social performance in an SCM is the number of jobs created as the result of a change in the production process (Cambero and Sowlati, 2016; Osmani and Zhang, 2017). In regard to data collection, this information is easier to obtain than the social risks data mentioned previously. Moreover, the data is quantifiable and easy to monetize. Nevertheless, the jobs created indicator is typically only used when the process and technology are known. Therefore, it is usually implemented in either a process or a product supply chain.

Despite limited research in the social dimension of SSCM, attempts to analyze the social footprint in the supply chain exists. In a global SCM context, the labor footprint is a common indicator discussed in the literature. Simas et al. (2014) quantify the "Bad Labor" footprints for social impact analysis, which include occupational health damage, vulnerable employment, gender inequality, child labor, and forced labor. Specifically, working time is the most important metric in quantifying the social impact, since it may directly or indirectly link to social or economic impacts (Weidema, 2016).

\subsection{Methodology to Assess Environmental and Social Impact}

In a traditional supply chain model, environmental and social objectives and constraints are rarely considered. The increasing importance of these factors has motivated various researchers to explore measuring this impact both quantitatively and qualitatively. This raises several questions that should be clarified when designing the supply chain 
(Eskandarpour et al., 2015). Which environmental and social factors should be considered? How can they be quantified? How can they be integrated into mathematical models and optimization methods?

This section will present the methodologies that are available to analyze environmental and social impacts in the supply chain. It will also briefly describe attempts to integrate the three dimensions in supply chain performance analysis.

\subsubsection{Life Cycle Analysis (LCA)}

LCA is the most common methodology used to assess the environmental impact of a supply chain. It collects inventory data for each stage of a process or product lifecycle, starting from material extraction until the end-of-life process (Burchart-Korol, 2013; Puri et al., 2009). Environmental LCA (E-LCA) is an important tool used in preventing pollution and enhancing green design efforts, such as the selection of product designs, material, and processes. Moreover, LCA models have been developed to follow the ISO 14000 standard (Finkbeiner et al., 2006), which is an international standard for environmental management systems.

Recently, the use of LCA was expanded to analyze social impacts, which is called Social LCA. A social and socio-economic Life Cycle Assessment (S-LCA) is a social impact assessment technique that aims to assess the social and socio-economic aspects of products and their potential positive and negative impacts, along their life cycle encompassing extraction and processing of raw materials; manufacturing; distribution; use; re-use; maintenance; recycling; and final disposal. S-LCA complements E-LCA with 
social and socio-economic aspects. It can either be applied on its own or in combination with E-LCA (Benoît et al., 2009). While, an E-LCA will mainly focus on collecting information on (mostly) physical quantities related to the product and its production/use and disposal, a S-LCA will collect additional information on organizational related aspects along the supply chain (Benoît et al., 2009; Brent and Labuschagne, 2006; Dreyer et al., 2005).

The primary critique of LCA research highlights the concern about the system boundary in LCA. In the context of the supply chain, the LCA system boundary could result in missing a link between tiers in the supply chain, so that the effort to capture the environmental impact of the whole supply chain fails (Suh and Huppes, 2002). In other words, the LCA model is powerful in assessing the environmental impact of a product or process within the system boundary, but not outside the boundary. Thus, it neglects the indirect impacts that come from upstream suppliers. For this reason, the LCA approach it is argued does not cover all supply chain activities.

\subsubsection{Input-Output Analysis}

Input-output analysis (IOA) is a top-down economic approach that uses sectoral monetary transaction data to account for the complex linkages between industries in modern economies (Miller and Blair, 2009). It was originally developed by Leontief (1949), as a framework to study the behavior of an economy. In some literature, it is referred to as Economic Input-Output Analysis (EIOA), since it focuses on monetary transactions (Haimes and Jiang, 2001). The result of a generalized input-output analysis is an $f x n$ matrix of factor multipliers. This matrix captures $f$ production factors (such as 
material, labor, energy, emission, etc) per unit of final consumption of commodities produced by $n$ industry sectors.

In the early years, IOA only focused on transactions between sectors in a region or country (Ghosh, 1958; Leontief, 1949). IOA has expanded to comprise global transactions between industries and countries. Thus, the IOA framework considers interdependencies and enables a discussion at a macroeconomic level. This framework will be the focus of this research.

Table 2.2 below shows a Multi-Regional Input-Output (MRIO) model transaction matrix (Tukker et al., 2013; Wood et al., 2014). Elements in rows show the direct and indirect coefficients that are normalized by the total economic output of the industrial sectors and countries. Each coefficient represents the dollar input from the country and sectors on the left of the row for each dollar output from the industry and country listed at the head of the column.

Table 2. 2 The basic MRIO matrix model

\begin{tabular}{|c|c|c|c|c|c|c|c|c|c|c|c|c|c|c|c|c|}
\hline \multirow{3}{*}{\multicolumn{2}{|c|}{$\begin{array}{l}\text { Output from } \\
\text { Countries and } \\
\text { sectors }\end{array}$}} & \multicolumn{12}{|c|}{ Input to Countries and sectors } & \multirow{4}{*}{$\begin{array}{c}\text { Intermediate } \\
\text { output } 0\end{array}$} & \multirow{4}{*}{\begin{tabular}{|c|}
$\begin{array}{c}\text { Final } \\
\text { Demand } \\
Y\end{array}$ \\
Y11 \\
\end{tabular}} & \multirow{4}{*}{$\begin{array}{c}\begin{array}{c}\text { Total } \\
\text { Output X }\end{array} \\
\text { X11 } \\
\end{array}$} \\
\hline & & \multicolumn{4}{|c|}{ Country1 } & \multicolumn{4}{|c|}{ Country2 } & \multicolumn{4}{|c|}{ Country $n$} & & & \\
\hline & & 1 & 2 & 3 & $\mathrm{n}$ & 1 & 2 & 3 & $\mathrm{n}$ & 1 & 2 & 3 & $\mathrm{n}$ & & & \\
\hline \multirow{4}{*}{ Country1 } & 1 & $\mathrm{X}_{11}{ }^{11}$ & $\mathrm{X}_{11}{ }^{12}$ & & & & $\ldots$ & & & & & & $X_{1 n}^{1 n}$ & & & \\
\hline & 2 & $\mathrm{X}_{12}{ }^{11}$ & $x_{12}{ }^{12}$ & & & & $\ldots$ & & & & & & $\mathrm{X}_{12}{ }^{11}$ & 012 & Y12 & $\mathrm{X} 12$ \\
\hline & 3 & $\mathrm{X}_{13}{ }^{11}$ & $\mathrm{x}_{13}{ }^{12}$ & & & & $\ldots$ & & & & & & $\mathrm{X}_{12}{ }^{11}$ & 013 & $\mathrm{Y} 13$ & $\mathrm{X} 13$ \\
\hline & $\mathrm{n}$ & $\mathrm{x}_{1 \mathrm{n}}{ }^{11}$ & $x_{1 n}{ }^{12}$ & & & & $\ldots$ & & & & & & $\mathrm{X}_{12}{ }^{11}$ & $01 n$ & Y1n & X1n \\
\hline \multirow{4}{*}{ Country2 } & 1 & $x_{21}{ }^{11}$ & $x_{21}{ }^{12}$ & & & & $\ldots$ & & & & & & $\mathrm{X}_{12}{ }^{11}$ & 021 & $\mathrm{Y} 21$ & $\mathrm{X} 21$ \\
\hline & 2 & $x_{22}{ }^{11}$ & $x_{22}{ }^{12}$ & & & & $\ldots$ & & & & & & $\mathrm{X}_{12}{ }^{11}$ & 022 & $\mathrm{Y} 22$ & $\mathrm{X} 22$ \\
\hline & 3 & $\mathrm{X}_{23}{ }^{11}$ & $x_{23}{ }^{12}$ & & & & $\ldots$ & & & & & & $\mathrm{X}_{12}{ }^{11}$ & 023 & Y23 & $\times 23$ \\
\hline & $\mathrm{n}$ & $x_{2 n}{ }^{11}$ & $x_{2 n}{ }^{12}$ & & & & $\ldots$ & & & & & & $\mathrm{x}_{12}{ }^{11}$ & $02 n$ & $Y 2 n$ & $X 2 n$ \\
\hline \multirow{4}{*}{ Country n } & 1 & $x_{n 1}^{11}$ & $x_{n 1}{ }^{12}$ & & & & $\ldots$ & & & & & & $\mathrm{x}_{12}{ }^{11}$ & On1 & Yn1 & $\mathrm{xn1}$ \\
\hline & 2 & $x_{n 2}^{11}$ & $x_{n 2}{ }^{12}$ & & & & $\ldots$ & & & & & & $\mathrm{X}_{12}{ }^{11}$ & On2 & $\mathrm{Yn}_{\mathrm{n}}$ & $\mathrm{Xn} 2$ \\
\hline & 3 & $x_{n 3}{ }^{11}$ & $x_{n 3}{ }^{12}$ & & & & $\ldots$ & & & & & & $\mathrm{X}_{12}{ }^{11}$ & On3 & Yn3 & $\mathrm{Xn} 3$ \\
\hline & $\mathrm{n}$ & $x_{n n}{ }^{11}$ & $x_{n n}{ }^{12}$ & & & & $\ldots$ & & & & & & $\mathrm{X}_{12}{ }^{11}$ & Onn & $Y n n$ & $\mathrm{Xnn}$ \\
\hline \multicolumn{2}{|c|}{ Intermediate Input } & 111 & 112 & 113 & $11 \mathrm{n}$ & 121 & 122 & 123 & $12 n$ & $\ln 1$ & $\ln 2$ & $\ln 3$ & $\operatorname{lnn}$ & \multirow{3}{*}{\multicolumn{3}{|c|}{ GDP }} \\
\hline \multicolumn{2}{|c|}{ Value Added } & V11 & $\mathrm{V} 12$ & $\mathrm{~V} 13$ & V1n & V21 & V22 & V23 & $\mathrm{V} 2 \mathrm{n}$ & Vn1 & Vn2 & Vn3 & Vnn & & & \\
\hline \multicolumn{2}{|c|}{ Total Input X } & $\mathrm{X} 11$ & $\mathrm{X} 12$ & $\mathrm{X} 13$ & $\mathrm{X} 1 \mathrm{n}$ & $\mathrm{X} 21$ & $\mathrm{X} 22$ & $\mathrm{x} 23$ & $x 2 n$ & $\mathrm{Xn} 1$ & $\mathrm{Xn2}$ & $\mathrm{xn} 3$ & $\mathrm{Xnn}$ & & & \\
\hline
\end{tabular}

Input-output based modeling is suitable for supply chain analysis because it includes the direct and indirect input of each sector. Thus, this method is more favorable 
than LCA due to its comprehensiveness to consider indirect inputs. In a global supply chain assessment, IOA fully covers the whole range of national economic activities (Acquaye et al., 2017).

An input-output model describes how supply $x$ follows demand with the following identity:

$$
\begin{gathered}
x=A x+y \\
A=\left[a_{i j}{ }^{n m}\right]=\frac{x_{i j}^{n m}}{X_{i}^{n}}
\end{gathered}
$$

where $x$ is total output, $A$ is the matrix of direct input coefficients, and $y$ is the vector of final demand. The $A$ matrix represents the ratio of input to output and is the amount required by one sector from another sector to produce one monetary unit of output. Solving the model for output gives (Miller and Blair, 2009):

$$
x=(I-A)^{-1} \cdot y=L y
$$

The matrix $(\mathrm{I}-\mathrm{A})^{-1}$ is commonly referred to as the Leontief-inverse and is denoted by $\mathrm{L}$, the multiplier matrix of direct and indirect industry output requirements per unit of final demand.

Recently, there have been attempts to extend the input-output analysis to include both environmental and social factors. Satellite accounts that contain various social and environmental impacts have been added to the IOA (Miller and Blair, 2009). The satellite account displays the total amount of impact as a result of the total economic output of each industry. These findings are the bridge to connect the areas within the global and sustainable supply chain by utilizing the input-output model to capture the impact of various sectors from various countries toward a sector in a specific country. By 
incorporating environmental and social satellite accounts, a vector of sustainability impacts can be formulated as follows:

$$
\begin{aligned}
& Z=F(I-A)^{-1} \cdot Y \\
& F=\left[\frac{f_{i}^{n}}{x_{i}^{n}}\right]
\end{aligned}
$$

where $Z$ denotes the total impact, direct and indirect, of environmental and social vectors that represent the sustainability impact per unit dollar of final demand, and $F$ is the vector describing the impacts coefficients of sustainability (3BL) across contributing countries and sectors based on per dollar of output.

In addition, databases that provide MRIO tables, as well as data related to environmental and social indicators, are available for public access (Lenzen et al., 2013; Timmer et al., 2015; Wood et al., 2014). These databases can be used to analyze the environmental and social footprint and are useful for decision making in the supply chain.

Table 2.3 summarizes the literature that uses an IO approach to assess the sustainability supply chain performance. As can be seen from the table, the IO approach enables the inclusion of various social indicators for the analysis. However, the literature only focuses on measuring sustainability performance. Therefore, this opens an opportunity for more research that focuses on including multiple social factors in sustainable supply chain, especially for decision making. 
Table 2. 3 Literature of sustainability in the supply chain using IO approach

\begin{tabular}{|c|c|c|c|c|c|c|}
\hline Authors & Topic & Economy & Environmental & Social & $\begin{array}{l}\text { Measureme } \\
\text { nt Method }\end{array}$ & Scope \\
\hline $\begin{array}{l}\text { (Lechón et } \\
\text { al., 2019) }\end{array}$ & $\begin{array}{l}\text { Biofuel } \\
\text { deployment }\end{array}$ & $\begin{array}{l}\text { Value } \\
\text { added, } \\
\text { revenue }\end{array}$ & $\begin{array}{l}\text { GHG } \\
\text { Emission }\end{array}$ & $\begin{array}{l}\text { Employment } \\
\text { generation }\end{array}$ & $\mathrm{IO}$ & Uruguay \\
\hline $\begin{array}{l}\text { (Xiao et } \\
\text { al., 2017) }\end{array}$ & $\begin{array}{l}\text { Social } \\
\text { Footprints } \\
\text { Analysis for } \\
\text { sustainable } \\
\text { development }\end{array}$ & $\begin{array}{l}\text { Export- } \\
\text { Import }\end{array}$ & - & $\begin{array}{l}\text { Gender equality, } \\
\text { women } \\
\text { empowerment }\end{array}$ & $\begin{array}{l}\text { SHDB- } \\
\text { EORA }\end{array}$ & Global \\
\hline $\begin{array}{l}\text { (Rodrígue } \\
\text { z-Serrano } \\
\text { et al., } \\
2017 \text { ) }\end{array}$ & $\begin{array}{l}\text { Sustainability } \\
\text { Assessment }\end{array}$ & $\begin{array}{l}\text { Investment, } \\
\text { O\&M cost, } \\
\text { Socio- } \\
\text { economic } \\
\text { costs }\end{array}$ & $\begin{array}{l}\text { Climate change, } \\
\text { Acidification, } \\
\text { Formation of } \\
\text { photochemical } \\
\text { oxidants }\end{array}$ & $\begin{array}{l}\text { Labor right, } \\
\text { health, and } \\
\text { safety, human } \\
\text { right, } \\
\text { governance, } \\
\text { community }\end{array}$ & $\begin{array}{l}\text { MRIO - } \\
\text { FISA }\end{array}$ & Mexico \\
\hline $\begin{array}{l}\text { (Acquaye } \\
\text { et al., } \\
2011 \text { ) }\end{array}$ & $\begin{array}{l}\text { Measuring } \\
\text { environmenta } \\
1 \\
\text { sustainability } \\
\text { performance } \\
\end{array}$ & - & $\begin{array}{l}\text { Water } \\
\text { footprint, } \\
\text { Carbon and } \\
\text { Sulphur } \\
\text { emission }\end{array}$ & - & MRIO & EU \\
\hline $\begin{array}{l}\text { (Papong et } \\
\text { al., 2016a) }\end{array}$ & $\begin{array}{l}\text { Development } \\
\text { social } \\
\text { intensity } \\
\text { database }\end{array}$ & - & - & $\begin{array}{l}\text { total employment, } \\
\text { paid workers, } \\
\text { vulnerable } \\
\text { employment, } \\
\text { wages, fatal, and } \\
\text { non-fatal } \\
\text { occupational } \\
\text { injuries }\end{array}$ & $\mathrm{IO}$ & Thailand \\
\hline $\begin{array}{l}\text { (N. Onat } \\
\text { et al., } \\
2014)\end{array}$ & $\begin{array}{l}\text { Life cycle } \\
\text { sustainability } \\
\text { assessment } \\
\text { framework }\end{array}$ & $\begin{array}{l}\text { GDP, } \\
\text { import, } \\
\text { profit }\end{array}$ & $\begin{array}{l}\text { GHG emissions, } \\
\text { Energy } \\
\text { consumption, } \\
\text { Water footprint, } \\
\text { and Hazardous } \\
\text { waste } \\
\text { generation }\end{array}$ & $\begin{array}{l}\text { Wages, Number } \\
\text { of injuries, } \\
\text { government tax. }\end{array}$ & IO-LCA & $\begin{array}{l}\text { US } \\
\text { Building }\end{array}$ \\
\hline
\end{tabular}

\subsubsection{Hybrid Approach IO-LCA}

The IO-LCA or EIO-LCA models trace the various economic transactions, resource requirements and various environmental emissions required, as well as social issues, involved in providing a particular product or service. The models capture all the various 
manufacturing, transportation, mining and related requirements to produce it (Hendrickson et al., 2006).

One important study in this area was conducted by Carnegie Melon University which provides software that utilizes the IO-LCA model to estimate material and energy resources required, as well as environmental emissions resulting from economic activities for several countries, such as US and Germany (Carnegie Melon University, 2008). This software has been widely used to estimate the effect of changing the output of a single sector. The method can be applied to any economy defined by the transaction between sectors.

The IO-LCA model is comprehensive and includes details that are not discussed in the general I-O model. However, similar to the I-O model, it only contains data from certain sectors and countries and the data is aggregated by sectors and countries. The IOLCA model provides a more comprehensive system boundary for economic and environmental assessment. The model is built on sector-country economic activities, but the transactions between countries are not captured in the model.

Research that utilizes the IO-LCA model mainly discusses which tier or process in the supply chain contributes the most to carbon emissions (Genovese et al., 2015; Rowley et al., 2009). None of the research discusses the application of IO-LCA in the global supply chain. The drawback of current research which utilizes the IO-LCA model is an assumption that the technology used in every country is the same, which is not typically the case. Moreover, the current model only includes economic and environmental indicators and the available data is not regularly updated due to the complexity of collecting data. 
Onat et al. (2014) apply the 3BL-based IO-LCA model to assess sustainability impacts in the building industry. However, they only cover the industry by industry interrelationship and their focus is only in the USA. They also did not provide a framework for strategic decision making for a global supply chain configuration.

\subsection{Integrated Approaches to Sustainable Supply Chain}

The importance of simultaneously analyzes 3BL dimensions in supply chain assessment has been discussed in the literature. Although the studies that considered integrating 3BL in supply chain decision making are limited, the literature is growing recently. Among them, most of the literature examined integration for sustainability assessment analysis. To our knowledge, research that focuses on sustainability at the strategic decision level is very few. This section reviews current approaches that deal with the trade-off between 3BL metrics in supply chain decision making.

\subsubsection{Multi-Criteria Decision Making}

Research in the field of sustainable supply chains has considered multiple objectives. The central problem is how to evaluate a set of alternatives with respect to a number of criteria where the solution must consider the preferences of the decision-maker. Regarding supply chain applications, traditionally, research has focused on a single objective that either minimizes costs or maximizes profits. The initial focus of multi-criteria in supply chain design decision making was to allow the use of a performance measurement 
system that includes factors such as cost, customer service levels, quality, and flexibility of volume or delivery (Wang et al., 2011; Woolley, 2010).

In the SSCM literature, some common methodologies used for decision making are AHP, Demeter, and DEA. These approaches are used either as an individual approach or combined with other methods for decision making. Typically, the problem objective is to address supplier selection or establish sustainable supplier criteria (Dai and Blackhurst, 2012; Hsu et al., 2013). When MCDM is combined with another method, it is typically used for defining the weight of criteria or preferences (Zhixiang Chen and Andresen, 2014; Zimmer et al., 2017a).

\subsubsection{Modelling Approach}

In this section, the two main categories for mathematical models for SSC design problems from the current literature are discussed. The models reviewed are only those that include literature that includes the three sustainability dimensions either in a single objective or multi-objective model.

\section{Single Objective Models}

A single objective model (SOM) is an approach to express the objective function as a weighted average of all objective functions. This requires applying conversion factors to convert different metrics into a single metric (Eskandarpour et al., 2015). In the context of SSC design, the environmental and social impacts are converted into their monetary equivalent by using conversion factors. Thus, all three dimensions of the SSC design are aggregated into a single objective. 
Although it is the simplest way to incorporate environmental and social dimensions into SSC design, it is hard to monetize environmental and social impacts. It is especially difficult to monetize social factors since each stakeholder in the supply chain will value the impacts differently, which makes the model difficult to put into practice. For example, firms and employees would have different standards for working conditions, human rights action, etc.

Most of the SOM for SSC design problem literature only integrates economic and environmental impacts in the model. The problem is often modeled as a Mixed-Integer Linear Program (MILP) and solved with standard solvers tools such as CPLEX or Lindo. One paper that utilized SOM to incorporate three dimensions of sustainability is by Bouzembrak et al. (2013). They proposed a MILP for the design of a waterway sediment supply chain in which the level of disposal is a social impact on the community.

2. Multi-objective Models

In practice, multi-objective (MO) models are commonly used for solving sustainable supply chain (SSC) issues. Most of the literature for MO models for SSC design utilize deterministic multi-objective linear models that include economic and environmental dimensions. A theoretical framework was developed by Nagurney and Toyasaki (2003) and was the first that allowed for multi-criteria decision-makers in different tiers of the supply chain with economic and environmental considerations, and the weight of the criteria (environmental) depends on the environmental consciousness of each decision-maker.

Wang et al. (2011) propose a MO optimization model that captures the tradeoff between the total cost and environment influence for the firm's strategic planning. Another 
recent contribution in this area is the work by Diabat and Al-Salem (2015). They addressed a joint location-inventory problem and included the reduction of carbon emissions as supporting criteria for decision-making. A genetic algorithm was used as a solution approach to solve the problem.

The general applications of multi-objective decision making into environmental analysis range from biomass energy supply, forest-based bioenergy (Cambero and Sowlati, 2016, 2014; Čuček et al., 2012b) to computer waste management (Ahluwalia and Nema, 2007). Various environmental impacts have been assessed in the literature and have included gas emission, water pollution, global warming index, etc.

The number of papers that incorporate the three dimensions of sustainable supply chain design has increased recently (Yawar and Seuring, 2015). Some authors formulate a MILP model to integrate economic, environmental and social supply chain in addressing the optimal design and planning (Santibañez-Aguilar et al., 2014; You et al., 2012a). Chen and Andresen (2014) incorporated three pillars of sustainability using the weighted-sum approach with weights determined by the Analytic Hierarchy Process (AHP). Recently, Cambero and Sowlati (2016) proposed an approach to quantify the potential job-related social benefit and include this indicator into a multi-objective LP model. Cruz and Wakolbinger (2008) adapted the work by Nagurney and Toyasaki (2003) to consider the minimization of risk and the associated levels of social responsibility.

Table 2.4 summarizes the literature on measuring sustainability performance that has been reviewed. Among them, six papers (Shaded) include the three-sustainability dimensions simultaneously in company's strategic decision making. Five papers attempted to use mathematical modeling, wherein all of them, the social objective focused only on 
employment (number of jobs created). Moreover, only one paper covers the global level of the supply chain. There is a need to introduce the concept of social sustainability at the strategic and global levels, and with respect to this, the literature is practically nonexistent (Seuring, 2013).

Table 2. 4 Integrated Sustainability in the Supply Chain Literature

\begin{tabular}{|c|c|c|c|c|c|c|c|c|c|c|c|c|c|}
\hline \multirow[b]{2}{*}{ Author } & \multicolumn{3}{|c|}{ Economic } & \multicolumn{3}{|c|}{ Environmental } & \multicolumn{3}{|c|}{ Social } & \multicolumn{3}{|c|}{$\begin{array}{l}\text { Measurement } \\
\text { Method }\end{array}$} & \multirow[b]{2}{*}{ Description } \\
\hline & $\begin{array}{l}\bigcup_{0}^{0} \\
\bigcup_{0}\end{array}$ & 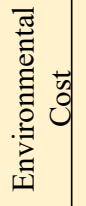 & $\begin{array}{l}\vec{\omega} \\
0 \\
\frac{0}{0} \\
0 \\
\infty\end{array}$ & రิ & 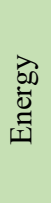 & $\frac{n}{\grave{D}}$ & 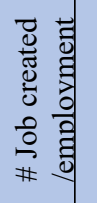 & 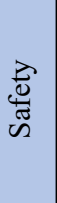 & $\begin{array}{l}\frac{n}{0} \\
\stackrel{5}{0}\end{array}$ & $\underset{త}{\circlearrowright}$ & $\varrho$ & $\begin{array}{l}\frac{n}{0} \\
\stackrel{ \pm}{0}\end{array}$ & \\
\hline $\begin{array}{l}\text { (Foran et al., } \\
\text { 2005) }\end{array}$ & $\mathrm{y}$ & & & & & & $\mathrm{y}$ & & $\mathrm{y}$ & & $\mathrm{y}$ & & $\begin{array}{l}\text { A framework to } \\
\text { measure social } \\
\text { performance at } \\
\text { national level }\end{array}$ \\
\hline $\begin{array}{l}\text { (Hugo and } \\
\text { Pistikopoulos, } \\
\text { 2005) }\end{array}$ & $\mathrm{y}$ & & & & & $\mathrm{y}$ & & & & $\mathrm{y}$ & & & $\begin{array}{l}\text { A MOMILP model } \\
\text { for sustainable } \\
\text { supply chain design }\end{array}$ \\
\hline $\begin{array}{l}\text { (Krajnc and } \\
\text { Glavič, 2005) }\end{array}$ & $\mathrm{y}$ & & & $\mathrm{y}$ & $\mathrm{y}$ & $\mathrm{y}$ & $\mathrm{y}$ & $\mathrm{y}$ & $\mathrm{y}$ & & & $\mathrm{y}$ & $\begin{array}{l}\text { A model to obtain } \\
\text { composite } \\
\text { sustainable } \\
\text { development index } \\
\text { using AHP }\end{array}$ \\
\hline $\begin{array}{l}\text { (Hutchins } \\
\text { and } \\
\text { Sutherland, } \\
\text { 2008) }\end{array}$ & $\mathrm{y}$ & & & & & & $\mathrm{y}$ & & $\mathrm{y}$ & & & $\mathrm{y}$ & $\begin{array}{l}\text { A method to } \\
\text { linkage social } \\
\text { sustainability matrix } \\
\text { to SC }\end{array}$ \\
\hline $\begin{array}{l}\text { (Bojarski et } \\
\text { al., 2009) }\end{array}$ & $\mathrm{y}$ & $\mathrm{Y}$ & & $\mathrm{y}$ & & $\mathrm{y}$ & & & & $\mathrm{y}$ & & $\mathrm{y}$ & $\begin{array}{l}\text { A MOMILP to } \\
\text { evaluate regulatory } \\
\text { policy for SC } \\
\text { production and } \\
\text { distribution network }\end{array}$ \\
\hline $\begin{array}{l}\text { (Pinto-Varela } \\
\text { et al., 2011) }\end{array}$ & $\mathrm{y}$ & & & $\mathrm{y}$ & & $\mathrm{y}$ & & & & $\mathrm{y}$ & & & $\begin{array}{l}\text { A Bi-objective } \\
\text { MILP model for } \\
\text { planning and design } \\
\text { supply chain } \\
\text { structures }\end{array}$ \\
\hline $\begin{array}{l}\text { (Chaabane et } \\
\text { al., 2012) }\end{array}$ & $\mathrm{y}$ & $\mathrm{Y}$ & & $\mathrm{y}$ & & & & & & $\mathrm{y}$ & & & $\begin{array}{l}\text { A MOLP for the } \\
\text { supply chain design } \\
\text { under different } \\
\text { environmental } \\
\text { policies }\end{array}$ \\
\hline
\end{tabular}




\begin{tabular}{|c|c|c|c|c|c|c|c|c|c|c|c|}
\hline $\begin{array}{l}\text { (You et al., } \\
\text { 2012a) }\end{array}$ & $\mathrm{y}$ & & $\mathrm{y}$ & & $\mathrm{y}$ & & & $\mathrm{y}$ & & & $\begin{array}{l}\text { A MO MILP model } \\
\text { for the optimal } \\
\text { network design }\end{array}$ \\
\hline $\begin{array}{l}\text { (Chen and } \\
\text { Andresen, } \\
\text { 2014) }\end{array}$ & $\mathrm{y}$ & & & $\mathrm{y}$ & & & & & & $\mathrm{y}$ & $\begin{array}{l}\text { A multi-objective } \\
\text { model of } \\
\text { production-sourcing } \\
\text { for SSC using AHP }\end{array}$ \\
\hline $\begin{array}{l}\text { (Santibañez- } \\
\text { Aguilar et al., } \\
\text { 2014) }\end{array}$ & $\mathrm{y}$ & & $\mathrm{y}$ & & $\mathrm{y}$ & & & $\mathrm{y}$ & & $\mathrm{y}$ & $\begin{array}{l}\text { A MO MP MILP } \\
\text { model to design and } \\
\text { plan the biomass } \\
\text { distribution system } \\
\text { using } \varepsilon \text {-constraint }\end{array}$ \\
\hline $\begin{array}{l}\text { (Diabat and } \\
\text { Al-Salem, } \\
\text { 2015) }\end{array}$ & $\mathrm{y}$ & $\mathrm{Y}$ & & & & & & & & $\mathrm{y}$ & $\begin{array}{l}\text { A model for a joint } \\
\text { location-inventory } \\
\text { problem with } \\
\text { stochastic demand }\end{array}$ \\
\hline $\begin{array}{l}\text { (Boukherroub } \\
\text { et al., 2015) }\end{array}$ & $\mathrm{y}$ & & $\mathrm{y}$ & & $\mathrm{y}$ & & & & & $\mathrm{y}$ & $\begin{array}{l}\text { A MO model for } \\
\text { SC operation plan } \\
\text { using GP. Case } \\
\text { study: Lumber } \\
\text { industry }\end{array}$ \\
\hline $\begin{array}{l}\text { (Mota et al., } \\
\text { 2015) }\end{array}$ & $\mathrm{y}$ & & $\mathrm{y}$ & $\mathrm{y}$ & $\mathrm{y}$ & & & $\mathrm{y}$ & & y & $\begin{array}{l}\text { A MO model for } \\
\text { facility location } \\
\text { problem. Case } \\
\text { study: battery } \\
\text { manufacturer in } \\
\text { Portugal }\end{array}$ \\
\hline $\begin{array}{l}\text { (Yue et al., } \\
\text { 2016) }\end{array}$ & $\mathrm{y}$ & & $\mathrm{y}$ & $\mathrm{y}$ & & & & $\mathrm{y}$ & $\mathrm{y}$ & & $\begin{array}{l}\text { A MO model for } \\
\text { sustainable biofuel } \\
\text { supply chain design } \\
\text { using } \varepsilon \text {-constraint. }\end{array}$ \\
\hline $\begin{array}{l}\text { (Arampantzi } \\
\text { and Minis, } \\
\text { 2017) }\end{array}$ & $\mathrm{y}$ & $\mathrm{Y}$ & $\mathrm{y}$ & $\mathrm{y}$ & $\mathrm{y}$ & & $\mathrm{y}$ & & & $\mathrm{y}$ & $\begin{array}{l}\text { A MOMILP model } \\
\text { for designing or } \\
\text { redesigning high- } \\
\text { performance } \\
\text { SSCND. Case } \\
\text { study: a global } \\
\text { refrigerator } \\
\text { manufacturer }\end{array}$ \\
\hline $\begin{array}{l}\text { (Zimmer et } \\
\text { al., 2017a) }\end{array}$ & & & & & $\mathrm{y}$ & $\mathrm{y}$ & $\mathrm{y}$ & & $\mathrm{y}$ & & $\begin{array}{l}\text { A model to asses } \\
\text { social risks along } \\
\text { the global supply } \\
\text { chain with the } \\
\text { FAHP method }\end{array}$ \\
\hline $\begin{array}{l}\text { (Gao and } \\
\text { You, 2018) }\end{array}$ & $\mathrm{y}$ & & $\mathrm{y}$ & $\mathrm{y}$ & & & & $\mathrm{Y}$ & $\mathrm{y}$ & & $\begin{array}{l}\text { A MILP with a } \\
\text { hybrid method in } \\
\text { the design and } \\
\text { operations of shale } \\
\text { gas supply chains }\end{array}$ \\
\hline
\end{tabular}




\subsection{Summary and Gap Analysis}

The integration of environmental and social criteria in SSC design is important to allow for the evaluation of the impact of a supply chain on its stakeholders. Overall the literature of sustainable supply chain can be categorized into two categories:

1. Measuring economic, environmental and social aspects for the sustainability performance assessment.

2. Managing economic, environmental and social aspects in strategic decision making

From the strategic decision-making perspective, there exist more papers on the environmental impacts of SSC design than for social sustainability. The most popular method used to deal with environmental SSC design is LCA. The limitation of an LCA approach is that it applies to a product or process with a boundary to justify the scope of analysis. Any comparison between different entities is only valid if the boundaries are the same. This does not fit for companies with a global network, because the economic, environmental and social impacts may occur beyond the boundaries. On the other hand, the literature on the social impacts of SSC design is limited. The incorporation of social impacts in the SSC design helps to obtain a balance between qualitative and quantitative decisions (Eskandarpour et al., 2015). The social impact is an inseparable issue for a sustainable supply chain, especially at the strategic and global level. Thus, there is a need to include this aspect in an integrated model.

It is worth noting that most of the literature focuses on the microeconomic level of supply chains, simplifying the supply chain at the firm level or process level. The literature 
shows that at this level, the number of jobs created is the social indicator used for the supply chain design. It is argued that a macroeconomic analysis is a better perspective to design the SSC, then the focus is on consumption-based impacts rather than production-based (Pascual-Gonzalez et al. 2016). A macroeconomic analysis allows direct and indirect consumption in sector activities with an IO approach. Foran et al. (2005) compared the embodied energy results from a life cycle analysis (process analysis) and a full input-output analysis. The study shows that the full input-output analysis captures more than twice the total embodied energy versus a traditional life cycle analysis. This supports the notion that the macroeconomic approach can integrate across a range of institutional scales and does not have boundary problems.

The macroeconomic analysis also enables assessing the environmental and social impacts of a global supply chain, which can include various social indicators. Besides the number of jobs created, issues related to employment and working conditions, such as the impact of vulnerable workers and the number of accidents in the workplace, can be used in the decision-making process.

Another opportunity found based on reviewing the literature on the macroeconomic level of SSC analysis is that only environmental and social impacts have been addressed, without examining integration within a 3BL context (Papong et al., 2016b; Xiao et al., 2017; Zimmer et al., 2017a). The challenge is that most social impacts are based on qualitative results. The inconsistency on how to value the impact in dollar terms is a significant challenge, particularly when dealing with globalized sourcing. Finally, the availability of national social data is still limited, especially for data from developing countries. 
Accordingly, there is a gap in the previously published papers in the area of global sustainable supply chain configuration. These papers lack the simultaneous consideration of $3 \mathrm{BL}$ dimensions for sustainability which can be attributed to the complexity of modeling environmental impacts and to some extent social aspects. To address these gaps, this research focuses on the three sustainability impacts at a global macroeconomic scale but will apply them to support supply chain decision making. A model to show the influence of the three-sustainability dimension on global supply chain design will be formulated. It examines the optimization of these three dimensions, both individually and in an integrated approach, by considering international economic transactions between countries.

In addition to reviewing the SSC design problem, this chapter reviewed various models used in designing SSCs. Many generic or specific models have been used in SSC design, including LCA, input-output models or hybrid. A variety of techniques have been implemented to solve this complex problem, including MIP, MILP and metaheuristic approaches. This research will integrate multi-objective optimization and MRIO models within a framework to identify the key economic sectors that significantly contribute to the total environmental and social impacts. Considering the importance of the threesustainability dimensions, this research focuses on trade-off analysis to examines the impacts of different sustainable dimensions. Working on various social indicators, together with economic and environmental aspects, especially for strategic decision making, can expand the knowledge base in the sustainable supply chain field of study. 


\section{CHAPTER 3 MEASURING SUSTAINABILITY IMPACTS IN TRANSPORT AND EQUIPMENT (TE) GLOBAL SUPPLY CHAIN DESIGN}

In recent years, sustainable supply chain management and practices have attracted significant interest among academia and practitioners. Economic, environmental and social factors are the three sustainability dimensions that have been accepted worldwide to assess sustainability performance. Several environmental and social certification standards, such as ISO 14001 and SA8000 were developed based on these dimensions (Mueller et al., 2009).

As the supply chain associated with manufacturing activities goes beyond the firm and country boundaries, the pressure to consider environmental and social issues in the global supply chain grows. Consequently, some firms or countries are applying stricter regulations related to environmental and social issues in their operational practices. The desired result is to improve company reputation and operational performance in the supply chain. Therefore, research on how to measure the impact of a sustainability initiative is critical to assessing GSSC performance. This chapter will present the economic, environmental and social performance of the TE supply chain at the national level, in order to analyze its impact at a global level. 


\subsection{Overview}

The literature addressing sustainability in the supply chain has focused on the firm or process level, resulting in boundary issues. However, sustainability impacts often occur beyond a firm's borders. Specifically, for companies operating in a global and interconnected supply chain context, the impacts upstream and downstream of the supply chain also influence the total sustainability impact.

The global supply chain design problem can be defined as a strategic supply chain design that involves international rules and financial issues and allows suppliers and facilities to be located in multiple countries (Vidal and Goetschalckx, 1997). Consequently, environmental and social issues are becoming increasingly important in designing a global supply chain. Most studies in this field have only focused on the economic and environmental aspects of sustainability (Gupta and Palsule-Desai, 2011; Mota et al., 2015; Seuring and Müller, 2008a)

The TE industry is one of the industries that has been particularly affected by the increasing opportunities for international trading. As a consequence, the economic, environmental and social risks of the upstream supply chain have become very important in practice. Measuring the impact of sustainability practices should be based on either a national or regional approach to cover impacts outside organizational or physical boundaries. This requires an analysis of the deep changes in the global production of the TE Industry in order to capture the three sustainable dimensions at the global level.

Therefore, this chapter will discuss the following challenges. First, it will explain the 3BL sustainable dimensions in the supply chain. This section will focus on the 
challenge of including social dimension indicators in the global supply chain and capturing their influence on overall global supply chain performance. Second, the challenge of analyzing the three-dimensional impact in a global supply chain and understanding the trade-offs that occur between the three dimensions in supply chain decisions is explored. The result of this chapter is to (a) create a definition of the economic, environmental and social dimensions considered by their impact in the global supply chain, (b) identify potential data sources, and (c) explain the sustainability impact calculation.

\subsection{Literature Review of Sustainability in Global Supply Chain Design}

The articles most relevant to the problem addressed in this chapter address the sustainability issues in the supply chain and their influence on global supply chain design. In the current supply chain literature, the majority of research focuses on the economic and environmental pillars of sustainability (Seuring, 2013; Seuring and Müller, 2008b). Many different concepts and methods have already been developed for the economic and environmental performance evaluations of processes, products or economic activities. Some of them are LCA, Life Cycle Cost Analysis (LCCA), the ecological footprint (EF), the measurement of net savings and IO analysis (Čuček et al., 2012a).

Hugo and Pistikopoulos (2005) incorporated an LCA model with eco-indicator 99 methods to calculate the environmental impact and used it in their strategic planning decision approach. Bojarski et al. (2009) embedded the LCA concept in their novel approach for SC design and planning. The LCA method was not used only to quantify overall environmental impact indicators, but also partial environmental impact categories. 
Research by Yue et al. (2016) presented an integrated model for supply chain design, where LCA was coupled with IO analysis to calculate the GHG emission.

Andrew et al. (2009) used the MRIO full model to estimate the national carbon footprint. Crawford (2009) applied an IO-based hybrid method to quantify embodied energy and greenhouse emissions. Ewing et al. (2012) developed the environmentally extended MRIO model that harmonizes ecological and water footprints accounts and aligns physical unit data for product use with standard economic and environmental accounting. Acquaye et al. (2017) applied MRIO analysis to measure the environmental performance of industry electricity and chemical-based on 15 -year time series. A method proposed by Dixit (2017) applied the IO-based hybrid method to quantify the embodied energy of 21 construction materials.

This is in contrast to the research that focuses either on the social factors or the integration of it in the supply chain design, which has seen less investigation (Seuring and Müller, 2008b). The articles most relevant to the problem addressed in this chapter address measuring the social supply chain performance. Particularly, research that focuses on quantifying social indicators, which could be linked to the supply chain of the TE sector.

Benoit-Norris et al. (2012) developed the Social Hotspot Database (SHDB) system as a tool to assess the social hotspots of product life cycles. The system allows data analysts to prioritize which production function is most desirable. The five criteria used in prioritization are labor intensity, risks related to human rights, labor rights, and decent work, lastly, the gravity of social issues. Gopalakrishnan et al. (2012) proposed a framework to integrate the three sustainability aspects. The social aspects included in their research are health and safety issues, community wellbeing, employment opportunity, 
charities, etc. Simas et al. (2014) provided a new perspective on how "bad labor" footprints are associated with global trade products. They implemented the IO method to quantify the social impacts of globalization.

In summary, social issues in the global supply chain literature cover a wide range of aspects and go beyond the limited sector and country boundaries. Consequently, it is necessary to understand which social indicators impact global supply chain design the most. Specifically, social indicators that might be linked to economic and environmental indicators for decision making in the global supply chain design.

\subsection{Methodology}

This study uses the 2008 MRIO table from the WIOD database which consists of a $1435 \times 1435$ matrix of countries-sectors (Dietzenbacher et al., 2013). The database covers 40 countries, including 27 EU countries and China, plus a Rest of the World (ROW) category, which when combined accounts for approximately $80-85 \%$ of the world's GDP (Löschel et al., 2013). The data is disaggregated into 35 manufacturing sectors. Moreover, the WIOD database also contains environmental and socioeconomic inventory datasets that are synchronized with the country-sector MRIO table.

The list of countries and manufacturing sectors covered by the database is given in Tables 3.1 and 3.2. 
Table 3. 1 List of countries in the WIOD database

\begin{tabular}{|l|l|l|l|}
\hline Europe & & America & Asia and Pacific \\
\hline Austria & Latvia & Brazil & Australia \\
\hline Belgium & Lithuania & Canada & China \\
\hline Bulgaria & Luxembourg & Mexico & India \\
\hline China & Malta & United States & Indonesia \\
\hline Cyprus & Netherlands & & Japan \\
\hline Czech Republic & Poland & & South Korea \\
\hline Denmark & Portugal & & Rusia \\
\hline Estonia & Romania & & Taiwan \\
\hline Finland & Slovak Republic & & \\
\hline France & Slovenia & & \\
\hline Germany & Spain & & \\
\hline Greece & Sweden & & \\
\hline Hungary & Turkey & & \\
\hline Ireland & United Kingdom & & \\
\hline Italy & & & \\
\hline
\end{tabular}

Table 3. 2 List of sectors in the WIOD Database

\begin{tabular}{|c|c|c|c|c|c|}
\hline r1 & Agriculture, hunting, forestry and fishing & $\mathrm{r} 13$ & Machinery, NEC & $\mathrm{r} 25$ & Other Air transport \\
\hline $\mathrm{r} 2$ & Mining and Quarrying & $\mathrm{r} 14$ & Electrical and optical equipment & r26 & $\begin{array}{l}\text { Other Supporting and auxiliary transport activities; } \\
\text { activities of travel agencies }\end{array}$ \\
\hline r3 & Food, beverages and tobacco & $\mathrm{r} 15$ & Transport equipment & r27 & Post and tellecomunication \\
\hline $\mathrm{r} 4$ & Textiles and textile product & r16 & Manufacturing \& NEC recycling & $\mathrm{r} 28$ & Financial intermediation \\
\hline $\mathrm{r} 5$ & Leather, leather and footware & $\mathrm{r} 17$ & Electricity, gas and water supply & $\mathrm{r} 29$ & Real estate activities \\
\hline r6 & Wood and product of wood and cork & $\mathrm{r} 18$ & Construction & r30 & Renting of m\&eq and other business activities \\
\hline r7 & Pulp, paper, paper product, printing and publishing & $\mathrm{r} 19$ & $\begin{array}{l}\text { Sale, maintenance and repair of motor vehicles and } \\
\text { motorcycles; retail sale of fuel }\end{array}$ & r31 & Public admin defence; compulsory social activities \\
\hline r8 & Coke, refined petroleum and nuclear fuel & $\mathrm{r} 20$ & $\begin{array}{l}\text { Wholesale trade and commission trade, except of motor } \\
\text { vehicles and motorcycles }\end{array}$ & r32 & Education \\
\hline r9 & Chemicals and chemical products & $\mathrm{r} 21$ & $\begin{array}{l}\text { Retail trade, except of motor vehicles and motorcycles; } \\
\text { repair of household goods }\end{array}$ & r33 & Health and social work \\
\hline $\mathrm{r} 10$ & Rubber and plastics & $\mathrm{r} 22$ & Hotels and restauranys & r34 & Other community, social and personal services \\
\hline r11 & Other non metallic mineral & r23 & Other Inland transport & $\mathrm{r} 35$ & Private households with employed persons \\
\hline $\mathrm{r} 12$ & Basic metals and fabricated metals & $\mathrm{r} 24$ & Other Water transport & & \\
\hline
\end{tabular}

The WIOD database provides Input-Output tables for 1995 - 2014. However, the environmental and socioeconomic inventory datasets only cover until 2009 and 2011, respectively. The newest data that includes monetary, environmental and socioeconomic data for most countries and sectors is the 2008 dataset. Therefore, the 2008 dataset is used in this research. 


\subsubsection{Economic Impact Indicators}

Value-added (VA) for each sector and country is the economic indicator in this research. This follows the Global Value Chain (GVC) introduced by (Timmer et al., 2015) to represent the economic sharing between sectors and countries. We calculate the VA impact on the basis of the WIOD and provide a contribution vector for all countries and sectors in each study, which are also present in the set of 40 countries in the WIOD. After determining the VA impact, we calculate the VA productivity in order to compare the ratio of production and value-added to see the most/least productive sectors and countries with respect to production in the TE industry.

\subsubsection{Environmental Impact Indicators}

Emission impact is the most popular indicator to analyze the environmental footprint in the supply chain. The indicators may range from air, water to soil emissions. Among all types of emissions, gas emission is the most common indicator used in the research of green supply chains. The indicators mainly measure the release of the GHG components, such as $\mathrm{CO}_{2}, \mathrm{~N}_{2} \mathrm{O}$ and $\mathrm{CH}_{4}$ to the air due to supply chain activities. The data is taken from the WIOD environmental inventory data, which enables the calculation of the environmental impact because it uses the same group of countries and sectors as the WIOD MRIO table.

Two indicators of gas emission, namely $\mathrm{CO} 2$ emissions and energy emissions, are used in this research. $\mathrm{CO}_{2}$ emissions are the emissions resulting from energy use and include process-based emissions. In agriculture, for example, it includes manure, 
agricultural soils, and field burning. It does not count any other air emissions such as $\mathrm{N}_{2} \mathrm{O}$ and $\mathrm{CH}_{4}$. The metric for $\mathrm{CO}_{2}$ emission is in 1000 tones (KT).

Energy use emission relevant (EM) is defined as the emission-related to energy use that is populated by sector and energy commodities. It is based on gross energy use but excludes the non-energy use of energy commodities and the input of energy commodities for transformation. For example, it excludes emissions from asphalt for road building or coal that is transformed into coke and coke oven gas. This exclusion is necessary to avoid double counting of emissions. The metric used for energy emissions in terajoules (TJ).

\subsubsection{Social Impact Indicators}

Unlike economic and environmental dimensions, there are no 'common' indicators for the social dimension. Research that discusses social dimensions employ various social indicators in their analysis. For example, in industry-level decision making, research that attempts to include social impact has used the number of jobs offered, severity class of injury, and the CSR scale as indicators. Meanwhile, some other research has included macroeconomic social aspects such as income distribution and employment as indicators.

One thing that is agreed upon by most of the stakeholders in the supply chain is that the social dimension captures the impact that affects human well-being. Thus, worker issues are considered crucial in assessing social impacts. This is the case since it can portray the effect of the supply chain on human well-being, as well as can be measured quantitatively, rigorously and consistently (Papong et al., 2016b). The social footprint 
indicators in this study consist of total employment, wages, working hours by skills, vulnerable employment, fatal occupational injury and nonfatal occupational injury.

1. The total employment - refers to all workers in any status group, such as salaried employees, self-employed, employers, etc. This is used to measure the labor footprint in a supply chain.

2. Wages - refers to the total money paid by employers to their employee by sector. It includes payment for the normal and nonnormal working period, such as money paid on holiday. This is the core concept of the cost of labor footprint. Purchasing Power Parity (PPP) based on USD currency is used to convert the monetary value of other currencies.

3. Working hour - refers to the total worker hours needed to produce goods/services to satisfy demand. Moreover, the working hour data will be classified based on Hour High Skill (HHS), Hour Medium Skill (HMS) and Hour Low Skill (HLS).

4. Vulnerable employment - corresponds to the portion of the labor group with no formal employment agreement, which likely has insufficient working conditions.

5. Fatal occupational injury indicators - the number of cases of an accident that results in injuries leading to death.

6. Non-fatal occupational injuries - cases of an occupational accident where the injured workers are unable to work temporarily or permanently after the incident.

The WIOD social inventory data used in this research are total employment, wages, and working hours. WIOD does not have data for total employment in China, thus the number of the paid workers is used to measure labor footprint for China. Moreover, due to this missing data, we could not quantify vulnerable employment for China. For the 
calculation, we use percentage of vulnerable employment from the World Bank website multiply by the number of employees by sector from the WIOD database as the number of vulnerable employee data.

The statistical data for non-fatal and fatal occupational injuries for some countries were obtained from the International Labor Organization (ILO) databases. The data is based on a 2007 dataset to match the WIOD dataset. Occupational injuries data from ILO consist of 14 major economic sectors, whereas WIOD data covers 35 sectors. Therefore, the fatal and non-fatal injuries inputs were distributed and allocated to each industry in the WIOD according to the proportion of workers with injuries per economic sector. This was calculated based on the assumption that the proportion of workers with injuries for the major economic sectors, would be the same as for specific economic sectors under a major sector (Papong et al., 2016b). In the case of a country where the data is not available in the ILO database, secondary references were used.

For Indonesia, the data for fatal and nonfatal occupational injury was obtained from Irfani (2015) with the assumption that the data distribution across the economic sector in 2008 would be the same as the proportion in 1997. The fatal injuries data for China was estimated using the 2005 fatality rate per economic sector (ILO Office, 2012). If the fatality rate is not available for certain economic sectors, then the national fatality rate was used. For nonfatal occupational injuries, the data was estimated based on the total number of people that benefited from work injury insurance (National Bureau of Statistics of China, 2008) and allocated them to each economic sector based on the proportion of fatal accident cases for China. For India, fatal and nonfatal injuries were estimated using fatal accident rates from Hämäläinen et al. (2009). 
In addition, for the countries that only have the aggregate of total activity data, the disaggregation per sector is based on its economic activity. Some countries with this additional calculation are Canada, India, Indonesia. Considering these limitations, the trade-off could be difficult to perform. Therefore, this research aims to show how the national data could be used for global social and environmental impact as the basis for supply chain design decision making. Figure 3.1 shows the calculations steps of the social impact coefficient database.

\section{Calculation direct social impact coefficient}

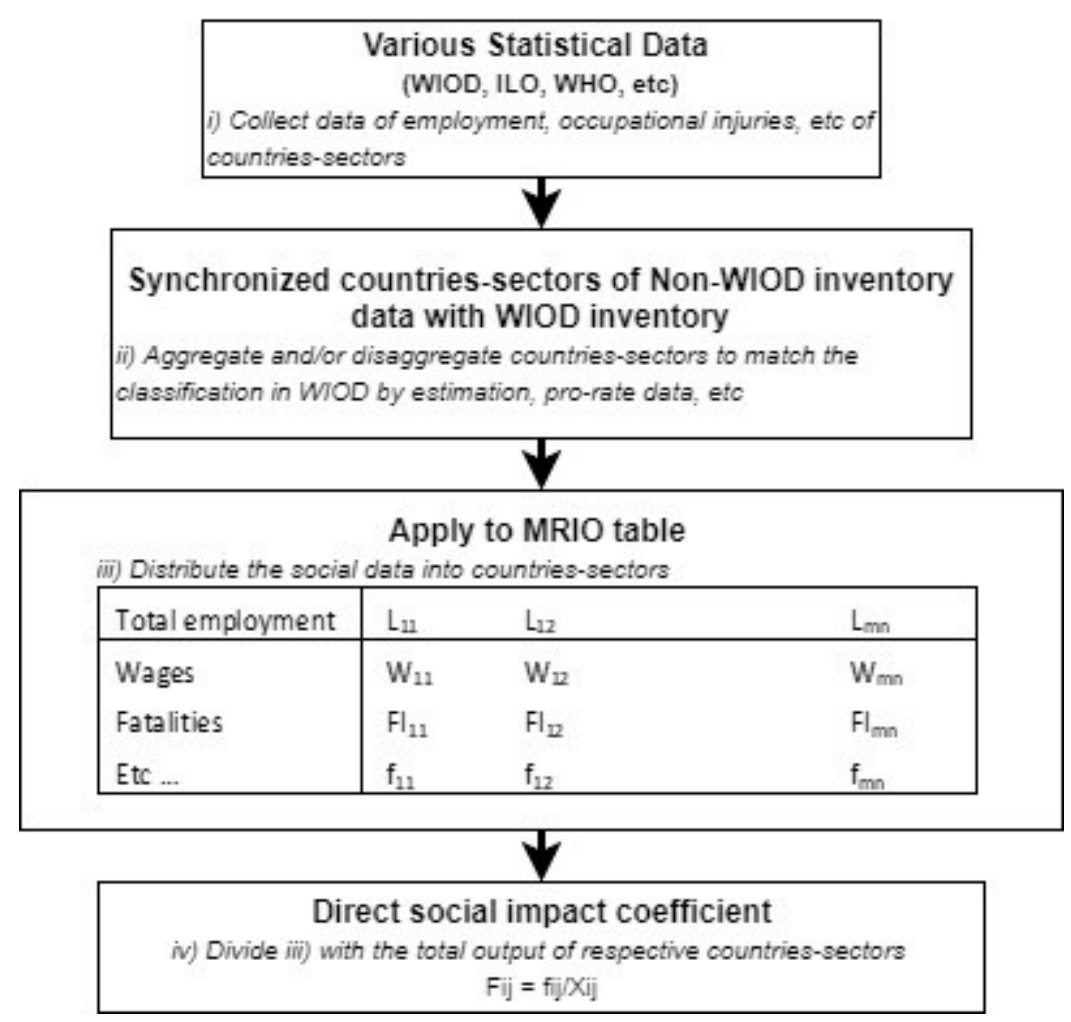

Figure 3. 1 Calculation steps of social impact coefficient 


\subsubsection{Calculation of environmental and social impact}

In this section, the extent to which every sector and country contributes to the production of the TE sector in the US is analyzed. The demand is assumed to be $\$ 1 \mathrm{~B}$ of TE, whereas, the other sectors and countries are zeros. The result of this calculation will capture the environmental and social impact due to the production of Transportation Equipment in the US as the main country and additional impact from other countries. Therefore, the impact generated in the US would be dominant compared to the results from other countries. For the analysis, the social impacts used in the analysis are working hours, total employees, labor wages, fatal incidents, and non-fatal incidents footprints.

The environmental and social impacts are calculated using the MRIO approach. First, the environmental and social coefficient matrix $(F)$ is computed by dividing the total impact of each indicator with the total output of each country and sector (Equation 2.5). Then, the technical-economic coefficients are calculated $(A)$ using Equation 2.2. The total footprints for specific environmental and social indicators can be calculated using the IO approach following Equation 2.4. The calculation steps are presented in Figure 3.2.

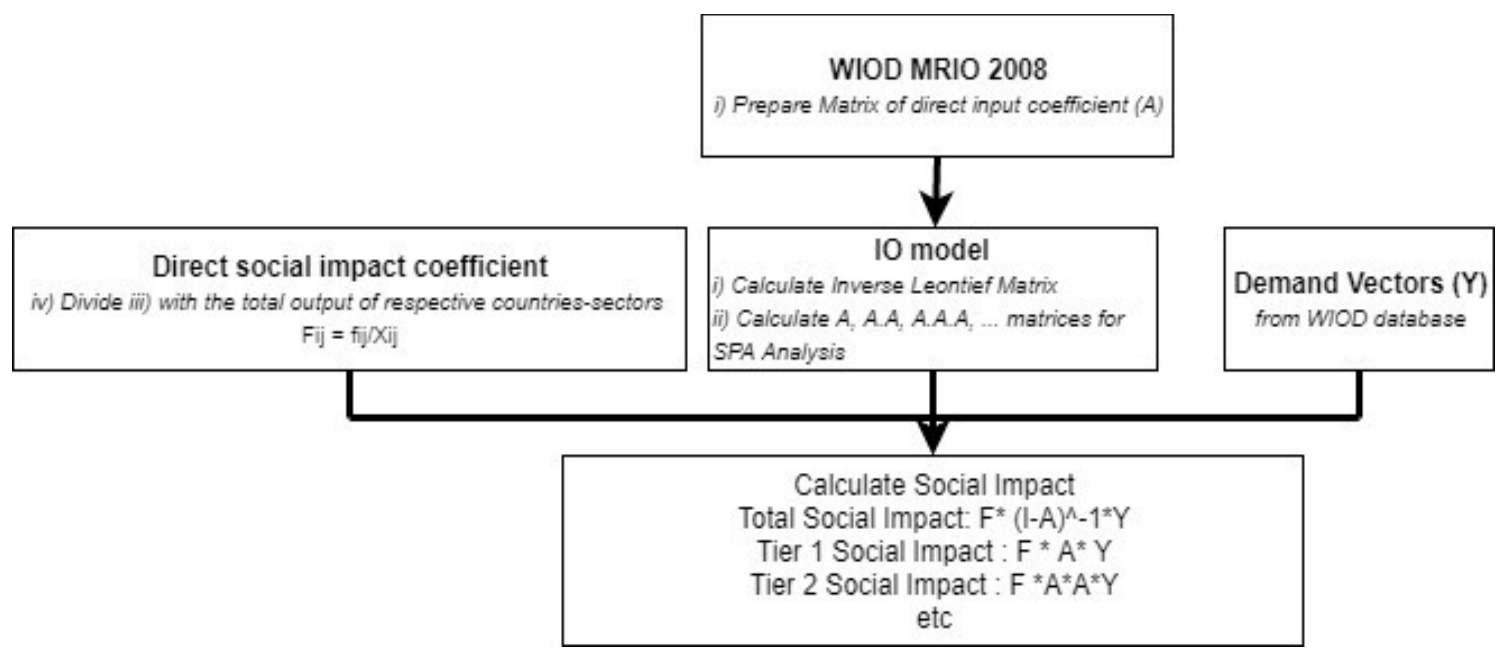

Figure 3. 2 The Calculation Steps for Social Impact 
Table 3.3 summarizes the total social and environmental multiplier coefficients by country. The asterisk $(*)$ sign indicates the highest coefficient for each indicator and the double asterisk $\left({ }^{*}\right)$ is the lowest. The table shows that India has the highest multiplier for total employee, vulnerable employee and the working hour coefficient followed by Indonesia. Although China ranks third in the number of employment, due to the limited available data, this research only used the data for the number of paid workers, instead of the total employment to represent the total employment. Thus, the real total employment of China could be a lot more. Cyprus is the country with the highest wages coefficient (\$wages/\$output). This means Cyprus is the country with the most expensive labor cost. The country with the least wage coefficient is France.

For fatal incidents, India is the country with the highest coefficient, while Malta is the highest for the non-fatal incidents. UK, Netherland, and Denmark are the countries with lowest fatal coefficients. Due to data limitations, this study does not capture the number of non-fatal incidents for several countries (India, China, and South Korea). Thus, the multiplier coefficient in Table 1 does not show the coefficient value of those countries. In addition, Taiwan has the highest coefficient for both environmental indicators; $\mathrm{CO}_{2}$ and Energy Emission. 
Table 3. 3 Environmental and Social Coefficient

\begin{tabular}{|c|c|c|c|c|c|c|c|c|}
\hline Country & $\begin{array}{c}\text { Total } \\
\text { Employee } \\
\text { (per MS) }\end{array}$ & $\begin{array}{c}\text { Wages } \\
(\mathrm{S} / \mathrm{S})\end{array}$ & $\begin{array}{c}\text { Working } \\
\text { Hour } \\
(\mathrm{Hr} / \mathrm{S}) \\
\end{array}$ & $\begin{array}{c}\text { Vulnerable } \\
\text { Employee } \\
\text { (per MS) }\end{array}$ & \begin{tabular}{|c|} 
Fatal \\
(\#case/MS)
\end{tabular} & $\begin{array}{l}\text { Non-Fatal } \\
\text { (\#case/MS) }\end{array}$ & EM (MJ/S) & $\mathrm{CO}_{2}(\mathrm{~kg} / \mathrm{S})$ \\
\hline AUS & 200.18 & 10.15 & 0.36 & 23.37 & \begin{tabular}{|l|}
0.006 \\
\end{tabular} & 1.82 & 160.94 & 11.58 \\
\hline AUT & 289.64 & 11.62 & 0.4 & 36.81 & 0.004 & 2.37 & $69.69 * *$ & $1.54^{* * *}$ \\
\hline BEL & 214.84 & 10.25 & 0.31 & 21.1 & 0.007 & 3.32 & 120.36 & 6.37 \\
\hline BGR & $1,505.32$ & 7.22 & 2.49 & 274.47 & 0.075 & 1.83 & 284.58 & 16.58 \\
\hline BRA & $1,296.70$ & 9.81 & 2.8 & 302.21 & 0.058 & 11.31 & 158.62 & 6.25 \\
\hline $\mathrm{CAN}$ & 296.64 & 9.27 & 0.52 & 22.39 & 0.008 & 4.65 & 211.69 & 10.78 \\
\hline $\mathrm{CHN}$ & $2,753.46$ & 4.98 & 5.58 & 0 & 0.179 & 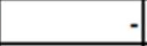 & 231.36 & 17.61 \\
\hline CYP & 489.7 & $22.75^{*}$ & 0.95 & 84.05 & 0.024 & 2.81 & 168.68 & 13.46 \\
\hline CZE & 470.33 & 10.76 & 0.92 & 69.5 & 0.029 & 8.04 & 164.34 & 8.37 \\
\hline DEU & 291 & 11.85 & 0.38 & 26.76 & 0.007 & 7 & 106.1 & 5.71 \\
\hline DNK & 202.33 & 11.74 & 0.32 & $10.63^{* *}$ & 0.002 & 2.43 & 102.29 & 6.75 \\
\hline ESP & 233 & 9.39 & 0.38 & 30.2 & 0.008 & 11.89 & 118.04 & 4.91 \\
\hline EST & 515.88 & 8.9 & 0.99 & 35.22 & 0.019 & 3.82 & 237.71 & 17.35 \\
\hline FIN & 224.9 & 10.91 & 0.37 & 21.94 & 0.003 & 6.48 & 165.86 & 7.25 \\
\hline FRA & 202.29 & $1.32 * *$ & 0.3 & 15.81 & 0.006 & 5.76 & 112.09 & 4.05 \\
\hline GBR & 215.01 & 12.47 & 0.33 & 26.19 & $0.002^{* * *}$ & 1.29 & 91.29 & 6.83 \\
\hline GRC & 378.04 & 12.75 & 0.79 & 109.05 & 0.003 & 0.35 & 135.49 & 11.41 \\
\hline HUN & 581.14 & 9.11 & 1.15 & 53.96 & 0.021 & 4.18 & 116.43 & 6.38 \\
\hline IDN & $3,658.86$ & 7.81 & 5.3 & $1,752.51$ & 0.521 & 23.91 & 312.49 & 21.3 \\
\hline IND & $7,084.91 *$ & 9.13 & 16.93* & $2,578.16^{*}$ & $1.123 *$ & 0.03 & 315.62 & 22.83 \\
\hline IRL & 199.54 & 10.33 & 0.37 & 37.36 & 0.006 & 2.81 & 84.26 & 4.64 \\
\hline ITA & 259.05 & 10.83 & 0.47 & 42.42 & 0.009 & 5.29 & 85.62 & 5.07 \\
\hline JPN & 266.2 & 10.47 & 0.49 & 56.74 & 0.007 & 0.62 & 126.3 & 7.29 \\
\hline KOR & 385.37 & 10.28 & 0.88 & 126.66 & 0.013 & & 190.68 & 12.11 \\
\hline LTU & 868.4 & 11.21 & 1.65 & 105.29 & 0.074 & 2.54 & 206.76 & 6.25 \\
\hline LUX & $170.97 * *$ & 10.35 & $0.28 * *$ & 14.84 & 0.018 & 1.35 & 90.79 & 2 \\
\hline LVA & 679.72 & 9.01 & 1.07 & 66.62 & 0.043 & 1.73 & 127.17 & 5.26 \\
\hline MEX & $1,708.23$ & 7.5 & 3.5 & 965.69 & 0.038 & 3.89 & 189.43 & 11.36 \\
\hline MLT & 394.45 & 10.83 & 0.74 & 46.74 & 0.014 & $46.77^{*}$ & 151.15 & 8.05 \\
\hline NLD & 274.76 & 9.25 & 0.31 & 116.73 & 0.002 & 17.58 & 99.14 & 5.41 \\
\hline POL & 642.24 & 9.95 & 1.15 & 112.97 & 0.027 & 5.02 & 165.18 & 11.74 \\
\hline PRT & 453.92 & 10.79 & 0.82 & 66.04 & 0.021 & 14.57 & 114.43 & 6.13 \\
\hline ROU & 912.92 & 9.3 & 1.74 & 146.65 & 0.063 & 0.67 & 146.49 & 9.02 \\
\hline ROW & & - & & - & - & - & 353.29 & 22.69 \\
\hline RUS & $1,336.15$ & 9.52 & 2.55 & 223.92 & 0.039 & 0.87 & 402.56 & 19.13 \\
\hline SVK & 517.92 & 6.81 & 0.91 & 55.6 & 0.028 & 4.28 & 128.01 & 6.85 \\
\hline SVN & 393.07 & 11.92 & 0.66 & 59.55 & 0.016 & 15.06 & 125.33 & 5.95 \\
\hline SWE & 178.54 & 10.92 & 0.3 & 11.38 & 0.004 & 1.26 & 143.05 & 4.53 \\
\hline TUR & 601.47 & 7.66 & 1.15 & 169.5 & 0.09 & $0.14^{* *}$ & 145.12 & 10.55 \\
\hline TWN & 589.1 & 9.87 & 1.29 & 146.2 & 0.026 & 2.58 & $431.46^{*}$ & $33.01^{*}$ \\
\hline USA & 240.32 & 10.96 & 0.42 & 13.65 & 0.009 & 1.93 & 224.65 & 13.09 \\
\hline
\end{tabular}

*The highest coefficient

** The lowest coefficient 


\subsection{Results and Discussions}

Using the methodology discussed above, both the sustainable impacts of the entire supply chain and individual tiers can be computed.

\subsubsection{Economic Impact}

Figure 3.3 shows that the production of TE in China requires around $20 \%$ more production value than production in the USA. The production value includes indirect economic share from other sectors and countries in the upstream supply chain to fulfill TE demand. Although both countries cannot fulfill the demand in their own countries, they utilize most of their domestic production compared to production from other countries. The figure also shows that the USA is slightly more dependent on production from other countries than China.

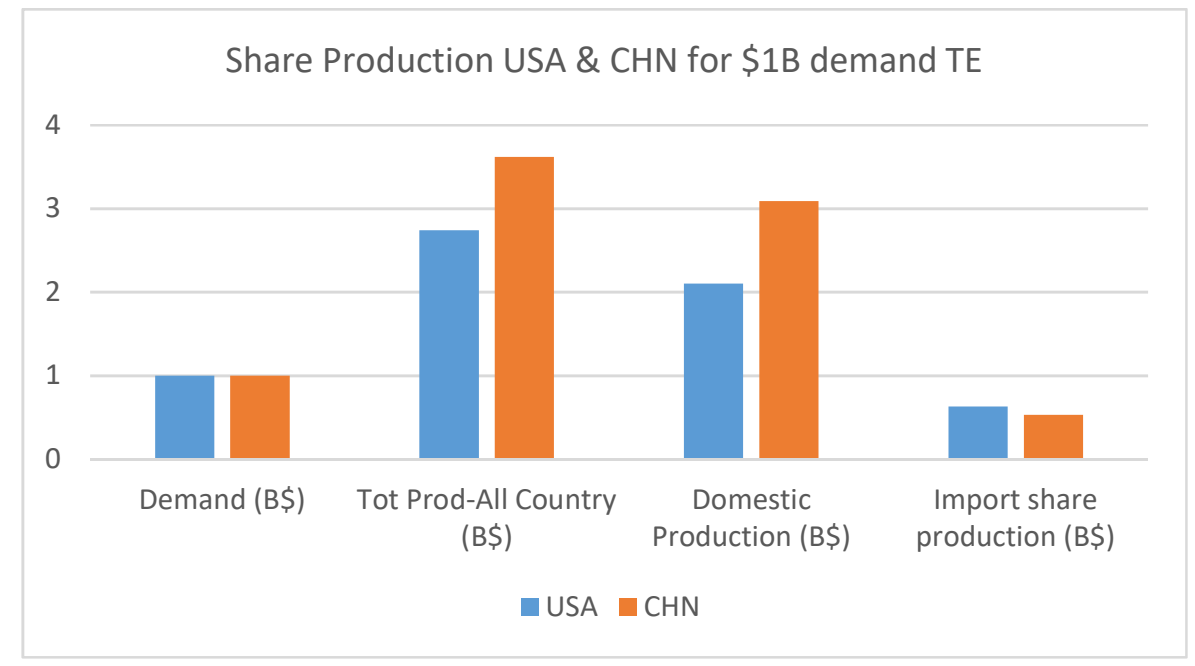

Figure 3.3 Production share for 1B USD Demand of sector TE 
The economic impact used in this analysis is the economic productivity by countriessectors needed to produce \$1B USD of sector TE value. Productivity in this research is calculated by dividing the value added with the total production.

Table 3.4 shows that the economic productivity in the USA is higher than the economic productivity in China. This shows there is a significant gap in economic activities in both countries. One dollar of production value in China returns $\$ 0.001$ value-added. This indicates there are waste sources in China production, which could be in the form of material, labor hour, etc. within the sectors.

Table 3. 4 Value-Added and Productivity of China and the USA

\begin{tabular}{|l|c|c|}
\hline Label & VA CHN & VA USA \\
\hline Direct TE VA (\$) & $2.81 \mathrm{E}+08$ & $3.18 \mathrm{E}+08$ \\
\hline Indirect VA (\$) & $6.97 \mathrm{E}+08$ & $6.53 \mathrm{E}+08$ \\
\hline Productivity TE & 0.001044 & 0.262989 \\
\hline Productivity Indirect & 0.001716 & 0.427543 \\
\hline
\end{tabular}

Figure 3.4 shows the sectors that are important to the TE industry supply chain in both countries. Besides the TE as the direct sector, the metal sector is the most important sector in the supply chain of TE industries in both the US and China. In the US, services sectors, such as renting and wholesaler sectors, are the next important sectors for the TE industry. China depends on its manufacturing industry, which is the machinery and the electronic and optic manufacturing to support the activities of its sector TE. For this research, based on the economic activities considered, the top four sectors by country are used as the main sectors for environmental and social impact analysis in the rest of the chapter. The top four sectors based on economic activities in the USA are TE, Metal, 
Renting, Wholesaler, whereas the top four sectors in China TE, Metal, Machine and Electric and Optic.
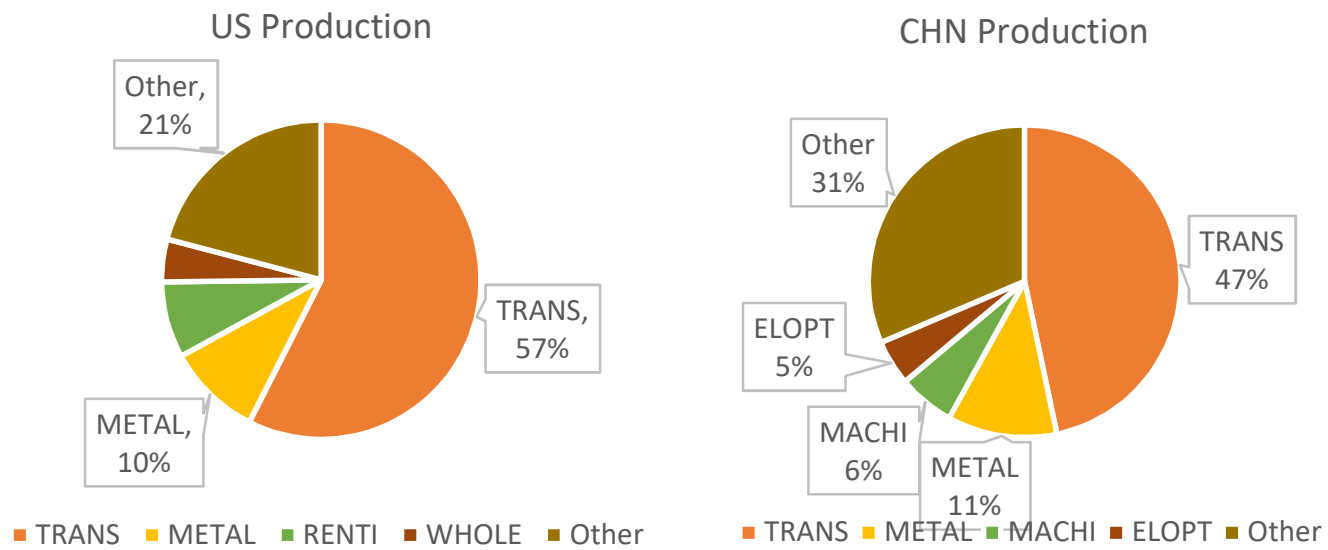

Figure 3. 4 Domestic production share by sectors

\subsubsection{Environmental Impact}

Similar to the economic impact, the environmental impact of \$1B USD production of the TE sector also shows that China produces more than twice the $\mathrm{CO}_{2}$ emission and around five times higher total energy use emission. Table 3.5 and Figure 3.5 shows the environmental impact of both countries.

Table 3.5 The environmental impact of the USA and China

\begin{tabular}{|c|r|r|}
\hline Label & \multicolumn{1}{|c|}{ USA } & \multicolumn{1}{c|}{ CHN } \\
\hline Total CO2 $(\mathrm{T})$ & 423,448 & $1,095,686$ \\
\hline Total EM (TJ) & 4,575 & 22,818 \\
\hline
\end{tabular}




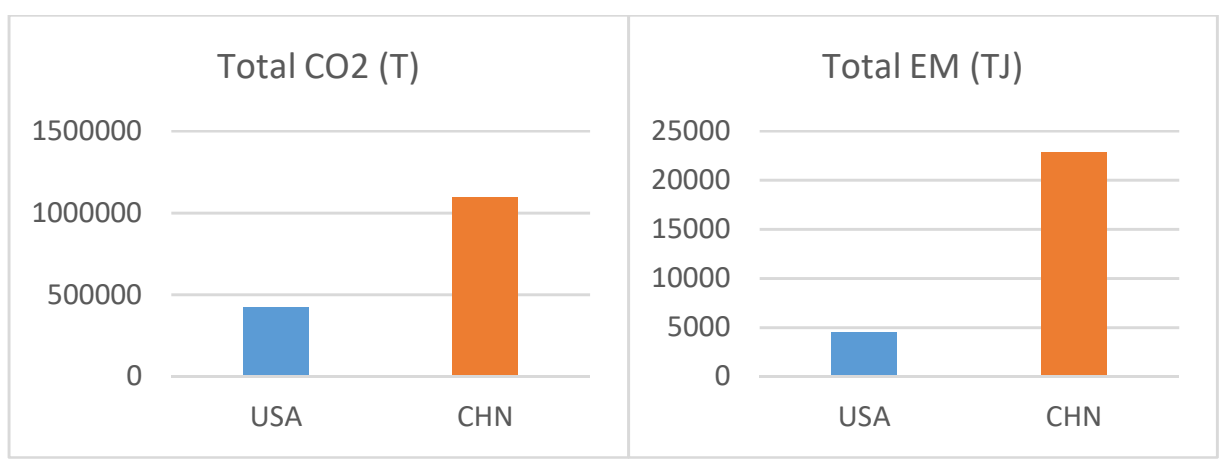

Figure 3. 5 Comparison of $\mathrm{CO}_{2}$ and Energy use emissions in the USA and China

Emission impacts by economic sector can be used as a suitable indicator to show the level of emission technology. This result indicates there is a significant gap between the technology used in these two countries. This is mainly because the TE sector in China uses energy commodities with higher $\mathrm{CO}_{2}$. From Figure 3.6, one can conclude that China mainly uses coal and electricity as the main energy commodities for sector TE, whereas the USA uses natural gas and electricity.

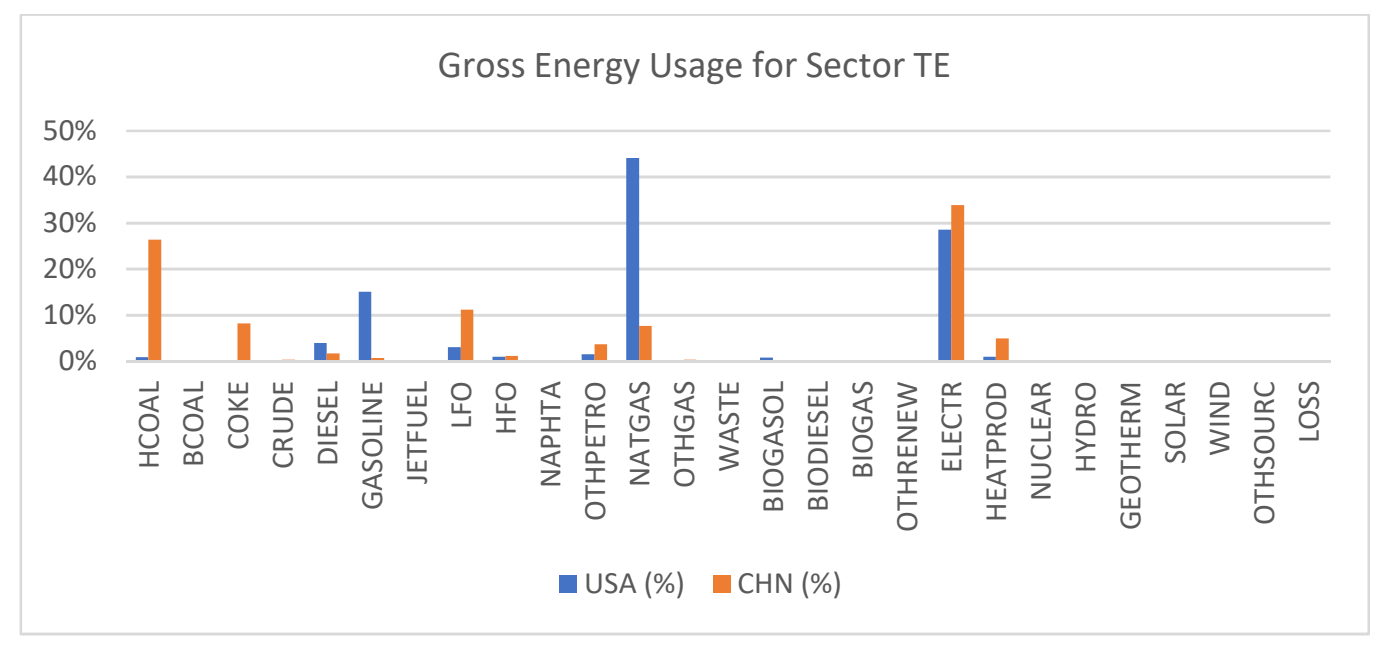

Figure 3. 6 Comparison of Energy Use for sector TE in USA and China 
In addition, the electricity industry is significant in generating emissions in both countries. By analyzing the energy commodity usage of the electricity sector, one can estimate the distribution of energy usage for other industries. Figure 3.7 shows that China mainly uses coal to generate its electricity, while the USA uses a combination of coal, nuclear power, and natural gas. This figure explains the higher $\mathrm{CO}_{2}$ and energy use emissions of China compared to the USA. In conclusion, China has a higher environmental impact compared to the USA, thus this will influence supply chain sustainability.

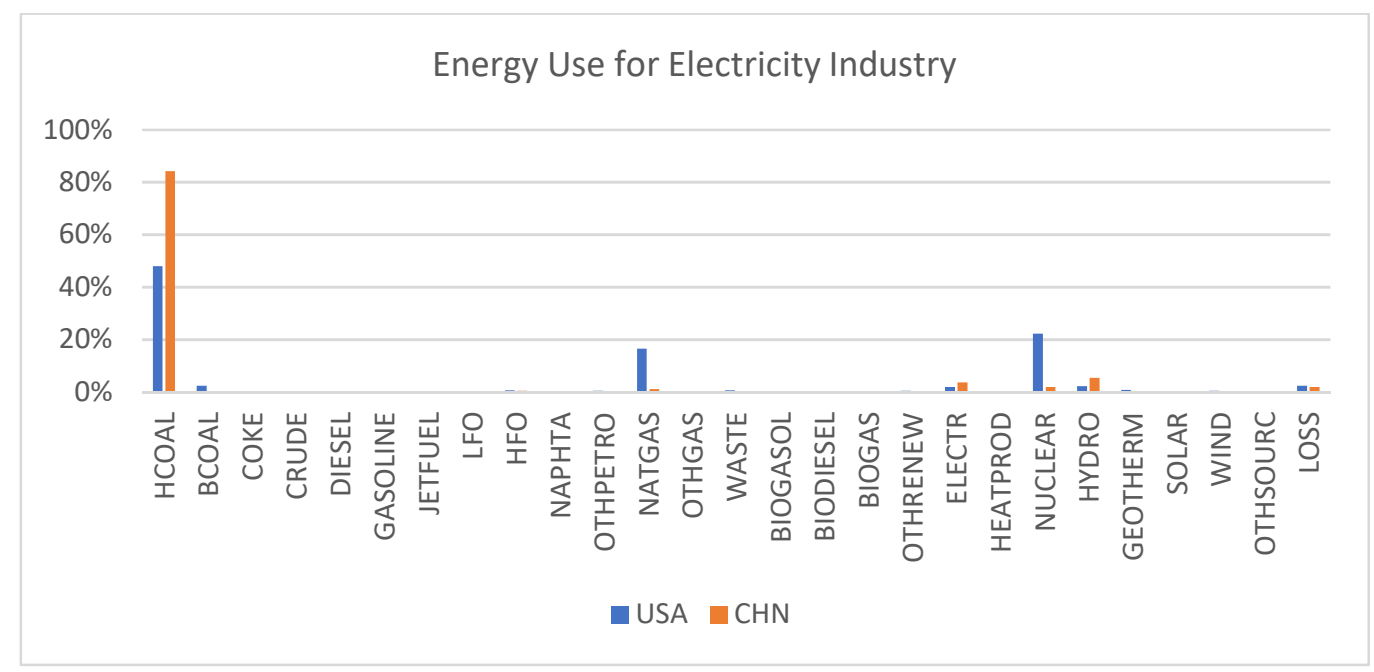

Figure 3. 7 Comparison of Energy Use for Electricity Industry in the USA and China

This finding corresponds to the detail figures showing environmental impact. The sector with the highest $\mathrm{CO}_{2}$ emission and energy use emission in China is the electricity sector. The metal and coke sectors are the next highest contributors to the level of EM emission in China. One can notice from Figure 3.8 that the highest $\mathrm{CO}_{2}$ emission of the TE sector in the USA comes from the TE sector itself. 


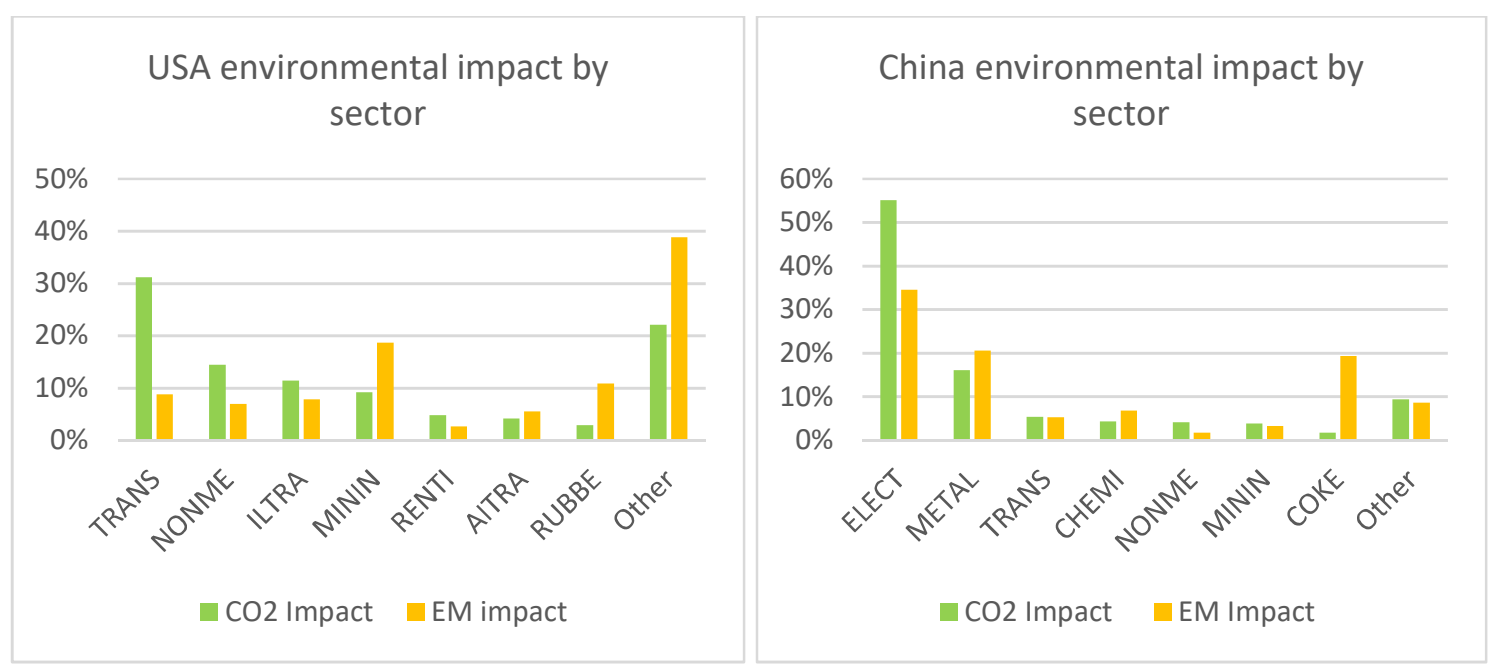

Figure 3. 8 Comparison of environmental impact in China and USA by sectors

It is important to point out that the highest $\mathrm{CO}_{2}$ emission does not always follow a linear relationship with the energy use emission. This indicates that the majority of the $\mathrm{CO}_{2}$ emission in the TE industry sector does not only come from energy used. In the USA, $\mathrm{CO}_{2}$ emissions come from transportation, chemical reactions, commercial and residential (EPA, 2017). The results also show that the group of "Other" sectors is the sector with the highest EM emission contributors in the supply chain, followed by the mining sector.

\subsubsection{Social Impact}

\section{Employment Impact}

The social impact in the USA and China is summarized in Table 3.5 and Figure 3.9. The employment impact is expressed in terms of person-year per \$1 billion USD output of the TE sector supply chain. The result shows that China has six times higher labor intensity than the USA. 
Table 3. 6 Social Impact of USA and China

\begin{tabular}{|l|r|r|}
\hline \multicolumn{1}{|c|}{ Label } & \multicolumn{1}{c|}{ USA } & \multicolumn{1}{c|}{ China } \\
\hline Employment (person) & $14,075.04$ & $75,444.90$ \\
\hline Wages (\$) & $5.36 \mathrm{E}+08$ & $1.60 \mathrm{E}+08$ \\
\hline Working hour & $29,174,058.20$ & $163,716,410.37$ \\
\hline Vulnerable employment & 2478 & 29507 \\
\hline Fatal (cases) & 0.73 & 8.02 \\
\hline Non-Fatal (cases) & 540.14 & $9,181.28$ \\
\hline
\end{tabular}

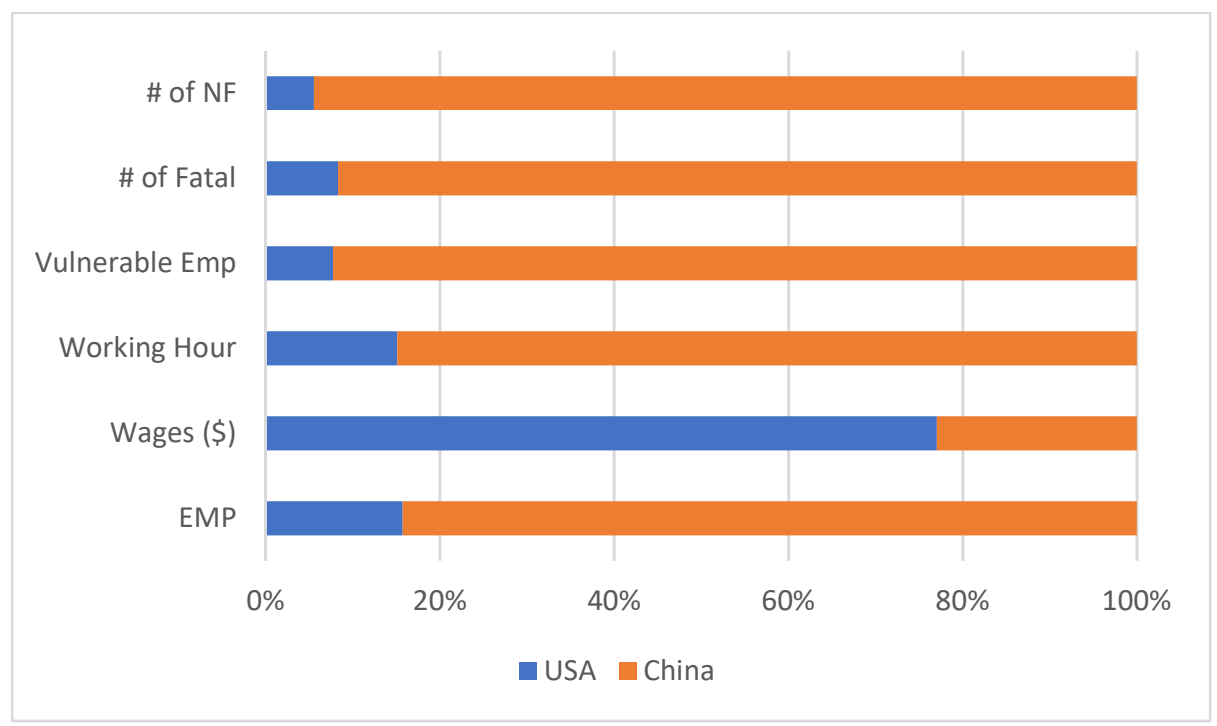

Figure 3. 9 Proportion of social impacts of sector TE China and the USA

The distribution of employment intensity for the four main economic sectors in China is presented in Figure 3.10. Interestingly, the four main economic sectors for the TE supply chain are only responsible for around $31 \%$ of the total labor intensity. This indicates that the four industries are quite significant in providing job opportunity for the people of China. However, this may influence the productivity. By looking at the nature of the four industries that generally require high technology, this may become one of the reasons of this result. Less employment intensity can increase the labor productivity of a sector. This also can reduce the risk of occupational incidents. This result shows there is a trade-off 
between economic and social impacts, thus supporting the importance of an integrated analysis to design a sustainable supply chain that includes economic, environmental and social dimensions.

The employment intensity of the four top economic sectors in the USA contributes $55 \%$ of the total employment. This means that the top four economic sectors will generate a lot of labor. This is expected because two of the sectors are service industries, which depend more on labor than on machines. From an economic perspective, this is good as it reduces unemployment.

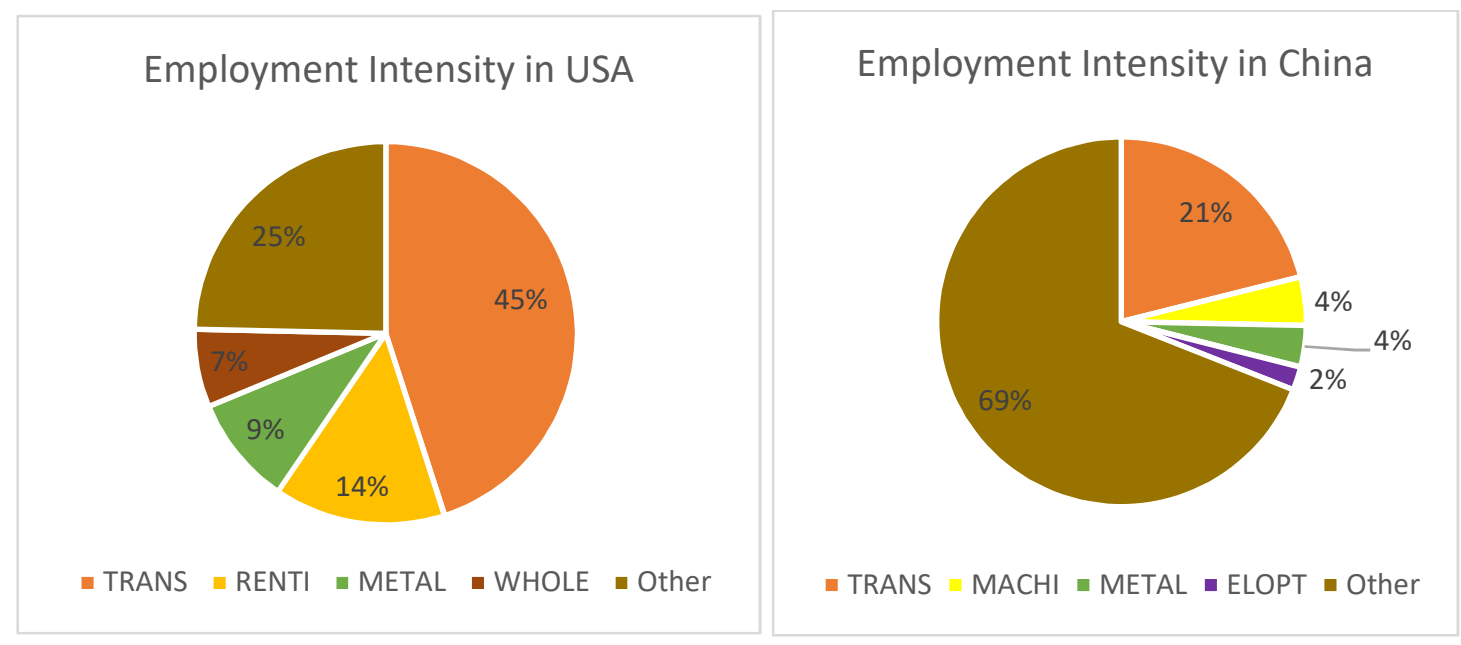

Figure 3. 10 Distribution of employment intensity in the USA and China

\section{Wages Impact}

The wage impact stated in terms of USD-year per \$1 billion USD output of the TE sector is given in Table 3.6. Figure 3.11 presents the distribution of wages by top four economic sectors in both countries. In both countries, the TE sector dominates the percentage of wages in comparison to other sectors. 

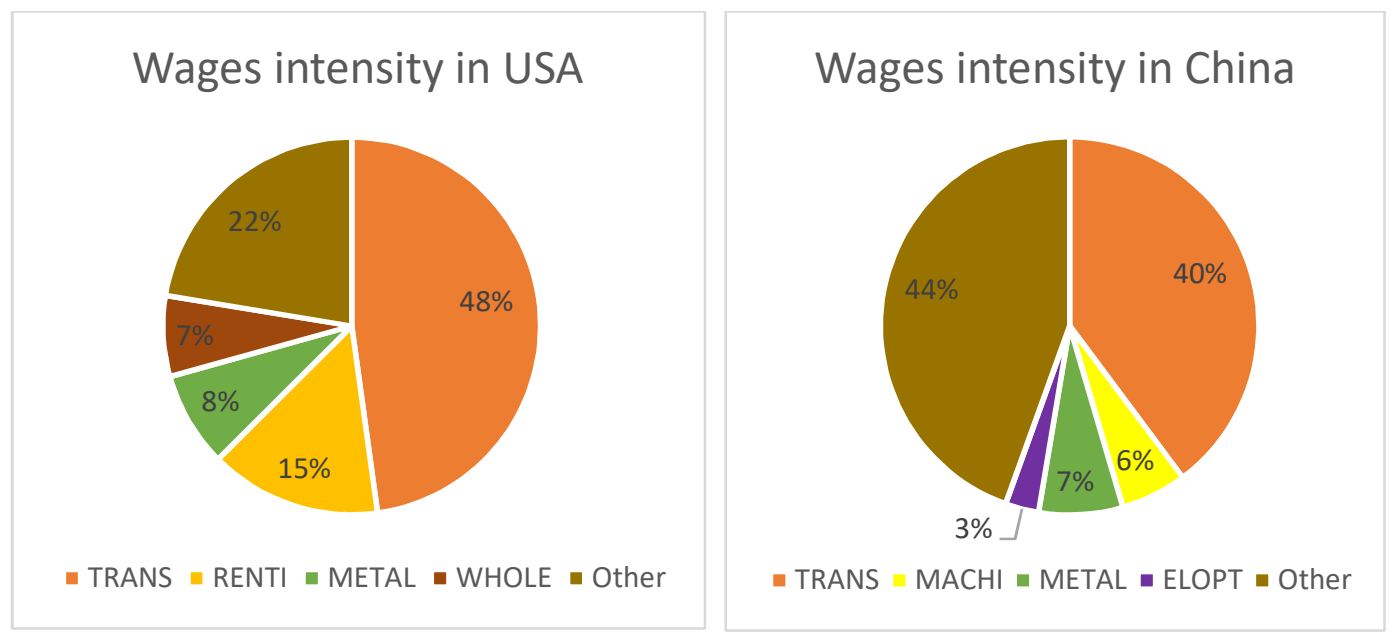

Figure 3. 11Distribution of wages intensity in USA and China

In contrast to the employment result, the wage impact shows five times higher labor cost intensity in the US versus China. The main reason is that US labor standard payment is higher than China. Chinese automotive industries experience insufficient protection of wages, and also have a large pay differential between first-tier and lower-tier companies (Lüthje, 2014). Moreover, particularly for TE sector, China employs more low skill and medium skill labor than the USA. Figure 3.11 shows the working hour of US and China total labor hours by skill level.

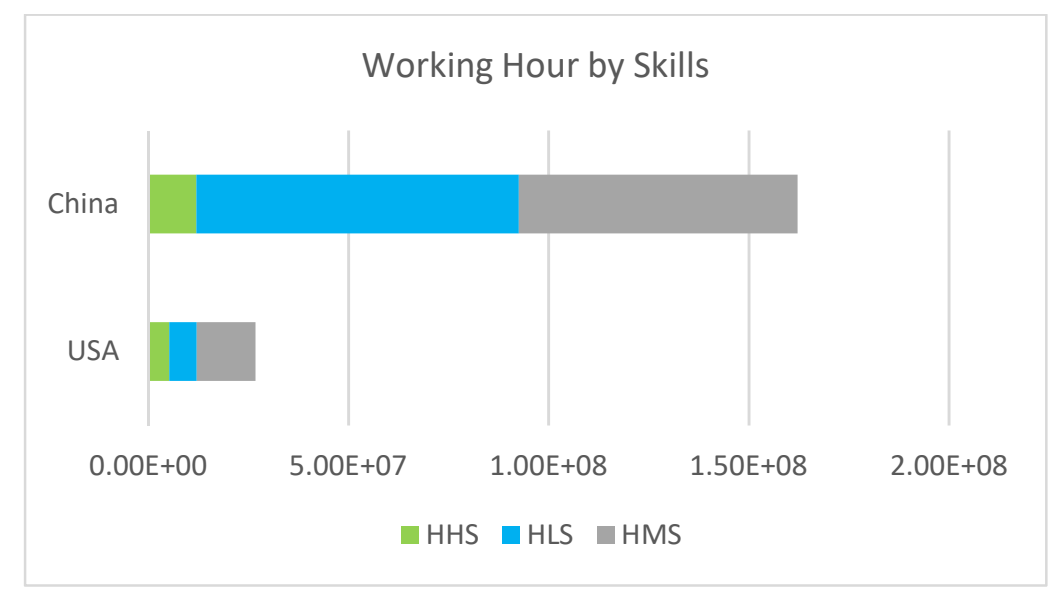

Figure 3. 12 The working hour impacts by skills 


\section{Working Hour Impact}

The working hour impact stated in terms of hour-year per \$1 billion USD output of the TE sector is given in Table 3.6. As expected, China needs more workers to produce the same value of transport equipment. The figure for total working hour impact is similar to employment. The figure shows that to produce 1B USD transport equipment in China requires almost $163 \mathrm{M}$ hours, but only $30 \mathrm{M}$ hours if produced in the USA. A possible reason for this is that TE sector in the USA uses more advanced technology than in China. Thus, the China TE sector needs more employees than in the USA.

\section{Vulnerable employment impact}

The result of the total embodied vulnerable employment impact is presented in Figure 3.12. The vulnerable employment impact in China is about $40 \%$ of the total employment, while it is only around $17 \%$ in the USA. The vulnerable employment indicates the percentage of employment with weak development, little job growth, and often a largely rural economy, thus it is undesirable in the supply chain (Worldbank, 2018). However, vulnerable employment is not concentrated in the four main sectors of the TE supply chain. The reason is that these four main sectors use more advanced technology than other sectors, thus they have lower employment intensity (Lüthje, 2014; Sardy and Fetscherin, 2009). 


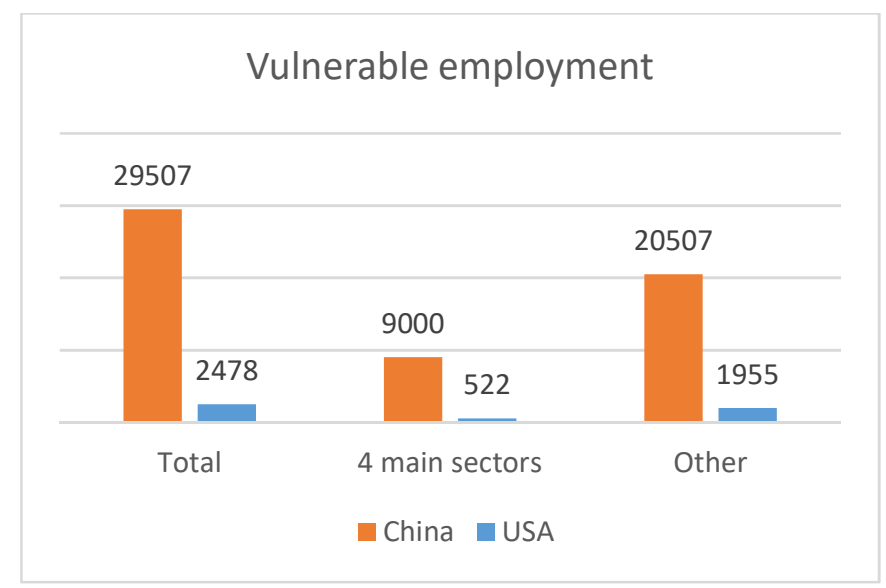

Figure 3. 13 Number of Vulnerable employment

\section{Fatal Incident Impact}

The fatal incident impact expressed in terms of a number of cases-year per $\$ 1$ billion USD output of sector TE is given in Table 3.6. The fatal incident is related to the employment intensity. Countries-sectors with higher employment intensity have a higher probability of fatal incident impact. As expected, the result shows that China has more fatal incident cases than cases in the USA. Besides the employment intensity, which is very high in China, another cause might be due to sectors that are considered dangerous for workers.

Further analysis was performed to determine which sectors are the most severe compared to other sectors. Figure 3.14 shows that the mining industry is the sector that contributes the most to fatal incidents in the USA TE supply chain. Moreover, the majority of the incidents in the mining industry happens in China as a result of indirect supply from China. This finding shows the importance of countries-sector social intensity on the total social impact of a supply chain. Nevertheless, the mining sector is not as important as the metal or transportation sectors from an economic perspective. However, it is very important if the social impact is the main consideration for decision making. 


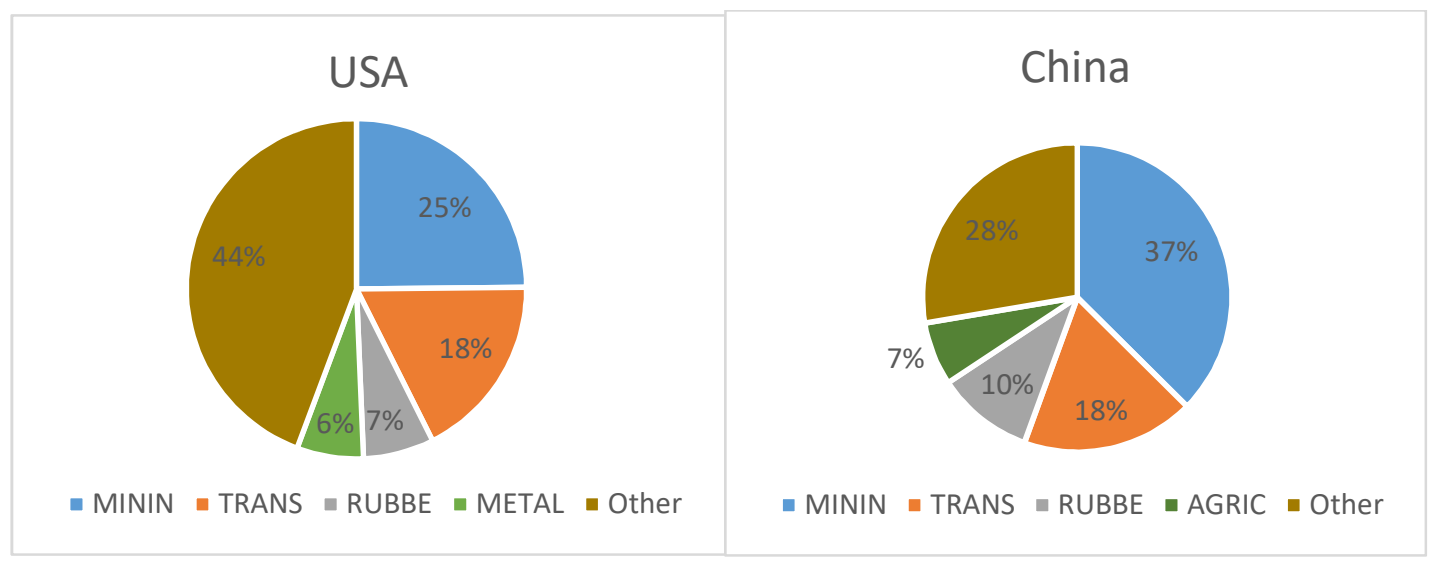

Figure 3.14 The proportion of fatal incident in the US and China TE supply chain by sector

\section{Non-Fatal Incident Impact}

In this analysis, the non-fatal incident conveys the number of non-fatal incident cases-year per $\$ 1$ billion USD output of the TE sector is given in Table 3.6. The result shows that the production of TE in China will result in a non-fatal incident impact that reaches 9,000 cases. While the number of cases is around 540 cases in the USA. The employment intensity, which is very high in China, maybe the main cause of this higher number of cases.

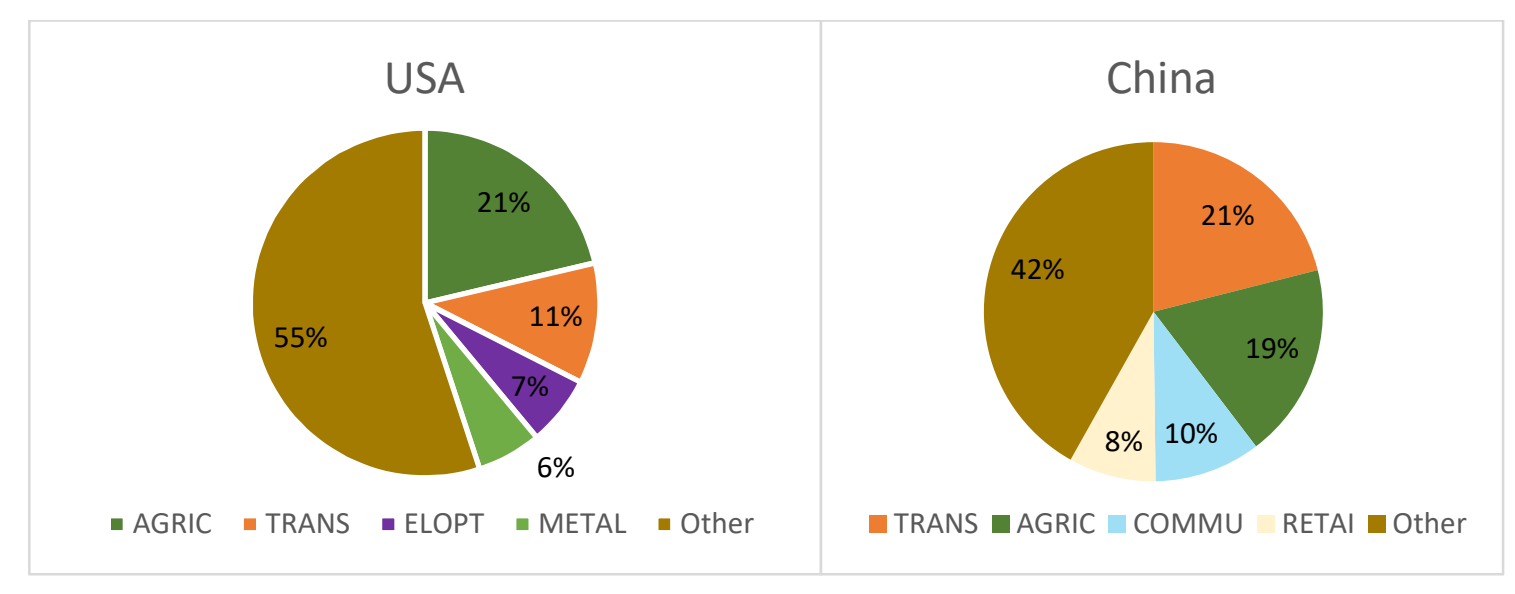

Figure 3. 15 Non-fatal cases by sector in USA and China TE supply chain 
Figure 3.15 shows the analysis of a number of cases by sector in the USA and China TE sector. In China, the result shows a similar pattern to the employment impact. This indicates that the employment intensity is the main factor that determines the number of non-fatal cases in the supply chain. This can be seen from sectors with higher employment intensity such as TE and Agriculture, which are the sectors where the most nonfatal incident cases are found.

\subsection{Conclusion}

The integration of environmental and social criteria in SSC design is needed to evaluate the impact of a supply chain on its stakeholders. This chapter presented an IO based economic, environmental and social impact analysis. It uses the USA Transport Equipment sector considering the international trade-links in the year 2008 as the base case for analysis. Analysis of the results revealed each environmental and social hotspot for the Transport Equipment sector and established a solid basis for future studies for using the IO framework for decision or policymakers.

The results point out the supply chain "hotspots" and enable decision/policymakers to develop more effective and sector-specific strategies to control the intensity of those footprints. The results of this analysis indicate sectors and countries might have different supply chain characteristics when environmental and social footprints are included in the decision making. Hence, each sector may require different effort to control their environmental and social footprints, thus a one-fit solution most likely would not be best 
and would require additional consideration to develop more effective and accurate analysis. 


\section{CHAPTER 4 INTEGRATED SUPPLY CHAIN AND INPUT- OUTPUT MODEL}

In the sustainable supply chain literature, an increasing number of optimization models have been proposed to analyze the supply chain from a wider perspective which integrates economic and environmental objectives. However, only a few studies have quantified and optimized social impacts in the supply chain. Integrated hybrid LCA is one of the methods that has been used by researchers when conducting sustainability studies. As a pioneer in this area, Suh (2004) proposed a model that combines process-based LCA and IO-based LCA to cover both life cycle processes and the macroeconomic system. Therefore, the sustainability impact as a result of this approach addresses both processbased activity and economy-wide aspects.

Yue et al. (2016) used the structure of an integrated hybrid LCA and then proposed an integrated hybrid LCO model, which is used not only for defining the sustainability impact factors but also decision making. Their proposed hybrid LCO framework was tested on a limited number of studies, mainly in the biofuel industry, and only included economic and environmental impacts of the supply chain.

This research proposes an integrated SC and IO model as the method to analyze sustainable supply chains. It considers the triple bottom line of sustainable dimensions. The model adopts the structure of the integrated hybrid LCO and consists of four parts: the SC system, the IO system (S), upstream cutoffs and downstream cutoffs (Yue et al., 2016). Figure 4.1 shows the relationship between these four systems. 


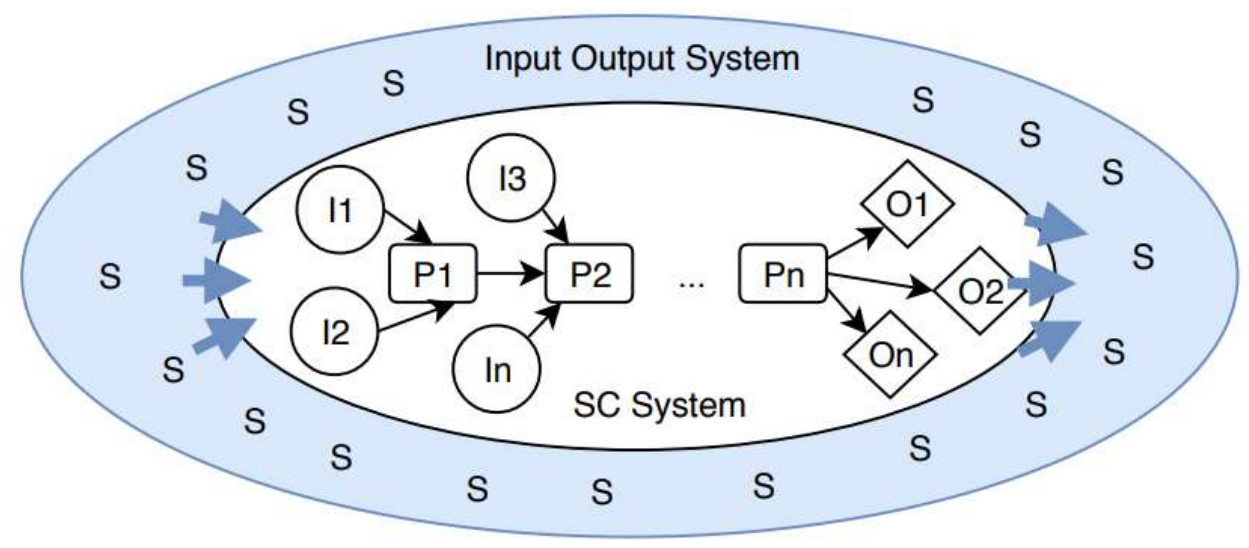

Figure 4. 1 The Integrated SC-IO framework

Downstream cut-offs show that the functional flow produced by the processes is supplied not only within the process-based system but also outside the system. For example, the disposal process supplies its service not only to the car use process within the SCM boundary but also to manufactured products and other products and services. Meanwhile, the upstream cut-off shows the amount, in monetary terms, of cut-off from input-output commodity $i$ to process $j$ during the unit operation time.

The goal of the approach presented in this chapter is to determine the supply chain structure and the flow amounts when three performance dimensions are optimized both individually, and then together in a global environment. Therefore, the ultimate result is minimizing the global supply chain cost, the environmental impact, and the social impact. The model developed is described in detail in the next section. 


\subsection{Mathematical Formulation of the Integrated SC-IO Model}

This section presents the Integrated SC-IO model formulation. As previously mentioned, the model follows the structure of the integrated hybrid LCO model. An important aspect of the model is to create a technical coefficient integrated matrix $\left(\mathrm{A}^{*}\right)$, which consists of a direct requirement matrix for the supply chain ( $\left.\mathrm{A}_{\mathrm{SC}}\right)$, an upstream cutoff matrix $\left(\mathrm{C}_{\mathrm{u}}\right)$, downstream cut-off matrix $\left(\mathrm{C}_{\mathrm{d}}\right)$, and the IO requirement matrix $\left(\mathrm{A}_{\mathrm{IO}}\right)$ (Wiedmann et al., 2011). In this research, the downstream matrix is assumed equal to zero, as suggested by a number of researchers (Acquaye et al., 2011; Heijungs, 1994).

$$
\mathrm{A}^{*}=\left[\begin{array}{cc}
A_{S C} & C_{d} \\
C_{u} & A_{I O}
\end{array}\right]
$$

\subsubsection{Model Formulation}

The supply chain under consideration involves $n$ tiers. It is assumed that the supply chain of an industry sector is known. This means that the number of tiers and the relationship of nodes between tiers is predetermined. In contrast to a traditional supply chain, where the nodes of the supply chain are mainly the processes or stages in a supply chain, the global supply chain in this research focuses on the industrial sector supply chain. This is necessary in order to ensure that the three dimensions of the sustainable supply chain are accounted for in national data, thus enabling the integration of the three different aspects. Moreover, the supply chain considers economic activity on a global level where national data can be used to support a computational experiment. 
The following notation and definitions are used in the development of the mathematical model.

Sets:

$M, \widehat{M}$ ' set of sectors

$\mathrm{I}, \mathrm{J}$ set of sectors in the process $\mathrm{SCM}, \mathrm{I} \in \mathrm{M}$

$\mathrm{B}(i, j)$ set of the relationships between sector $i$ and the supply sector $j$

$\mathrm{N}$ set of tiers $n=$ tier 1, tier $2, \ldots, N s$

An $(n, i)$ set of sectors $i$ in tier $n$

$G, \widehat{G}$ set of countries

\section{Parameters:}

Onig - the fixed cost of sector $i$, tier $n$ at country $g$

$\mathrm{t}_{\mathrm{i}}$ - unit transport cost of sector $i(\$ / \mathrm{unit} / \mathrm{km})$

$\gamma_{j i \hat{g}}$ - conversion factor for material sector $i$ from input $j$ in country $\hat{g}$ (unit material $i / \$$ material $j$ in $\hat{g})$

$\alpha_{i g}$ - the unit price of input from sector $i$ in country $g(\$ / \mathrm{kg})$

$\mathrm{e}_{\mathrm{ig}}$ - environmental multiplier of sector $i$ in country $g$

$\mathrm{Sig}_{\mathrm{g}}$ - social multiplier of the sector I in country $\mathrm{g}$

$\mathrm{C}_{\mathrm{ig}}$ - capacity of sector $i$ in country $g$ (unit)

$c_{m \hat{g} i g}-$ upstream technical coefficient $(\$ / \$)$

$a_{m g \hat{m} \hat{g}}-$ the technical coefficient in the input-output table $(\$ / \$)$

$\delta_{\mathrm{jig}}$ - proportion requirement of output sector $j$ to supply $i$ in country $g$ 
$d_{g \hat{g}}-$ distance between country $g$ to $\hat{g}(\mathrm{~km})$

$\widetilde{M}$ - a big number

Binary Variables:

$\mathrm{E}_{\text {nig }} \quad=1$, if $g$ is selected to produce $i$ at tier $n$

$\mathrm{F}_{\mathrm{mg}}=1$, if SUM of number of tiers $=0\left(\mathrm{n}, \mathrm{E}_{\mathrm{nmg}}=0\right)$

Free variables:

$X_{\text {nigj } j \hat{g}}$ - the flow rate of sector $i$ in country $g$ and receive supply from sector $j$ country $\hat{g}$

$D_{\text {nig }}$ - demand for sector $i$ from tier $n$ in country $g$

$\mathrm{Q}_{\mathrm{ig}}$ - Total input from sector $i$ in country $g$ (from each sector of the SC)

$\mathrm{U}_{\mathrm{mg}}$ - Upstream input from sector $m$ country $g$ to the SC system

$\mathrm{P}_{\mathrm{mg}}$ - Total output sector $m$ country $g(\$)$

Mathematical Formulation

Economic OF:

$T C=\sum_{n, i, g} o_{n i g} \cdot E_{n i g}+\sum_{n, i, g, j, \hat{g}} X_{n i g j^{\wedge}} *\left(1+\gamma_{j i}{ }^{*} t_{i} * d_{g \hat{g}}\right)$

Environmental OF:

$T E N V=\sum_{n, i, g, j, \hat{g}} e_{i g} \cdot X_{n i g j^{\wedge}}+\sum_{m, g} e_{m g} \cdot Y_{m g}$

Social OF: 
$T S O C=\sum_{n, i, g, j, \hat{g}} s_{i g} \cdot X_{n i g j \hat{g}}+\sum_{(m, g)} s_{m g} \cdot Y_{m g}$

Constraints:

$\sum_{\hat{g}} X_{n i g j \hat{g}}=\delta_{j i g} * D_{n i g} \quad \forall g \in G,(n, i) \in A,(j, i) \in B$

$\sum_{(n, i) \in A,(i, j) \in B, g \in G} X_{n i g j \hat{g}}=\sum_{(n, i) \in A,(i, j) \in B, g \in G} X_{(n+1) j \hat{g} i g} \quad \forall j \in J, g^{\prime} \in G^{\prime}, n \neq N s$

$C_{i g}^{m i n} \cdot E_{n i g} \leq \sum_{(j, i) \in B, \hat{g}} X_{n i g j \hat{g}} \cdot \gamma_{j i \hat{g}} \leq C_{i g}^{m a x} \cdot E_{n i g} \quad \forall(n, i) \in A, g \in G$

$\sum_{g} E_{\text {nig }}=1 \quad \forall i \in I, n \in N$

$D_{\text {tier } 1, p, u s a}=100$

$X_{n i g j \hat{g}}=0 \quad \forall\left(N_{S}, i\right) \in A, j \in J, g \neq \hat{g}$

$E_{\text {nig }} \in\{0,1\}$

$Q_{i g}=\sum_{n\|(n, i) \in A, j\|(i, j) \in B, \hat{g}} X_{n i g j^{\wedge}} \cdot \gamma_{j i \hat{g}} \quad \forall i, g$

$U_{m \hat{g}}=\sum_{i, g} c_{m \hat{g} i g} \cdot Q_{i g} \cdot \alpha_{i g} \quad \forall m, \hat{g}$

$P_{m g}-\sum_{\hat{m} \hat{g}} a_{m g \hat{m} \hat{g}} \cdot P_{\widehat{m} \hat{g}} \geq R_{m g} \quad \forall m, g$

$\left(N N * F_{m g}\right)+W_{m g}+\sum_{n \|(n, m) \in A} E_{n m g}=N N \quad \forall m, g$

$W_{m g} \leq N N * \sum_{n \|(n, m) \in A} E_{n m g} \quad \forall m, g$

$Y_{m g} \leq \widetilde{M} * F_{m g} \quad \forall m, g$

$Y_{m g}+\widetilde{M} *\left(1-F_{m g}\right) \geq P_{m g} \quad \forall m, g$

$Y_{m g}-\widetilde{M} *\left(1-F_{m g}\right) \leq P_{m g} \quad \forall m, g$

$R_{m g} \leq \widetilde{M} * F_{m g} \quad \forall m, g$ 


$$
\begin{aligned}
& R_{m g}+\widetilde{M} *\left(1-F_{m g}\right) \geq U_{m g} \quad \forall m, g \\
& R_{m g}-\widetilde{M} *\left(1-F_{m g}\right) \leq U_{m g} \quad \forall m, g \\
& P_{m, g}, Q_{i g}, U_{m \hat{g}}, X_{\text {nigj } \hat{g}}, D_{\text {nig }} \geq 0
\end{aligned}
$$

\section{Objective Functions}

Equations (4.1) to (4.3) are the multi-criteria objective functions. Three objective functions are employed in designing a sustainable global supply chain structure. The first part of the optimization addresses the economic impact of the system (Equation 4.1). The optimization only considers the economic activities within the supply chain. The reason is that in most cases, it is difficult to get monetary information from indirect industries/sector partners. Moreover, the decision-maker has more coordination with partners in the supply chain compared to the indirect partners, thus the application of strategic decisions becomes feasible to apply within the supply chain. In summary, the economic objective function minimizes the total cost, which consists of total fixed cost and total operational costs, where the operational cost includes production and transportation cost of the supply chain.

The environmental objective function (Equation 4.2) includes the minimization of both direct environmental impact (in the supply chain) and indirect environmental impacts (from upstream supply chain). The reason is that in global economic activities it is hard to exclude the environmental impacts from other economic activities. The environmental impact can come as a result of not only a particular production process and/or industry but also those of its suppliers at large. Thus, it is necessary to reach deep into a supply chain to capture all of the environmental impacts. The environmental objective optimizes the 
supply chain configuration that minimizes the environmental footprint that comes from direct and indirect economic activities.

Equation (4.3) is the social objective function, which is the minimization of total social impacts. Similar to the environmental objective, the social objective function considers both the direct and indirect impacts of the supply chain structure. This objective uses the IOA based framework to measure the social footprint, which adopts the framework of the environmental footprints indicators. The social objective function minimizes the impact of the social footprint that comes from direct and indirect economic activities.

\section{Constraints}

Equations (4.4) to (4.10) are constraints for economic activities in the supply chain. Equation (4.4) calculates the demand required by sector and multiplies the demand with the proportion of each contributing sector. Equation (4.5) is the balance flow constraint. This ensures that the financial flow that comes into the sector/industry is equal to the flow out. Equation (4.6) ensures that the amount of production is in the range of capacity. Equation (4.7) ensures that only one country is selected for each sector. Equation (4.8) is the final demand of the first tier in the supply chain. Equation (4.9) ensures that $g=g$ in the last tier of the supply chain. This assumes that the most upstream sector in the supply chain can supply its own demand. Equation (4.10) is a binary constraint to ensure only one country is selected for each industrial sector in each tier.

Equations (4.11) to (4.13) represent constraints for supply chain optimization that relates to the environmental and social impacts as the result of the supply chain, as well as economy-wide activities. These constraints are adapted from Yue et al. (2016) and applied to the social impacts. Equations (4.14) to (4.15) ensure the value of $F_{m g}$ is one when the 
summation of $\mathrm{E}$ is zero. The group of equations (4.16) to (4.21) force the relationship that if $F_{m g}=0$, then $R_{m g}$ and $Y_{m g}=0$, and if $F_{m g}=1$, then $Y_{m g}=P_{m g}$ and $R_{m g}=U_{m g}$. Finally, Equation 4.22 presents nonnegative constraints.

\subsubsection{Illustrative Example of Combined SC-IO}

This section illustrates the proposed integrated SC-IO modeling framework through a simple example. It is modified from an example by Suh (2004) that considers two different alternative countries, A and B, as the sources in the supply chain system. Thus, this allows the interrelationship between countries to be captured within the global supply chain. Figure 4.1 shows a hypothetical system for the supply chain. The objective is to identify the supply chain configuration that has lower $\mathrm{CO}_{2}$ emissions, as well as labor risk in its supply chain.

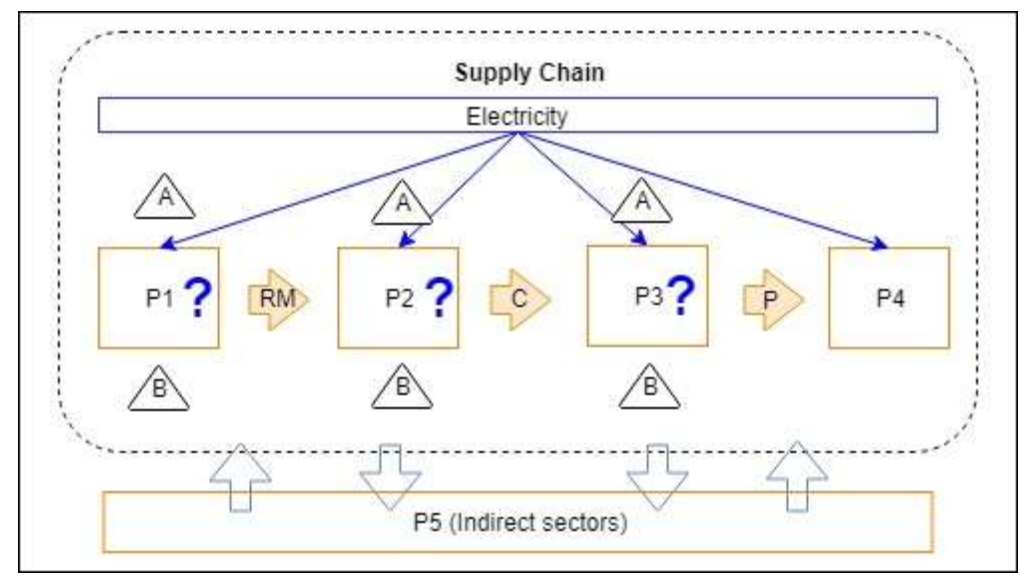

Figure 4. 2 Superstructure of the illustrative example 
As shown in Figure 4.2, the supply chain consists of P1, P2, P3, P4, and the electricity industry, while P5 is the indirect sector/industry in the IO system. Specifically, in this system raw material is retrieved from sector P1, such as agriculture sector, where it can be supplied by country A or B. Then, the raw material is converted to component $\mathrm{C}$ at P2, in either country A or B. An instance of P2 could be the food and beverage sector. In the last phase, component $\mathrm{C}$ is converted into final product $\mathrm{P}$ at process $\mathrm{P} 3$, in the wholesale trade sector. P4 is the last consumer sector in the supply chain. An example of P4 might be the hotel and restaurant sector. Lastly, P5 is any sector from Table 3.2 that is not included in the direct supply chain. An example of an indirect sector might be the education sector.

At every stage of the supply chain, there are economic, environmental, and social direct impacts. Moreover, environment and social impacts also occur from the outside system as the result of indirect economic activities. There are both direct and indirect sustainability impacts, which would eventually be embedded and reflected as economic, environmental and social footprints of the supply chain.

Based on the structure given in Figure 4.2, the data for the simplified supply chain model is presented in the following tables. Table 4.1 shows the technical coefficient inputoutput matrix between the processes/sectors in the system for a monetary $(\$ / \$)$ steady-state approximation. The values in the table are the ratio of economic activities between row and column with the total economic activities of each column using Equation 2.2, $\mathrm{A}=\frac{\mathrm{x}_{\mathrm{ij}}^{\mathrm{nm}}}{\mathrm{X}_{\mathrm{i}}^{\mathrm{n}}}$ 
Table 4. 1Example Input-Output Table

\begin{tabular}{|c|c|c|c|c|c|c|c|c|c|c|c|c|}
\hline & \multicolumn{11}{|c|}{ Output } \\
\hline & & P1A & P2A & P3A & $\mathrm{P} 4 \mathrm{~A}$ & P5A & P1B & P2B & P3B & P4B & P5B & electricity \\
\hline \multirow{11}{*}{$\begin{array}{l}\text { 플 } \\
\text { 드 }\end{array}$} & P1A & 0.2 & 0.15 & 0 & 0 & 0 & 0 & 0.015 & 0.01 & 0.05 & 0 & 0.2 \\
\hline & $\mathrm{P} 2 \mathrm{~A}$ & 0 & 0.1 & 0.1 & 0 & 0 & 0 & 0 & 0 & 0 & 0 & 0 \\
\hline & P3A & 0.2 & 0 & 0.1 & 0 & 0 & 0 & 0 & 0 & 0 & 0 & 0 \\
\hline & P4A & 0 & 0 & 0.1 & \begin{tabular}{l|l}
0.1 \\
\end{tabular} & 0 & 0 & 0 & 0.05 & 0 & 0.03 & 0 \\
\hline & P5A & 0 & 0 & 0 & 0 & 0.2 & 0.1 & 0 & 0 & 0.2 & 0.2 & 0 \\
\hline & P1B & 0 & 0 & 0 & 0 & 0 & 0.3 & 0.1 & 0 & 0 & 0.1 & 0 \\
\hline & $\mathrm{P} 2 \mathrm{~B}$ & 0.1 & 0 & 0 & 0 & 0 & 0.1 & 0.2 & 0.2 & 0.1 & 0.2 & 0.01 \\
\hline & P3B & 0.1 & 0 & 0 & 0 & 0.1 & 0.2 & 0.2 & 0.3 & 0.2 & 0 & 0.1 \\
\hline & P4B & 0 & 0.1 & 0 & 0 & 0.2 & 0.1 & 0.1 & 0.2 & 0.1 & 0.2 & 0 \\
\hline & P5B & 0 & 0.1 & 0 & 0.1 & 0.2 & 0.1 & 0.2 & 0.1 & 0.2 & 0.1 & 0 \\
\hline & electricity & 0.3 & 0.1 & 0.2 & 0 & 0 & 0 & 0.05 & 0.08 & 0 & 0.01 & 0.1 \\
\hline
\end{tabular}

Table 4.2 represents the physical unit requirement table of the supply chain. For example, the entry at the intersection of row $\mathrm{P} 1$ and column P2A represents the row coefficient of the input (P1) sector required by the column sector (P2A) to produce one unit of column sector output (P2A). A and B are the alternative countries available for each stage. A negative sign represents the requirement (input), whereas a positive sign represents the output. For example, negative 2.5 in row P1, column P2B, shows the amount of $\mathrm{P} 1$ required to produce 1 unit of $\mathrm{P} 2$ in country $\mathrm{B}$.

Table 4. 2 The quantity required in the supply chain by country

\begin{tabular}{|l|r|r|r|r|r|r|r|}
\hline & P1 & Electricity & \multicolumn{2}{|c|}{ P2 } & \multicolumn{2}{|c|}{ P3 } & P4 \\
\cline { 2 - 9 } & A\&B & A\&B & \multicolumn{1}{|c|}{ A } & B & A & B & A\&B \\
\hline P1 & 1 & -0.5 & -2 & -2.5 & 0 & 0 & 0 \\
\hline Electricity & -0.5 & 1 & -0.1 & -0.2 & -1 & -0.5 & 0 \\
\hline P2 & 0 & 0 & 1 & 1 & -1 & -1 & 0 \\
\hline P3 & 0 & 0 & 0 & 0 & 1000 & 1000 & 0 \\
\hline P4 & 0 & 0 & 0 & 0 & -1 & -1 & 1 \\
\hline
\end{tabular}

It is assumed that the electricity supply will come from the country selected and only one country can be selected in the supply chain.

In the integrated SC-IO model, the SC system-level data and the economic activities level data are integrated to compute the total sustainability impact. The vector of 
sustainability impact is formulated using Equation 2.4, $F=\left[\frac{f_{i}^{n}}{x_{i}^{n}}\right]$. In this example, the economic factor is the variable cost related to the production cost in each country. The fixed cost is assumed the same for each country. Due to the fact that it is not easy to gather monetary data from indirect economic activities, the economic impact is only based on supply chain activities. Whereas, the environmental and social impacts both include direct and indirect economic activities.

It is assumed that each process produces $\mathrm{CO}_{2}$ emissions as given in vector $e$. The vector e consists of two parts: $e_{p}$, which represents the emission factor of the supply chain, and the vector $e_{i o}$ represents the $\mathrm{CO}_{2}$ emission factors for its indirect economic activities. Similarly, the vector $s_{c}$ represents the labor risk associated with each process and $s_{i o}$ represents the labor risk associated with indirect economic activities. Table 4.3 shows the $\mathrm{CO}_{2}$ emission (e) and the labor risk (s) as the result of production in all sectors in each country.

Table 4. 3 The environmental and social multipliers

\begin{tabular}{|c|c|c|c|c|c|c|c|c|c|c|c|}
\hline Dimension & P1A & Electricity & P2A & P3A & P4A & P1B & P2B & P3B & P4B & P5A & P5B \\
\hline$e$ & 1 & 4 & 2 & 1 & 0.5 & 0.5 & 3 & 2 & 0.1 & 1 & 1 \\
\hline$s$ & 0.5 & 3 & 3 & 2 & 0.25 & 2 & 1 & 0.75 & 2 & 0.4 & 0.4 \\
\hline
\end{tabular}

In order to further clarify how these vectors are used, the vectors below show $\mathrm{CO}_{2}$ emission and social risk when country A is selected as the location for the whole process in the supply chain. Finally, the vector $y$ represents the demand (P3) of 1,000 units of product. The demand from the other process is zero.

$$
e_{p}=\left[\begin{array}{lllll}
1 & 4 & 2 & 1 & 0.5
\end{array}\right] \quad e_{i o}=\left[\begin{array}{llllll}
0.5 & 3 & 2 & 0.1 & 1 & 1
\end{array}\right]
$$


$s_{\mathrm{c}}=\left[\begin{array}{lllll}0.5 & 3 & 3 & 2 & 0.25\end{array}\right]$

$$
s_{i 0}=\left[\begin{array}{llllll}
2 & 1 & 0.75 & 2 & 0.4 & 0.4
\end{array}\right]
$$

$y=\left[\begin{array}{lllll}0 & 0 & 0 & 1,000 & 0\end{array}\right]$

Suppose that the supply chain also has data for the direct requirement matrix input and output $\mathrm{A}_{\mathrm{io}}$, upstream matrix $\mathrm{C}_{\mathrm{u}}$ and downstream matrix $\mathrm{C}_{\mathrm{d}}$, as shown in Table 4.1. Then the mathematical notation to calculate the sustainability impact using an integrated SC-IO model is given by (Yue et al., 2016):

$$
\text { Full sustainability impact }=\left[m_{p} m_{i o}\right]\left[\begin{array}{cc}
A_{p} & -C_{d} \\
-C_{u} & I-A_{i o}
\end{array}\right]^{-1}\left[\begin{array}{l}
y \\
0
\end{array}\right]
$$

Matrix M is formed by $m_{p}$ and $m_{i o}$ and is an $m x n$ matrix where $m$ represents the number of indicators and $n$ is the economic sectors. In this example, $\mathrm{M}$ is the matrix of $\mathrm{CO}_{2}$ emissions $(e)$ and social indicators $(s)$ of each process and country. Since this example problem only involves two countries, the solution approach is simple. The full integrated matrix where all sectors of P1, P2, P3, P4 located in country A is shown in Table 4.4.

Table 4. 4 The integrated SC-IO matrix

\begin{tabular}{|l|r|r|r|r|r|r|r|r|r|r|r|}
\hline & P1A & electricity & P2A & P3A & P4A & P1B & P2B & P3B & P4B & P5A & P5B \\
\hline P1A & 1 & -0.5 & -2 & 0 & 0 & 0 & -0.015 & -0.01 & -0.05 & 0 & 0 \\
\hline electricity & -0.5 & 1 & -0.1 & -1 & 0 & 0 & -0.05 & -0.08 & 0 & 0 & -0.01 \\
\hline P2A & 0 & 0 & 1 & -1 & 0 & 0 & 0 & 0 & 0 & 0 & 0 \\
\hline P3A & 0 & 0 & 0 & 1000 & 0 & 0 & 0 & 0 & 0 & 0 & 0 \\
\hline P4A & 0 & 0 & 0 & -1 & 1 & 0 & 0 & -0.05 & 0 & 0 & -0.03 \\
\hline P1B & 0 & 0 & 0 & 0 & 0 & 0.7 & -0.1 & 0 & 0 & 0 & -0.1 \\
\hline P2B & -0.1 & -0.01 & 0 & 0 & 0 & -0.1 & 0.8 & -0.2 & -0.1 & 0 & -0.2 \\
\hline P3B & -0.1 & -0.1 & 0 & 0 & 0 & -0.2 & -0.2 & 0.7 & -0.2 & -0.1 & 0 \\
\hline P4B & 0 & 0 & -0.1 & 0 & 0 & -0.1 & -0.1 & -0.2 & 0.9 & -0.2 & -0.2 \\
\hline P5A & 0 & 0 & 0 & 0 & 0 & -0.1 & 0 & 0 & -0.2 & 0.8 & -0.2 \\
\hline P5B & 0 & 0 & -0.1 & 0 & -0.1 & -0.1 & -0.2 & -0.1 & -0.2 & -0.2 & 0.9 \\
\hline
\end{tabular}

The full $\mathrm{CO}_{2}$ emissions $\left(\mathrm{Q}_{\mathrm{e}}\right)$ and labor risk $\left(\mathrm{Q}_{\mathrm{s}}\right)$ for countries $\mathrm{A}$ and $\mathrm{B}$ are calculated below: 


$$
\begin{aligned}
& Q e_{\text {hybrid }}^{A}=\left[e_{p} e_{i o}\right]\left[\begin{array}{cc}
A_{p} & -C_{d} \\
-C_{u} & I-A_{i o}
\end{array}\right]^{-1}\left[\begin{array}{l}
y \\
0
\end{array}\right]=30.6 \\
& Q e_{\text {hybrid }}^{B}=\left[e_{p} e_{i o}\right]\left[\begin{array}{cc}
A_{p} & -C_{d} \\
-C_{u} & I-A_{i o}
\end{array}\right]^{-1}\left[\begin{array}{l}
y \\
0
\end{array}\right]=32.05 \\
& Q s_{\text {hybrid }}^{A}=\left[s_{p} s_{i o}\right]\left[\begin{array}{cc}
A_{p} & -C_{d} \\
-C_{u} & I-A_{i o}
\end{array}\right]^{-1}\left[\begin{array}{l}
y \\
0
\end{array}\right]=23.53 \\
& Q s_{\text {hybri }}^{B}=\left[s_{p} s_{i o}\right]\left[\begin{array}{cc}
A_{p} & -C_{d} \\
-C_{u} & I-A_{i o}
\end{array}\right]^{-1}\left[\begin{array}{l}
y \\
0
\end{array}\right]=33.41
\end{aligned}
$$

There are four different solutions, which are shown in Table 4.5. The sustainability impact indicators for the supply chain are also calculated $(q)$, where $h_{e}$ is the $\mathrm{CO}_{2}$ emission and $q_{s}$ is the social risk.

Table 4.5 The example possible solutions

\begin{tabular}{|l|l|l|l|l|c|c|c|c|}
\hline & $\mathrm{P} 1$ & $\mathrm{P} 2$ & $\mathrm{P} 3$ & $\mathrm{P} 4$ & $q_{e}$ & $q_{s}$ & $Q_{e}$ & $Q_{s}$ \\
\hline Option 1 & $\mathrm{A}$ & $\mathrm{A}$ & $\mathrm{A}$ & $\mathrm{A}$ & 18.1 & 15.35 & 30.6 & 23.5 \\
\hline Option 2 & $\mathrm{B}$ & $\mathrm{B}$ & $\mathrm{B}$ & $\mathrm{B}$ & 17.7 & 14.95 & 32.1 & 33.4 \\
\hline Option 3 & $\mathrm{A}$ & $\mathrm{B}$ & $\mathrm{A}$ & $\mathrm{A}$ & 20.7 & 17.12 & 53.5 & 36.8 \\
\hline Option 4 & $\mathrm{B}$ & $\mathrm{A}$ & $\mathrm{B}$ & $\mathrm{B}$ & 15.1 & 13.18 & 18.7 & 22.4 \\
\hline
\end{tabular}

The results from the supply chain model show that country A produces more $\mathrm{CO}_{2}$ than country B $(18.1>17.7)$. A similar result is seen in the labor risk where country A is higher than country B (15.35> 14.95). However, the measurement of these impacts using the integrated SC-IO shows a different result. In this case, country A produces more $\mathrm{CO}_{2}$ in the supply chain, but less in the total life cycle than country B $(30.6<32.9)$. Similar to the results for $\mathrm{CO} 2$ emissions, the social risk in country $\mathrm{A}$ is higher than country $\mathrm{B}$ at the supply chain level but is reversed at the total life cycle system. Considering the interrelation 
between countries can also impact the decision-making process. Table 4.5 shows that Option four is the most efficient supply chain with the lowest $\mathrm{CO} 2$ emission and social risk.

\subsection{The Solution Approach}

This section presents the application of the mathematical model and solves it using multi-criteria decision-making approaches. This problem considers three tiers of the supply chain, which consists of six industrial sectors. The six industrial sectors selected are manufacturing sectors with the highest economic interrelationship with the TE sector. It is assumed the material requirements between industrial sectors are known. This supply chain is part of a bigger system of 14 industrial sectors that operate in 17 top manufacturing countries (Table 4.6).

Table 4. 6 List of sectors and countries

\begin{tabular}{|l|l|}
\hline \multicolumn{1}{|c|}{ Code } & \multicolumn{1}{|c|}{ Sector } \\
\hline C1 & Machinery, NEC \\
\hline C2 & Basic metals and fabricated metals \\
\hline C3 & Agriculture, hunting, forestry and fishing \\
\hline C4 & Food, beverages and tobacco \\
\hline C5 & Textiles and textile product \\
\hline C6 & Leather, leather and footware \\
\hline P & Transport equipment \\
\hline RM1 & Mining and Quarrying \\
\hline RM2 & Coke, refined petroleum and nuclear fuel \\
\hline RM4 & Wood and product of wood and cork \\
\hline RM5 & Pulp, paper, paper product, printing and publishing \\
\hline RM6 & Chemicals and chemical products \\
\hline RM7 & Rubber and plastics \\
\hline
\end{tabular}

\begin{tabular}{|c|c|}
\hline No. & Country \\
\hline 1 & CHN \\
\hline 2 & DEU \\
\hline 3 & ESP \\
\hline 4 & FRA \\
\hline 5 & GBR \\
\hline 6 & IND \\
\hline 7 & IND \\
\hline 8 & ITA \\
\hline 9 & JPN \\
\hline 10 & KOR \\
\hline 11 & MEX \\
\hline 12 & NLD \\
\hline 13 & POL \\
\hline 14 & RUS \\
\hline 15 & TUR \\
\hline 16 & TWN \\
\hline 17 & USA \\
\hline
\end{tabular}

Figure 4.3 shows the supply chain system used as the basis of this example. 


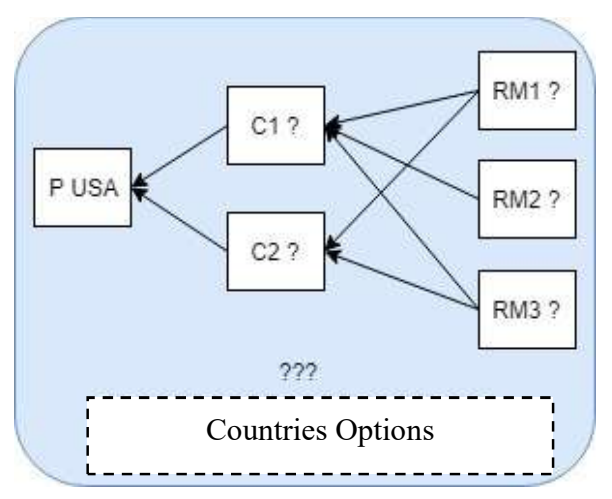

Figure 4. 3 The Transport and Equipment Supply Chain

This example uses the $\mathrm{CO}_{2}$ emission multiplier and vulnerable working hour multiplier taken from the WIOD database. Table 4.7 shows the six sectors which will be used as industries to calculate direct supply chain impacts. These six sectors are manufacturing sectors with the highest economic activities.

\section{Table 4.7 The direct sectors}

\begin{tabular}{|l|l|l|}
\hline & Industry Code & \multicolumn{1}{c|}{ Sector } \\
\hline P & R15 & Transport equipment \\
\hline C1 & R13 & Machinery, NEC \\
\hline C2 & R12 & Basic metals and fabricated metals \\
\hline RM1 & R2 & Mining and quarrying \\
\hline RM2 & R8 & Coke, Refined petroleum and nuclear fuel \\
\hline RM3 & R17 & Electricity, gas and water supply \\
\hline
\end{tabular}

It is assumed that there is 1B US demand for P in the USA and the requirements for the demand from each supplier is known. The sections below present the solution approach used to solve the multi-objective model. 


\subsubsection{Single Objective Optimization}

The model is initially solved considering each objective function individually. The purpose of this method is to show how the supply chain configuration would be different when each objective function is optimized individually. Three different scenarios are considered:

- Scenario A: an optimal solution, obtained when minimizing cost;

- Scenario B: an optimal solution, obtained when minimizing environmental impact;

- Scenario C: an optimal solution, obtained when minimizing the social impact (risk).

The model is solved using CPLEX in GAMS 27.3 software. The time required to obtain solutions was a total of 2 minute 52 second. Table 4.8 shows the results based on the optimization of the economic objective, environmental objective, and the social objective. It shows that when minimizing total cost, the $\mathrm{CO}_{2}$ emissions and the vulnerable working hours are the worst.

Table 4.8 The results of single-objective optimization

\begin{tabular}{|l|r|r|r|}
\hline & \multicolumn{1}{|c|}{ Scenario A } & \multicolumn{1}{|c|}{ Scenario B } & \multicolumn{1}{|c|}{ Scenario C } \\
\hline Cost (M\$) & 4670.58 & 7293.71 & 7582.88 \\
\hline CO2 Emission (MT) & 6.4 & 1.47 & 2.38 \\
\hline VUL Hour (M Hr) & 74.76 & 7.34 & 6.98 \\
\hline
\end{tabular}

Table 4.9 shows that when minimizing supply chain cost (Scenario A) the model returns a network where China and the USA are selected for the supply chain configuration, with China as the main suppliers of tier 2 and 3. This result is expected due to China is the country with the lowest international trading cost compares to other countries. 
Table 4.9 Detailed results for Scenario A

\begin{tabular}{|c|c|c|c|c|c|c|}
\hline Tier 1 & \multicolumn{3}{|c|}{ Tier 2} & \multicolumn{3}{|c|}{ Tier 3} \\
\hline \multirow{5}{*}{$\begin{array}{l}\text { P.USA } \\
\$ 100 \mathrm{M}\end{array}$} & \multirow{3}{*}{$\mathrm{C} 1$} & \multirow{3}{*}{$\mathrm{CHN}$} & \multirow{3}{*}{50} & RM1 & $\mathrm{CHN}$ & 24.5 \\
\hline & & & & RM2 & $\mathrm{CHN}$ & 20 \\
\hline & & & & RM3 & $\mathrm{CHN}$ & 5.5 \\
\hline & \multirow{2}{*}{$\mathrm{C} 2$} & \multirow{2}{*}{$\mathrm{CHN}$} & \multirow{2}{*}{50} & RM3 & $\mathrm{CHN}$ & 10 \\
\hline & & & & RM1 & $\mathrm{CHN}$ & 40 \\
\hline
\end{tabular}

Figure 4.4 (a) and (b) present the environmental impact as an outcome of the TE supply chain for production in the USA. It shows that the majority of direct $\mathrm{CO}_{2}$ emission comes from sectors in tier 1 and tier 2, with sector electricity as the main contributors. Meanwhile, from the indirect sector perspective (Figure 4.4 b), TE sector has a strong interrelation with Electricity and Metal sector in the USA and China. In total, these sectors contribute around 4.5 MT CO2 emission, which is about $70 \%$ of total $\mathrm{CO} 2$ emission. This also indicates that a sustainable supply chain design needs to include indirect impacts as they also play important role in increasing/decreasing sustainability impact.

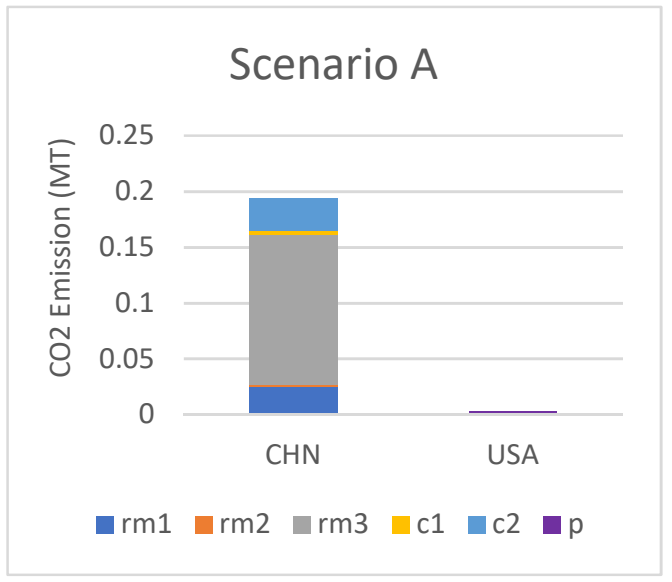

(a)

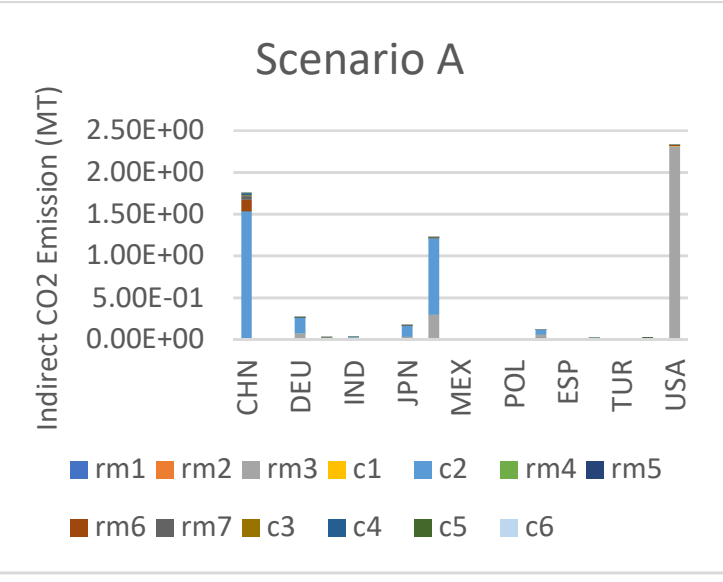

(b)

Figure 4. 4 Direct and indirect CO2 emission impact of Scenario A 
From the social impact perspective, cost minimization generates a high level of vulnerable hours, which mostly found in China. It is important to highlight that most vulnerable hours are the result of the indirect supply chain. Figure 4.5 shows that demand from TE industry in the USA would have an impact of $60 \mathrm{M}$ vulnerable working hours in China, which is equal to 30,000 full time workers (Assume: 1 year $=250$ days, 1 day $=8$ hours). The majority of vulnerable worker hours in China come from the Chemical industry. Besides chemical industry, we could also find a high total of vulnerable hours in agriculture sector. The majority of vulnerable worker hours in China come from the Mining and Machinery sector. From the direct supply chain perspective, the 100M USD TE industry demand requires around $3.5 \mathrm{M}$ direct vulnerable working hours, which is equal to 1,750 workers in the direct industry sectors in China.

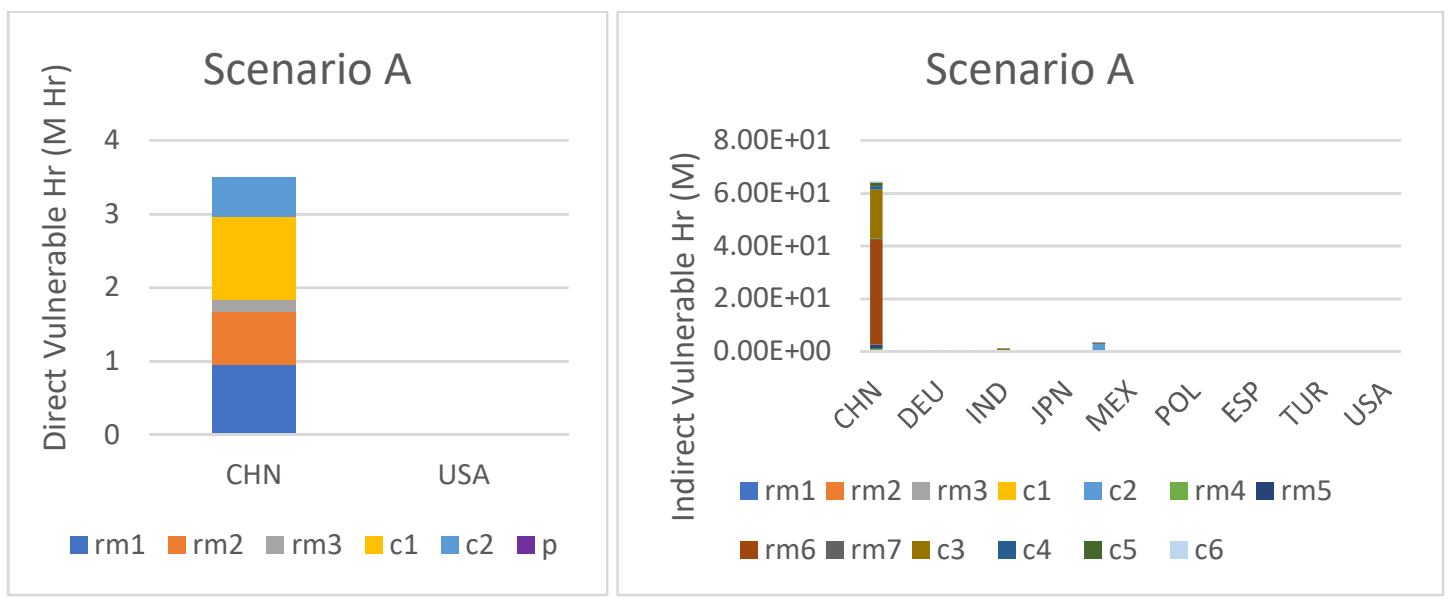

Figure 4. 5 Direct and Indirect Vulnerable Hour of Scenario A

When minimizing environmental impact (Scenario B) the model returns Turkey, Netherland, and the USA as the best fit for the supply chain network. In comparison with 
the result of economic optimization, this configuration reduces $\mathrm{CO}_{2}$ emission by $77 \%$. The vulnerable hour footprint is reduced by $90 \%$. However, this configuration will increase the cost by $56 \%$, which would come from production cost and travel distance costs from these countries. Table 4.10 shows the detailed results of Scenario B.

Table 4.10 Detailed results for Scenario B

\begin{tabular}{|c|c|c|c|c|c|c|}
\hline Tier 1 & \multicolumn{3}{|c|}{ Tier 2} & \multicolumn{3}{|c|}{ Tier 3} \\
\hline \multirow{5}{*}{$\begin{array}{l}\text { P.USA } \\
\$ 100 \mathrm{M}\end{array}$} & \multirow{3}{*}{$\mathrm{C} 1$} & \multirow{3}{*}{ TUR } & \multirow{3}{*}{50} & RM1 & USA & 9 \\
\hline & & & & RM2 & NLD & 27.5 \\
\hline & & & & RM3 & USA & 13.5 \\
\hline & \multirow{2}{*}{$\mathrm{C} 2$} & \multirow{2}{*}{ USA } & \multirow{2}{*}{50} & RM1 & USA & 17.5 \\
\hline & & & & RM3 & USA & 32.5 \\
\hline
\end{tabular}
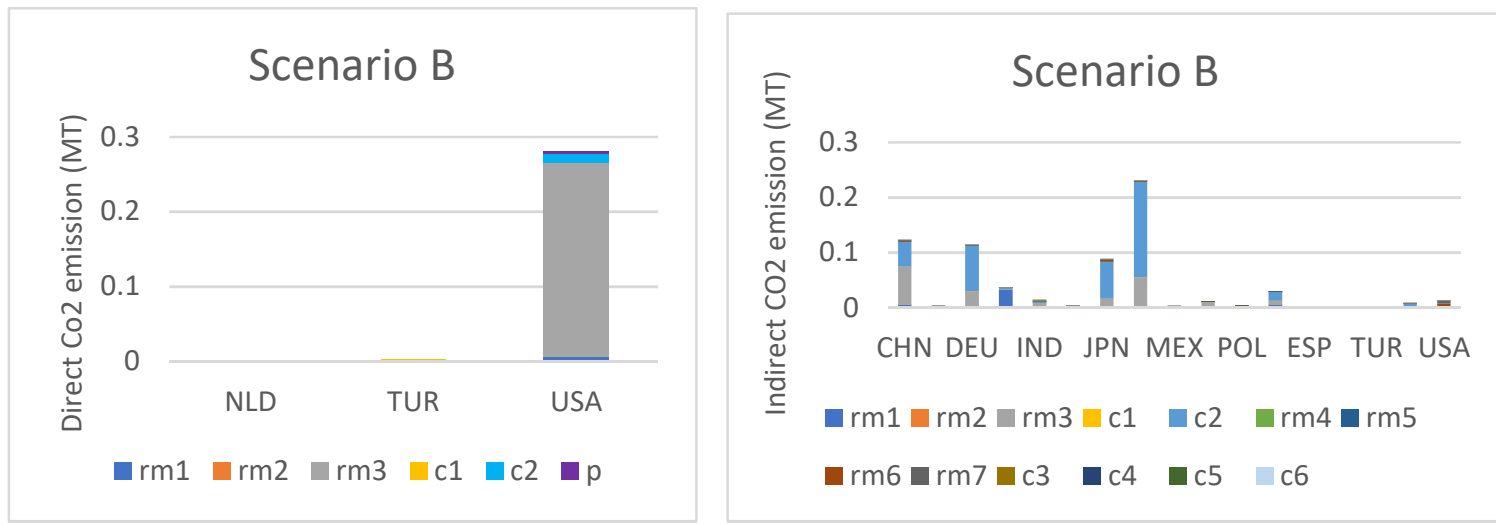

Figure 4. 6 Direct and indirect $\mathrm{CO}_{2}$ impact of Scenario B

Figure 4.6 shows the direct and indirect $\mathrm{CO}_{2}$ emissions as a result of the supply chain activity. The model selects countries with low $\mathrm{CO}_{2}$ emission multipliers. Similar to the results obtained in Scenario A, the indirect $\mathrm{CO}_{2}$ emission also contributes more than $50 \%$ of the total $\mathrm{CO}_{2}$ emission. South Korea, China, and Germany are the top three countries with highest indirect $\mathrm{CO}_{2}$ emission, with the metal sector contributing the most $\mathrm{CO}_{2}$ emissions. Meanwhile, the electricity sector contributes almost $0.25 \mathrm{MT}$ of direct $\mathrm{CO}_{2}$ emissions. This indicates the demand from Turkey, Netherland and the USA results in the indirect $\mathrm{CO}_{2}$ emissions that mostly come from the Metal and Electricity sectors in other 
countries. Overall the selection of countries with lower coefficient multipliers will reduce the supply chain total $\mathrm{CO}_{2}$ emissions.

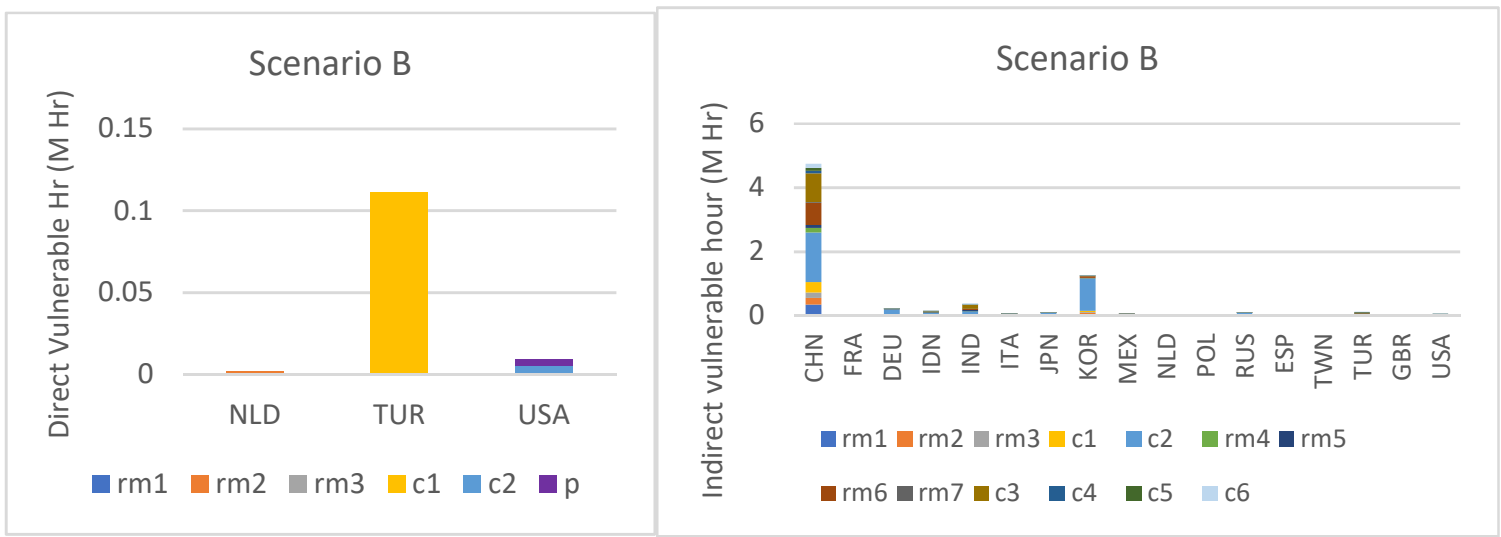

Figure 4. 7Direct and indirect vulnerable hour impact of Scenario B

Figure 4.7 shows that the direct vulnerable hour impact is mostly from the machinery sector in Turkey with the total around $0.1 \mathrm{M} \mathrm{Hr}$. The major contribution to the total vulnerable hour comes from indirect economic activities. China is the country that has the highest number of vulnerable hours.

Finally, Table 4.11 presents the minimization of the social objective function (Scenario C) where France, Netherland, Turkey, and USA are selected for the supply chain configuration. The minimization of vulnerable hours also reduces the $\mathrm{CO} 2$ emissions in comparison to the Scenario A. By adding $62 \%$ cost, the $\mathrm{CO} 2$ emissions are reduced by $63 \%$. The Electricity and Metal sectors are the main sources of $\mathrm{CO} 2$ which are mostly concentrated in France and the USA respectively.

Table 4. 11 Detailed result for Scenario C

\begin{tabular}{|c|c|c|c|c|c|c|}
\hline Tier 1 & \multicolumn{3}{|c|}{ Tier 2} & \multicolumn{3}{|c|}{ Tier 3} \\
\hline \multirow{5}{*}{$\begin{array}{l}\text { P.USA } \\
\$ 100 \mathrm{M}\end{array}$} & \multirow{3}{*}{$\mathrm{C} 1$} & \multirow{3}{*}{ TUR } & \multirow{3}{*}{50} & RM1 & USA & 9 \\
\hline & & & & $\mathrm{RM} 2$ & NLD & 27.5 \\
\hline & & & & RM3 & FRA & 13.5 \\
\hline & \multirow{2}{*}{$\mathrm{C} 2$} & \multirow{2}{*}{ USA } & \multirow{2}{*}{50} & RM1 & USA & 17.5 \\
\hline & & & & RM3 & FRA & 32.5 \\
\hline
\end{tabular}




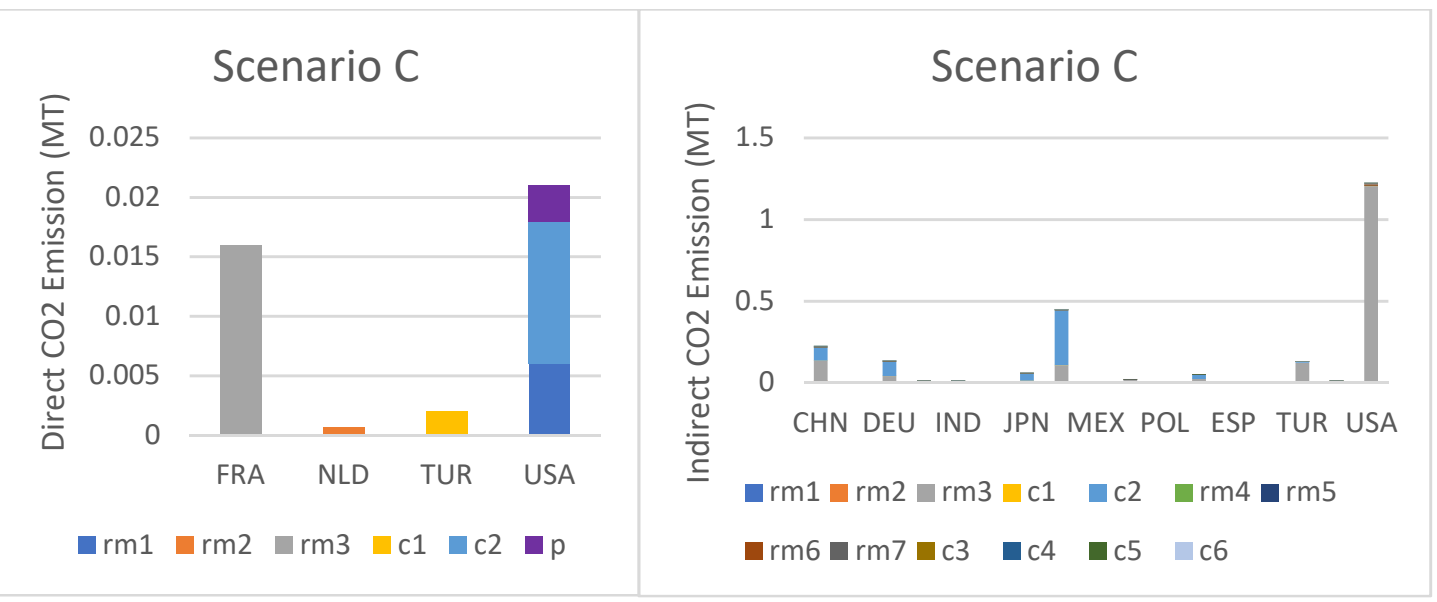

Figure 4. 8 Direct and indirect $\mathrm{CO}_{2}$ impact of scenario $\mathrm{C}$

The minimization of vulnerable hours significantly reduces the total vulnerable hours impact by $90 \%$ with more than $62 \%$ additional cost in comparison to the scenario A. The Machinery industry in Turkey is the main source of direct vulnerable workers hours in the supply chain. From the social factor perspective, the agriculture sector in China is the main source of indirect vulnerable workers hours in the supply chain, with approximately $4.5 \mathrm{M}$ vulnerable workers from various sectors. This number is possible because according to 2008 data from the World Bank, more than $50 \%$ of total employment in China is considered vulnerable.

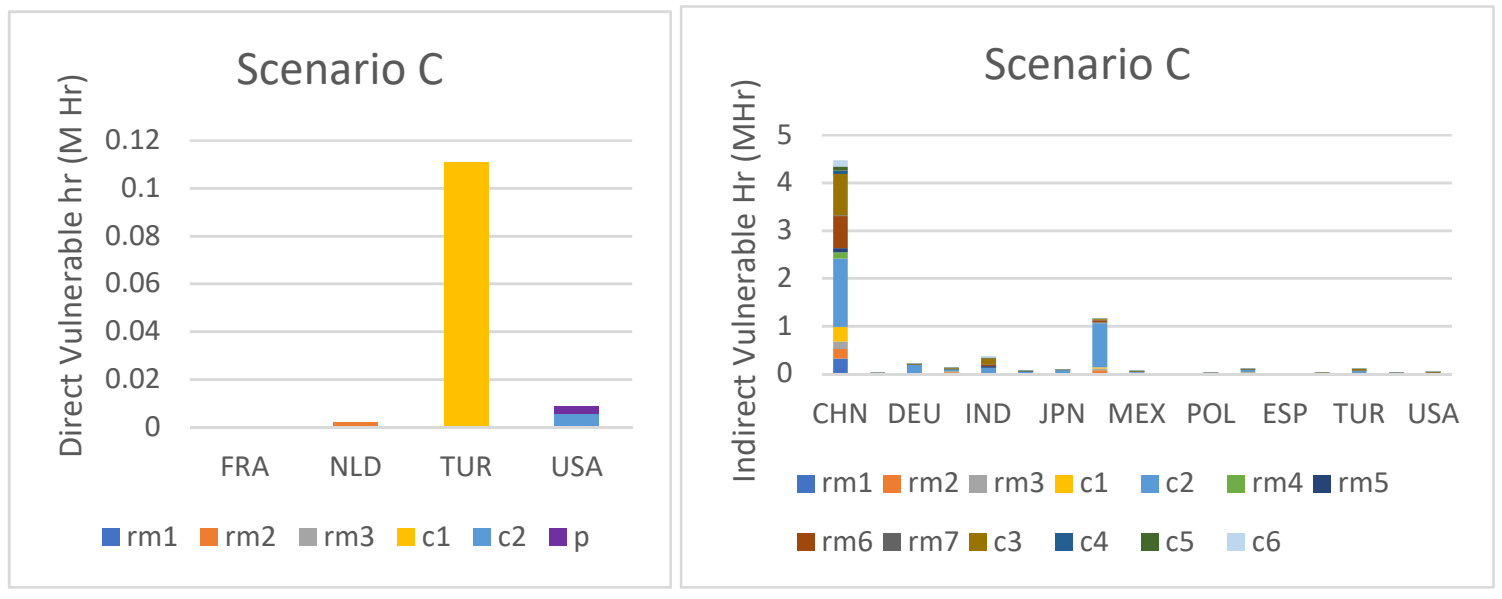

Figure 4. 9 Direct and Indirect vulnerable hour in Scenario C 
In conclusion, to improve the sustainability of a supply chain, the inclusion of both direct and indirect impacts is important to quantify the total impact. The single objective method shows the sector and country with a significant contribution toward the total impact. However, this method does not clearly show the tradeoff between different scenarios. Therefore, a model that enables inclusion of direct and indirect impact, as well as could shows the trade-off between different objectives is needed.

\subsubsection{The Epsilon Constraint (\&-constraint) Method}

The $\varepsilon$-constraint method is one of the simplest and most efficient methods that is widely used to solve multi-objective optimization problems. Considering the threedimensional performance measures in this research, this method is used to obtain the Pareto optimal solution. The general concept is to optimize one of the objective functions by incorporating other objective functions as constraints in the model.

Mavrotas (2009) introduced the augmented $\varepsilon$-constraint (AUGMECON), where the payoff table is only constructed for efficient solutions by using lexicographic optimization. In this way, the efficiency of the obtained solution is guaranteed and results in a more reliable calculation of the objective function ranges. Lexicographic optimization ranks the sequential solutions for single-objective optimization objectives based on their order of importance. Then, an objective function is selected arbitrarily, and the other objective functions are converted into constraints to generate Pareto-optimal solutions. The augmented $\varepsilon$-constraint method is shown below: 
$\operatorname{Max}\left(f_{1}(x)+\delta \times\left(s_{2}+s_{3}+\cdots+s_{n}\right)\right)$

St:

$$
\begin{aligned}
& f_{2}(x)-s_{2}=\varepsilon_{2} \\
& f_{3}(x)-s_{3}=\varepsilon_{3} \\
& \ldots \\
& f_{n}(x)-s_{n}=\varepsilon_{n} \\
& x \in S \text { and } s_{i} \in R^{+}
\end{aligned}
$$

Where $\delta$ is a small number (usually $10^{-3}$ and $10^{-6}$ ).

This research employed the AUGMECON procedure using the GAMS modeling system (www.gams.com). The time required to obtain solutions was a total of 7 minutes 36 second using CPLEX run in GAMS 27.3 software. The Pareto optimal sets are generated by selecting each objective function as the main optimization goal and then transforming the remaining objective functions into constraints. A set of 10 Pareto optimal solutions generated by the AUGMECON method are given in Table 4.12.

Table 4.12 Solutions obtained by AUGMECON method, where the economic OF is the main goal

\begin{tabular}{|r|r|r|r|}
\hline No & \multicolumn{1}{|c|}{$\begin{array}{c}\text { COST } \\
(\text { M\$) }\end{array}$} & $\begin{array}{c}\text { CO2 Emission } \\
\text { (MT) }\end{array}$ & Vulnerable Hr \\
\hline 1 & $4,670.58$ & 4.75 & 116.14 \\
\hline 2 & $5,630.74$ & 4.5 & 105.66 \\
\hline 3 & $5,700.96$ & 4.48 & 51.54 \\
\hline 4 & $5,755.14$ & 2.7 & 43.54 \\
\hline 5 & $5,834.74$ & 2.53 & 30.91 \\
\hline 6 & $5,931.41$ & 2.41 & 42.79 \\
\hline 7 & $6,040.78$ & 1.94 & 38.13 \\
\hline 8 & $6,048.94$ & 1.4 & 36.34 \\
\hline 9 & $6,284.16$ & 1.36 & 35.85 \\
\hline 10 & $6,713.15$ & 1.06 & 28.04 \\
\hline
\end{tabular}




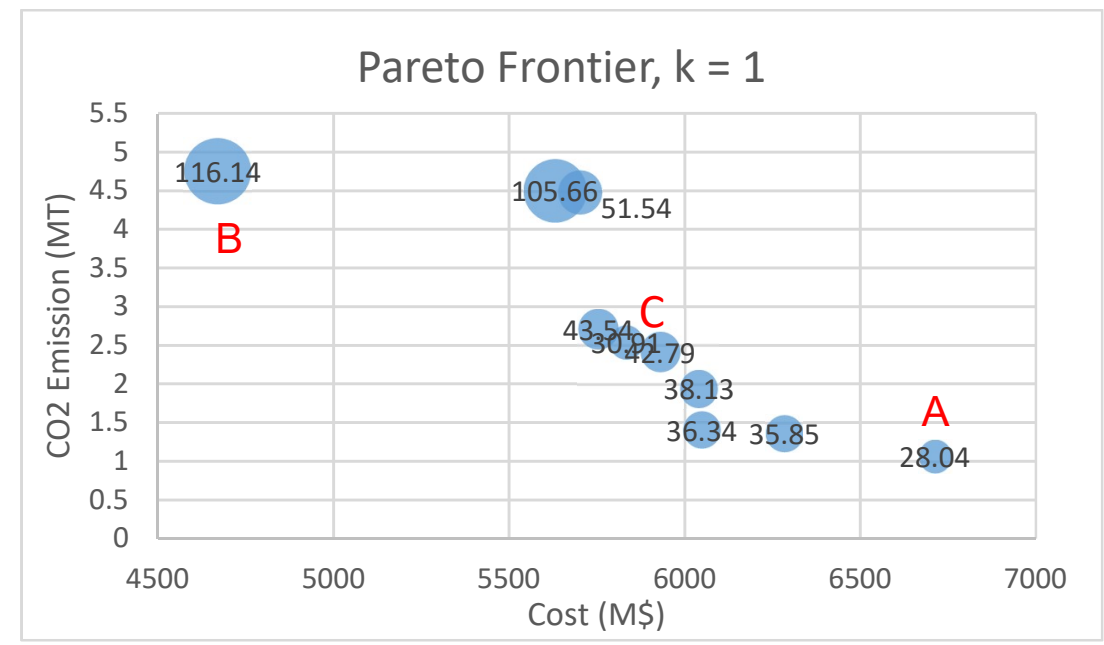

Figure 4. 10 Pareto solution when the economic objective is the main optimization

Figure 4.8 is the Pareto Frontier result when the economic objective function is the main minimization when solving the problem. It uses epsilon $(\varepsilon)=10^{-3}$. The result presents the trade-offs between the three-objective functions. The bubble size shows the social factor (vulnerable hours). Bubble A shows the point with the lowest $\mathrm{CO}_{2}$ emission and vulnerable hours, but the most expensive supply chain. Bubble B shows the lowest cost option, but the highest $\mathrm{CO}_{2}$ emission and the worst vulnerable hours.

We can identify a "good solution"; bubble C (point no 5) has the $2^{\text {nd }}$ lowest vulnerable hours ( $\pm 10 \%$ more than A), but $15 \%$ lower cost than A. Moreover, it produces twice the $\mathrm{CO}_{2}$ emissions in comparison to the total emissions of A. The Pareto results provide possible options for decision-makers by considering the three dimensions at the same time. By restricting attention to the set of choices that are Pareto-efficient, a decisionmaker can make trade-offs within this set, rather than considering the full range of every parameter. 


\subsection{Summary}

This research proposes an integrated hybrid SC and IO model as the method to analyze sustainable supply chains. It considers the triple bottom line of sustainable dimensions. The model adopts the structure of the integrated hybrid LCO. It consists of four parts: the SC system, the IO system (S), upstream cutoffs and downstream cutoffs.

A mathematical model is developed that includes economic, environmental and social dimensions. An illustrative example is presented to shows how the model works and detail of calculation. It also shows how the decision may change due to inclusion of direct impact. Finally, the single objective optimization is run to see the result when the objective function is solved individually.

The results show that China will be selected as the main supplier in the supply chain when we optimize the economic objective. This is because operational cost of China is very cheap in comparison to other countries. In contrast, the model selected developed countries, when the optimization id based on environmental or social objective. 


\section{CHAPTER 5 OPTIMAL PLANNING IN THE GLOBAL}

SUSTAINABLE SUPPLY CHAIN (GSSC): AN INTEGRATED MULTIOBJECTIVE INPUT-OUTPUT DECISION-MAKING PROCESS

Concern about environmental and social factors in sustainability has grown significantly during the last two decades. This is mainly because of increased awareness among stakeholders of the impact of industry actions which causes environmental and social issues. Public support for a sustainable supply chain is usually justified in terms of its contribution to an expansion of economic activity, an improvement in environmental quality and enhancement in human well-being (Papong et al., 2016a; Santamaría and Azqueta, 2015). This leads many companies, especially those who trade globally to incorporate sustainability standards into their strategic design planning to reduce environmental and social risks as well as ensure profitability and growth (Ke et al., 2016). This chapter focuses on the integration of sustainability in the global supply chain design for strategic purposes.

\subsection{Introduction}

Globalization has connected countries through trade to outstanding levels. This leads to an integrated economic system that cuts across multiple national boundaries. This involves the flow of resources and the consumption of goods and services produced in a supply country and consumed in another country. Furthermore, the flow is not only the 
transfer of goods and services between countries, but trade has several hidden entities. In general, the products traded in global markets have several social and environmental impacts embodied in them, which originate during their production processes (e.g. pollution, environmental degradation, or bad working conditions). This implies there are environmental and social impacts exchanged, which may result in an imbalance of environmental and social issues between participating countries (Jiang et al., 2016; Lenzen et al., 2007; Zaks et al., 2009)

Stricter regulations by governments and pressure from various stakeholders with regard to social and environmental issues have contributed to the rising importance of including sustainability in the supply chain design (Sarkis, 1998; Zimmer et al., 2016). However, environmental and social effects are often neglected, when decisions or policymakers assess the supply chain design. Although, some countries consider environmental and social improvement in their overall objectives, however strong economic growth and better profit are still the immediate goals. This is especially true for developing countries, which view with disfavor policies that sacrifice economic objectives simply to improve environmental and social quality (Resosudarmo and Thorbecke, 1996).

Therefore, when considering alternative strategic design planning with respect to environmental and social improvement, quantifying their implications should help decision-makers identify the tradeoff, which optimizes environmental and social performance. For this reason, in order to compare the positive and negative effects with each other, a multi-objective optimization model that incorporates three sustainable dimensions is needed to show the impact of each alternative. Figure 5.1 shows the framework of sustainability performance in the sustainable supply chain design. 


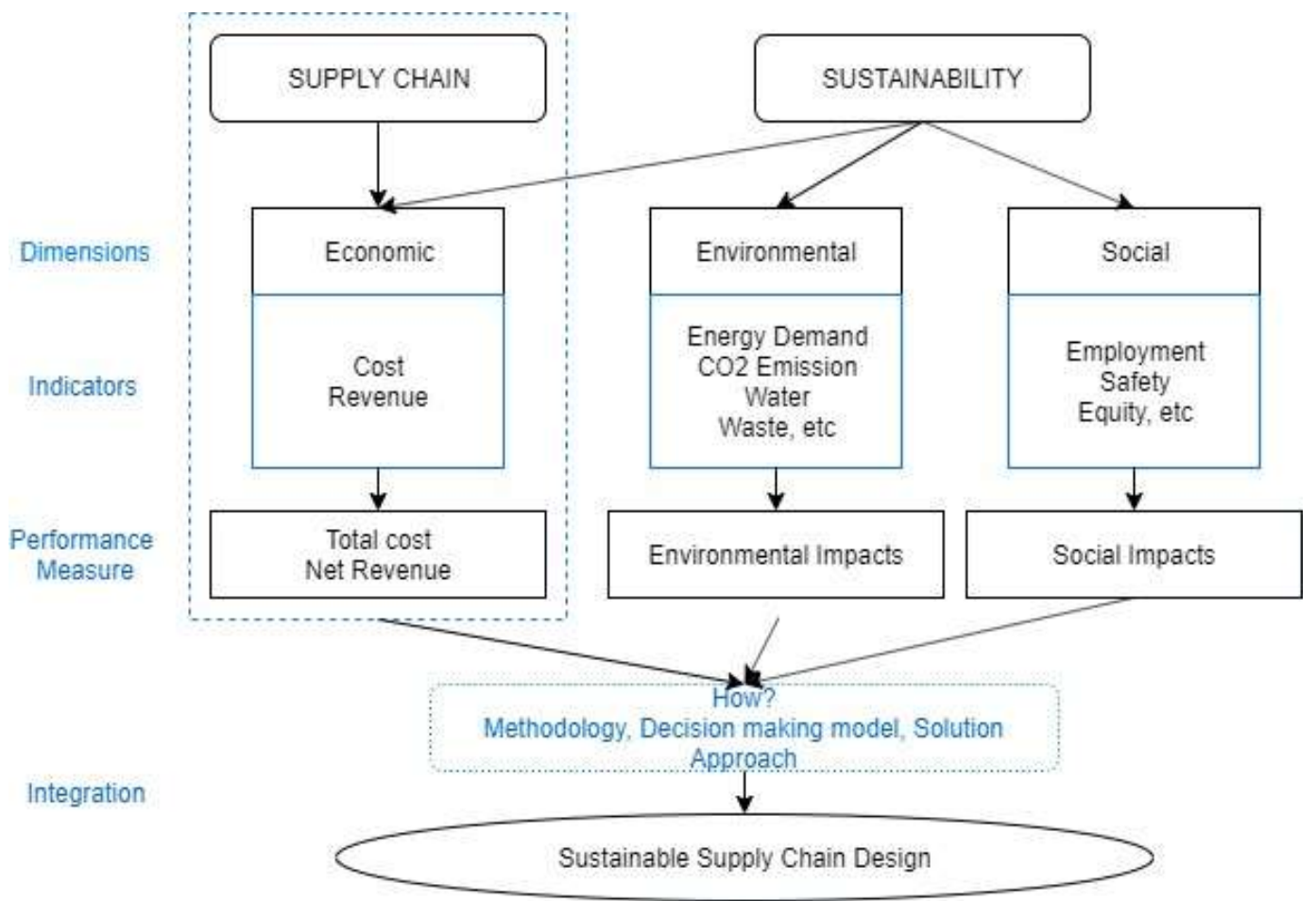

Figure 5. 1 The Sustainable Supply Chain Design Framework

This chapter addresses these issues by:

- Employing an Integrated Supply Chain and Input-Output Model that simultaneously considers economic, environmental and social impacts of the transport and equipment sector.

- Developing a number of scenarios that explore the impact of changing environmental and social aspects in transport and equipment supply chains.

\subsection{Literature Review}

The articles most relevant to the problem addressed in this chapter are on the optimal design of the sustainable supply chain. The design of a sustainable supply chain 
requires the consideration of economic, environmental and social aspects. Therefore, the demand for a multiobjective model has increased recently, because the real supply chain design problem is not a single objective. It is considered as comprising several objectives, which sometimes conflict with each other.

A number of papers over the last decade have proposed methods to address a sustainable supply chain. You et al. (2012) developed an optimal design model for sustainable biofuel supply chains. The MO-MILP model was coupled with LCA and IO Analysis to provide detailed techno-economic, social and emission analysis results. In line with this, Mota et al. (2015) presented a generic multi-objective model for the design and planning of supply chains, in order to minimize cost and environmental impact and maximize social benefit. Similar to You et al. (2012) the number of jobs created is considered as the main factor for social benefit in the model. The social benefit indicator aims to improve overall social benefit, thus it will also include regional factors, such as regional population density, unemployment rate, etc. In this way, underpopulated regions will have a higher overall social benefit, thus are preferable in decision making.

Social indicators related to health and safety in the working area are common social indicators for sustainable supply chain design. Chabanne et al. (2014) considered the minimization of the number of accidents in the working area together with minimizing cost and environmental factors. El-Halwagi et al. (2013) developed a model to minimize cost and fatalities in the biorefineries industry. Martinez-Gomez et al (2014) included safety issues related to the facility location and industrial process in their multi-objective model.

Other authors have developed bi-objective models. Pishvaee et al. (2012) developed a model that minimizes the total supply chain cost and maximizes supply chain 
responsibility. The responsibility includes environmental and social responsibility. Chaabane et al. (2012) introduced a MILP model to minimize cost and carbon emission in the aluminum industry. The model considers LCA in its material balance constraints. A more recent model was presented by Yue et al. (2016), who developed a model to minimize total project cost and, direct and indirect GHG emission.

Zhang et al. (2016) designed a network model that minimized total cost, maximized customer demand coverage and also minimized environmental influence. Arampantzi and Minis (2017), by the usage of MO-MILP, developed an optimal solution for designing or redesigning high performing sustainable supply chain. Their model contains investment, operational and emission costs as the economic objective. The environmental objective includes emissions quantities and waste generation. The social objective captures employment opportunities, social community development, and improved labor conditions. They used goal programming and the $\varepsilon$-constraint in the analysis. Oliveira et al. (2016) reviewed how multi-objective models, coupled with input-output analysis, for assessing the trade-offs associated with economy, environmental and social policies.

The exploration in the GSSC network design problem has been conducted using different solution methodologies, network configurations, types of product/process and the number of periods. Table 5.1 illustrates the characteristics of some important studies relevant to this research. 
Table 5. 1 Literature in Sustainable Supply Chain Design

\begin{tabular}{|c|c|c|c|c|c|c|}
\hline \multirow{2}{*}{ Authors } & \multicolumn{2}{|c|}{ Period } & \multirow{2}{*}{ Objectives } & \multirow{2}{*}{ Industry } & \multirow{2}{*}{$\begin{array}{l}\text { Modeling } \\
\text { Approach }\end{array}$} & \multirow{2}{*}{$\begin{array}{l}\text { Multi-objective } \\
\text { Solution } \\
\text { Method } \\
\end{array}$} \\
\hline & Single & Multiple & & & & \\
\hline $\begin{array}{l}\text { (Mota et } \\
\text { al., 2015) }\end{array}$ & $\mathrm{X}$ & & $\begin{array}{l}\text { 1. Min Cost, } \\
\text { 2. Min environmental } \\
\text { impact } \\
\text { 3. Max Social Benefit }\end{array}$ & $\begin{array}{l}\text { Battery } \\
\text { Manufacturing }\end{array}$ & MILP & $\varepsilon$-constraints \\
\hline $\begin{array}{l}\text { (You et } \\
\text { al., 2012b) }\end{array}$ & $\mathrm{X}$ & & $\begin{array}{l}\text { 1. Min Cost } \\
\text { 2. Min GHG Emission }\end{array}$ & $\begin{array}{l}\text { Cellulosic } \\
\text { Biofuel } \\
\end{array}$ & MILP & $\varepsilon$-constraints \\
\hline $\begin{array}{l}\text { (Chaabane } \\
\text { et al., } \\
\text { 2012)a }\end{array}$ & & $\mathrm{X}$ & $\begin{array}{l}\text { 1. Min Cost } \\
\text { 2. Min Environmental } \\
\text { factor }\end{array}$ & 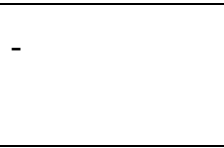 & $\mathrm{MIP}+\mathrm{LCA}$ & LINGO \\
\hline $\begin{array}{l}\text { El- } \\
\text { Halwagi } \\
\text { (2013) }\end{array}$ & $\mathrm{X}$ & & $\begin{array}{l}\text { 1. Min Cost } \\
\text { 2. Min Fatalities }\end{array}$ & Biorefineries & MILP & Pareto Curves \\
\hline $\begin{array}{l}\text { Martinez- } \\
\text { Gomez et } \\
\text { al (2014) }\end{array}$ & $\mathrm{X}$ & & $\begin{array}{ll}\text { 1. } & \text { Min Cost } \\
\text { 2. } & \text { Min Social Risk }\end{array}$ & $\begin{array}{l}\text { Distillation } \\
\text { process }\end{array}$ & MILP & $\varepsilon$-constraints \\
\hline $\begin{array}{l}\text { Zhang et } \\
\text { al. (2016) }\end{array}$ & $\mathrm{X}$ & & $\begin{array}{ll}\text { 1. } & \text { Min Cost } \\
\text { 2. } & \text { Max Customer } \\
\text { service } \\
\text { 3. Min environmental } \\
\text { influence }\end{array}$ & - & MDCSCN & $\begin{array}{l}\text { ABC } \\
\text { Algorithm }\end{array}$ \\
\hline Our study & $\mathrm{X}$ & & $\begin{array}{ll}\text { 1. } & \text { Min Cost, } \\
\text { 2. Min CO2 } \\
\text { emission, } \\
\text { 3. Min vulnerable } \\
\text { hour, non-fatal } \\
\text { incidents, fatal } \\
\text { incidents }\end{array}$ & $\begin{array}{l}\text { Transport and } \\
\text { Equipment } \\
\text { Sector }\end{array}$ & $\begin{array}{l}\text { MIP } \\
\text { coupled } \\
\text { with IO }\end{array}$ & $\varepsilon$-Constraint \\
\hline
\end{tabular}

Based on a systematic review of the sustainable supply chain and multi-objective supply chain network design articles, the contributions of this research to the literature are:

1. It is among the pioneering research which considers social perspectives in designing a sustainable supply chain network. Although several research studies have been carried out in this field, the integration of social aspects in developing a sustainable supply chain is a new perspective, which this research aims to shed light on. 
2. The development of a global sustainable supply chain model that could be applicable in the transport and equipment industry. The model covers not only direct impact due to economic activities of the supply chain but also indirect impacts from the upstream supply chain.

3. The use $\varepsilon$-constraint as the method for solving a proposed GSSC network model

\subsection{Research Methodology}

The following section outlines the methods used to conduct the analysis of the global sustainable supply chain (GSSC). In this research, the integrated supply chain and IO methodology from Chapter 4 are applied as the methodology to select the optimal design of the global supply chain. This methodology incorporates a supply chain optimization model combined with IO methodology to measures the direct and indirect impact of the sustainable effects in the supply chain.

In order to capture a complete economic analysis, the SC-IO model from chapter 4 is modified to include carbon cost and labor cost. An overview of the case study is given and the need for use of the integrated supply chain and IO methodology is outlined. Finally, the case study data and assumptions used in this research are detailed.

\subsubsection{Economic, Environmental and Social Factors Considered}

This research proposes methodologies to assess a set of relevant economic, environmental and social implications of designing a GSSC. This section provides the three sustainable dimension factors from the GSSC design indicating effects that are considered 
in this research. Additionally, it includes the selected indicators that could be used to quantify such effects, how to quantify and, weather the indicators have been incorporated in the decision making.

The total annual cost represents the economic objective of this paper. It consists of fixed cost and variable cost. The fixed cost is represented by the cost of export, which consists of the border compliance cost and document compliance cost. Variable costs are based on operational cost, transportation cost, carbon cost, and labor cost multiply with production level. Table 5.2 provides the cost definitions and sources of data.

Table 5. 2 Cost Parameter Definitions and Data Sources

\begin{tabular}{|l|l|l|}
\hline \multicolumn{1}{|c|}{ Parameter } & \multicolumn{1}{c|}{ Description } & \multicolumn{1}{c|}{ Source } \\
\hline Fixed Cost & $\begin{array}{l}\text { The cost to export (border compliance cost and } \\
\text { document compliance cost) }\end{array}$ & www.doingbusiness.org \\
\hline Transportation cost & $\begin{array}{l}\text { It depends on the distance from suppliers to a } \\
\text { production facility, as well as on the quantity } \\
\text { shipped. }\end{array}$ & Google map \\
\hline Total carbon cost & $\begin{array}{l}\text { Based on average CO2 emission tax price (\$/T } \\
\text { CO2) and CO2 quantity }\end{array}$ & OECD \\
\hline Total Labor Cost & $\begin{array}{l}\text { Based on the number of Labor (Employee and } \\
\text { Vulnerable employee) and wages per hour }\end{array}$ & WIOD, ILO \\
\hline
\end{tabular}

The environmental impact includes the level of $\mathrm{CO}_{2}$ emission. $\mathrm{CO}_{2}$ emissions are the emissions resulting from energy use and include process-based emissions. It does not count any other air emissions such as $\mathrm{N}_{2} \mathrm{O}$ and $\mathrm{CH}_{4}$. In order to calculate the $\mathrm{CO} 2$ impact, the $\mathrm{CO}_{2}$ multiplier is calculated by obtaining data from the environmental accounts of the WIOD database. Furthermore, the IO method is used to calculate the contribution of country-sectorial $\mathrm{CO}_{2}$ in the model. 
Three social factors were explored in this work, namely: vulnerable employment, fatal incident and non-fatal incidents. In order to calculate the impacts on employment, a vulnerable employment vector is used in Equation 2.5. In order to construct this vector, the country-sectorial employment average data referring to the years 2006, 2007 and 2008 obtained from the Socio-Economic Accounts of WIOD database, have been used (Dietzenbacher et al., 2013). The vulnerable employment vector reflects the number of employees in each sector of the economy with no formal employment agreement, which likely has insufficient decent working conditions. For this indicator to better reflect the employee situation, the vector has been constructed considering the average production by sectors from 2006 to 2008 .

In order to identify the number of non-fatal and fatal incidents, it is necessary to construct a non-fatal and fatal incidents vector. Due to the lack of sufficiently detailed data, several adjustments are made. First, sector disaggregation from the ILO database to match the sector in the WIOD database. Occupational injuries data from ILO consist of 12-14 economic sectors, whereas WIOD data of each country cover 35 industry sectors, which provides better information on economic sectors than the data from ILO. The number of non-fatal and fatal incidents from ILO is prorated according to the proportion of workers with injuries per economic sector in WIOD. The disaggregation was calculated based on the assumption that, for the major economic sector, the proportion of incidents would be the same as for the specific economic sector under the major sector. Second, the data on the number of incidents from 2006 to 2008 is used. If the data for those years are missing, the closest year data is used based on the assumption that the proportion of workers involved in an accident in each economic sector was similar in those years. 
Through the integration of the sustainability dimensions, this model offers a tool for decision-makers to analyze what level of economic inducement would provide a competitive advantage in their supply chain `planning decisions. The critical advantage of this model is that it uses MRIO to analyze environmental and social impacts. This includes both the direct or immediate effects as well as the indirect effects attributed through large and distant tiers of the supply chain. The incorporation of most upstream effects, therefore, expands the range of issues and effects within the analytical boundary. Industries/sectors can then be assessed properly in stainable chain management (SCM), thus improving decision-makers selection of key inputs on a wider range of criteria, rather than on price alone.

\subsubsection{Application of the GSSC approach to a case study on the transport and equipment industry}

The transport and equipment (TE) industry is chosen because the share of procured materials and components in the industry has risen over the years and planning selection has taken up a key role in the TE market. In the TE industry, the role of other countries in international trading become very important in terms of various aspects due to the high share of outsourced manufacturing (Timmer et al. 2015). Recently, various stakeholders require the final customer country-sector (focal country) to be more responsible for their supply chains. The more they purchase from these chains the higher the embodied environmental and social risks for focal countries (Zimmer et al., 2017b). Therefore, the need exists to assure that global supply chain design complies with the minimum environmental and social requirements. Moreover, it should minimize environmental and 
social risks along the entire supply chain, not only examine direct supplier countries but also upstream countries in the $2^{\text {nd }}, 3^{\text {rd, }}$ and beyond tiers. Therefore, the TE industry in the USA has selected as the focal sector-country for this research.

In order to trace the environmental and social impact in TE production, we make use of Leontief's decomposition method outlined in Chapter 3. We trace the countries contributing to the embodied environmental and social risk of consumption good, by identifying the global value chain (GVC), which was introduced by Timmer et al. (2015b) This is done by appropriately choosing the final demand vector $Y$ in equation (5.1), which refers to the consumption of goods delivered by the USA TE industry. By using the result, we calculate the environmental and social impacts from primary producer sectors to final consumer sectors. This decomposition method provides the environmental and social impacts that being generated in any stage of the USA TE industry.

The IO data from the World Input-Output Database (WIOD) is used (Dietzenbacher et al., 2013). The European Commission, Research of Directorate General is the body in charge of funding the WIOD project. The last published matrix is for 2016 and contains information, in million USD, for $28 \mathrm{EU}$ countries and 15 other major countries in the world for the period from 2000 to 2014. However, the environmental and socioeconomic data only covers the years until 2009 and 2011, respectively.

The data that includes monetary, environmental and socioeconomic data for most countries and sectors is the 2008 dataset. In this version, data for 35 sectors are classified according to the International Standard Industrial Classification Revision 4 (ISIC Rev. 4). From this table, the technical coefficients for each economic activity have been calculated as an intermediate step required in order to obtain the Leontief inverse matrix. 
In particular, this case study considers three tiers of the TE supply chain, which consists of six industrial sectors. It is approached from the production facility's perspective with only one period of time under consideration. It is assumed that the interrelationship between industrial sectors is known. This supply chain is part of a bigger system of 14 industrial sectors that operate in the 17 top manufacturing countries. Figure 5.2 shows the supply chain system used as the basis of this example.

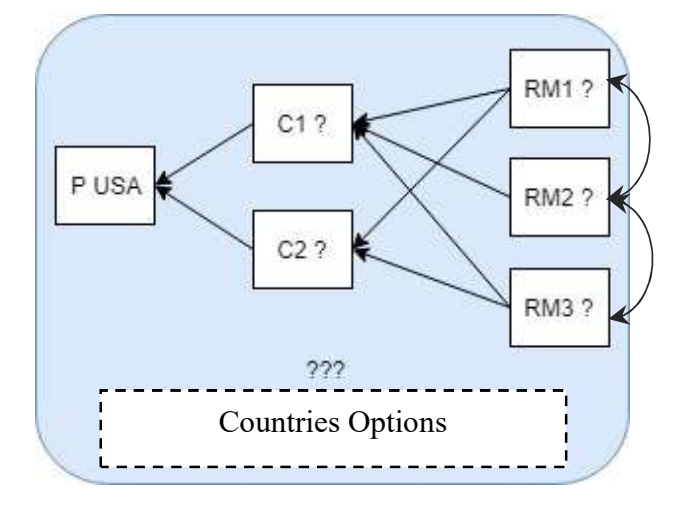

Figure 5. 2 The Transport and Equipment Supply Chain

Table 5.3 below presents the list of 17 countries and 14 sectors considered in the case study.

Table 5. 3 List of sectors and countries

\begin{tabular}{|l|l|}
\hline Code & \multicolumn{1}{|c|}{ Sector } \\
\hline C1 & Machinery, NEC \\
\hline C2 & Basic metals and fabricated metals \\
\hline C3 & Agriculture, hunting, forestry and fishing \\
\hline C4 & Food, beverages and tobacco \\
\hline C5 & Textiles and textile product \\
\hline C6 & Leather, leather and footware \\
\hline P & Transport equipment \\
\hline RM1 & Mining and Quarrying \\
\hline RM2 & Coke, refined petroleum and nuclear fuel \\
\hline RM4 & Wood and product of wood and cork \\
\hline RM5 & Pulp, paper, paper product, printing and publishing \\
\hline RM6 & Chemicals and chemical products \\
\hline RM7 & Rubber and plastics \\
\hline
\end{tabular}

\begin{tabular}{|c|c|}
\hline No. & Country \\
\hline 1 & CHN \\
\hline 2 & DEU \\
\hline 3 & ESP \\
\hline 4 & FRA \\
\hline 5 & GBR \\
\hline 6 & IND \\
\hline 7 & IND \\
\hline 8 & ITA \\
\hline 9 & JPN \\
\hline 10 & KOR \\
\hline 11 & MEX \\
\hline 12 & NLD \\
\hline 13 & POL \\
\hline 14 & RUS \\
\hline 15 & TUR \\
\hline 16 & TWN \\
\hline 17 & USA \\
\hline
\end{tabular}


For the optimization of the supply chain, several assumptions are made:

(1) It is assumed that there is a $\$ 100 \mathrm{M}$ demand for the TE industry (P) in the USA and the requirements for the demand from each supplier are known.

(2) The supply is organized in a just-in-time manner so that the effect of incoming items inventory can be neglected.

(3) The ordered quantities of all materials will meet the needs of production.

(4) Both the production facility and supplier options have capacity constraints.

(5) All suppliers, when combined, can fulfill the ordered quantities needed for production and meet the demand of customers.

(6) Production emissions depend on the selected producers' countries, as well as the produced quantity.

\subsection{Analysis of Results and Discussion}

The following sections present results from using the solution approach to solve the multi-objective model. The goal is to illustrates how the described approach could help the decision-maker understanding and making trade-offs with respect to the performance of the three sustainability dimensions. First, Pareto Frontier is generated for three objective functions, to see the influence of the single indicator of each objective function. As we want to learn more about the social impact in the decision making, we generated Pareto Frontier with four and five objective functions.

1. Three Objective Functions: Cost, CO2 Emission, and Vulnerable Hour 
All three objectives for the economic, environmental, and social performance of the TE supply chains are considered in this scenario. The time required to obtain solutions was a total of 15 min $38 \mathrm{sec}$ using CPLEX run in GAMS 27.3 software. The resulting Pareto curve is given in Figure 5.3 and the values are shown in Table 5.4. All the optimal solutions that take into account the economic and environmental objectives lie on the Pareto curve. Hence, the solutions above the curve in Figure 5.3 are suboptimal solutions, and any solution below this curve is infeasible.

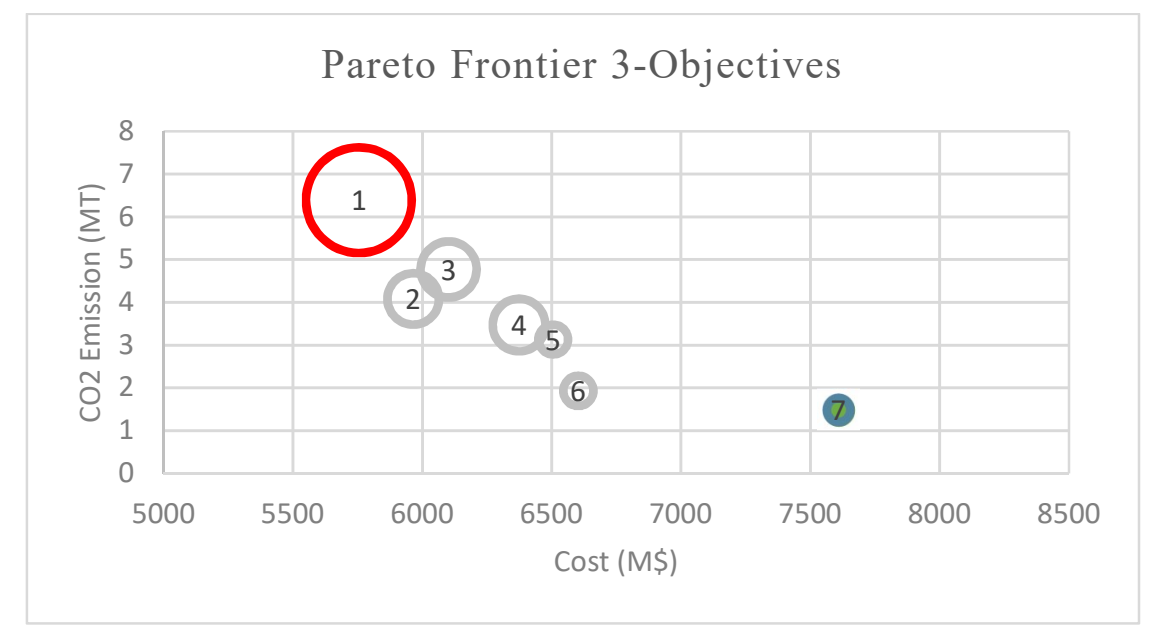

Note: The number in the circles refer to the options in Table 5.4

Figure 5. 3 Pareto Curve Showing the Tradeoff between the Three Objectives

We first consider the tradeoff between economic and environmental performance. We can see from Figure 5.3 that as the optimal total annualized cost decreases, the annual $\mathrm{CO} 2$ emissions resulting from the operation of the supply chain increases. The trend of this Pareto curve reveals the tradeoff between economic and environmental performance. In particular, by comparing the two solutions with the red and green circles in Figure 5.3, together with detail results in Table 5.4, we can identify a "good choice" solution (option 
5) that significantly reduces the GHG emissions by more than $50 \%$ with only $13 \%$ cost increase over the minimum cost solution.

Table 5. 4 The Three Objectives Results

\begin{tabular}{|c|r|r|r|}
\hline Option & COST (M\$) & \multicolumn{1}{|c|}{$\begin{array}{c}\text { CO2 Emission } \\
\text { (MT) }\end{array}$} & $\begin{array}{c}\text { Vulnerable Hours } \\
\text { (M Hr) }\end{array}$ \\
\hline 1 & $5,754.89$ & 6.39 & 94.124 \\
\hline 2 & $5,964.72$ & 4.08 & 26.01 \\
\hline 3 & $6,101.4$ & 4.77 & 30.12 \\
\hline 4 & $6,373.89$ & 3.47 & 27.1 \\
\hline 5 & $6,505.93$ & 3.14 & 10.56 \\
\hline 6 & $6,603.09$ & 1.93 & 7.39 \\
\hline 7 & $7,609.82$ & 1.48 & 10.83 \\
\hline
\end{tabular}

Table 5.5 shows the detailed supply chain configuration and how the cost effects environmental and social factors. We can see from Table 5.6 that an increase in cost to around $4 \%$ reduces $\mathrm{CO} 2$ emission by $36 \%$. The best reduction of $\mathrm{CO} 2$ emission, which is a $76 \%$ improvement, would need a $32 \%$ increase in total cost.

Table 5. 5 Supply Chain Configuration - Three Objectives

\begin{tabular}{|l|c|c|c|c|c|c|c|}
\hline \hline & Option 1 & Option 2 & Option 3 & Option 4 & Option 5 & Option 6 & Option 7 \\
\hline \hline TIER1.p & USA & USA & USA & USA & USA & USA & USA \\
\hline TIER2.c1 & CHN & CHN & CHN & CHN & USA & USA & TUR \\
\hline TIER2.c2 & USA & USA & USA & USA & USA & USA & USA \\
\hline TIER3.rm1 & CHN & USA & USA & USA & USA & USA & USA \\
\hline TIER3.rm2 & CHN & CHN & CHN & CHN & CHN & CHN & NLD \\
\hline TIER3.rm3 & CHN & POL & CHN & USA & DEU & USA & USA \\
\hline \hline COST & 5754.89 & $3.65 \%$ & $6.02 \%$ & $10.76 \%$ & $13.05 \%$ & $14.74 \%$ & $32.23 \%$ \\
\hline ENV & 6.39 & $-36.15 \%$ & $-25.35 \%$ & $-45.70 \%$ & $-51.02 \%$ & $-69.80 \%$ & $-76.84 \%$ \\
\hline Vul Hr & 94.124 & $-72.38 \%$ & $-68.00 \%$ & $-71.21 \%$ & $-88.78 \%$ & $-88.49 \%$ & $-92.15 \%$ \\
\hline \hline
\end{tabular}

When we consider the tradeoff between economic and social performance, the trend is similar to the one between economic and environmental performance. Table 5.6 shows how a small cost increase can greatly reduce overall vulnerable hours in the supply chain. 
This can be seen from the percentage of vulnerable hours which decrease more than $70 \%$ with a cost increase of only $4 \%$. Therefore, the results indicate that changing the supply chain configuration may significantly improve environmental and social performance.

The minimum annualized cost for the USA TE sector global supply chain is $\$ 5754.89$ M. The optimal supply chain configuration consists of China as the dominant country producer in the supply chain. China has resources and capacity to meet the production requirement and provides the lowest production cost among other countries. Thus, when the decision is only based on an economic objective, China would always be selected.

However, depending on only one country alone is risky in international trade, especially when the bilateral relationship is not positive. Also, environmental and social issues are worse among other optimal options. When the supply chain decision is driven by environmental and economic reduction, the configuration includes countries with better technology and low risks for vulnerable employees, such as the US and Germany. Consider Option 4 as an example, although the production cost increases as the countries are selected, due to higher production and labor cost, the total $\mathrm{CO} 2$ emission and vulnerable hours are significantly reduced.

2. Four Objective Functions: Cost, $\mathrm{CO} 2$ Emission, Vulnerable Hour, and Number of Nonfatal (NF) Incidents

For this scenario, we also addressed the tradeoff between the economic, environmental and social objectives. Beside vulnerable hours, a number of non-fatal incidents are considered a second social factor. Table 5.6 shows the seven points result of $\varepsilon$-constraint for four objective functions. We again used the $\varepsilon$-constraint method to solve 
the four-criterion optimization problem and generate the Pareto curve shown in Figure 5.4 by first calculating the normalization index of environmental and social results. The time required to obtain solutions was a total of 21 minutes 18 second using CPLEX run in GAMS 27.3 software. The blue dot shows the $\mathrm{CO}_{2}$ emissions index of all options. The orange square shows the total vulnerable hours index of all instances. The grey triangle shows the number of non-fatal incidents index.

Table 5. 6 The Four Objectives Results

\begin{tabular}{|c|r|r|r|r|}
\hline Option & COST (M\$) & \multicolumn{2}{|c|}{$\begin{array}{c}\text { CO2 Emissions } \\
\text { (MT) }\end{array}$} & \multicolumn{2}{|c|}{$\begin{array}{c}\text { Vulnerable } \\
\text { Hours }\end{array}$} & $\begin{array}{c}\text { Non-Fatal } \\
\text { Incidents (Cases) }\end{array}$ \\
\hline 1 & $5,754.89$ & 6.39 & 94.12 & 124.82 \\
\hline 2 & $6,101.4$ & 4.77 & 30.12 & 43.89 \\
\hline 3 & $6,373.89$ & 3.47 & 27.1 & 35.82 \\
\hline 4 & $6,405.85$ & 4.54 & 16.43 & 29.88 \\
\hline 5 & $6,603.16$ & 1.93 & 10.81 & 18.91 \\
\hline 6 & $6,825.87$ & 1.49 & 8.18 & 15.47 \\
\hline 7 & $7,007.63$ & 1.49 & 8.12 & 15.46 \\
\hline 8 & $7,433.84$ & 1.48 & 7.43 & 14.69 \\
\hline
\end{tabular}

The tradeoff trend between cost and the three other dimensions shows that as the total supply chain cost increases, the environmental and social issues decrease. Regarding the NF incidents, the results show that as the total annualized cost increases from $\$ 5,754$ $\mathrm{M}$ to $\$ 7,433 \mathrm{M}$, the NF incidents (full-time equivalent for one year) decreases from around 124.8 to around 14.7 cases. 


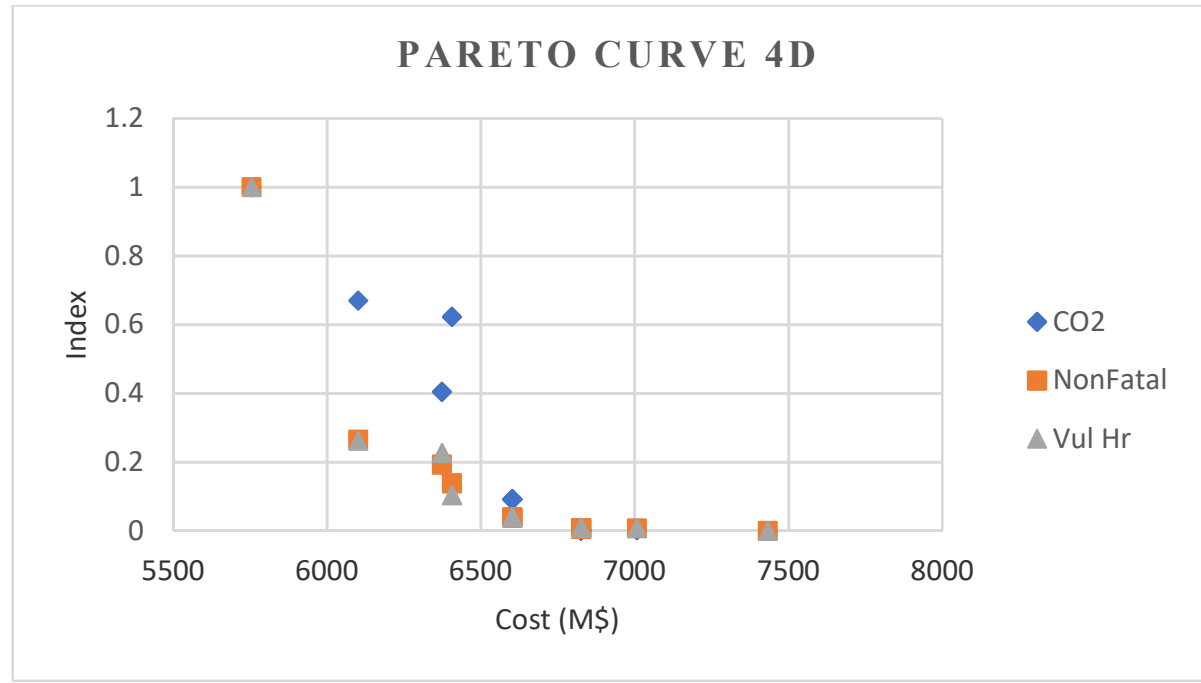

Figure 5. 4 Normalized Pareto Curve Showing Tradeoff between the Four Dimensions

In Figure 5.4, we can identify option 2 as a "good" solution that significantly reduces the GHG emissions as well as total vulnerable hours and number of non-fatal incidents with only a small increase (around 6\%) over the minimum cost solution. This option yields 4.77 MT CO2 emissions, 30 M vulnerable hours/year representing 15,000 vulnerable employees globally and 44 cases of non-fatal incidents (assuming one year = 250 days, 8 working hours/day). With respect to option 1 (minimum cost), there is a reduction of $25 \%, 68 \%$, and $65 \%$ respectively.

Table 5.7 shows the detailed supply chain configuration and how the cost affects the environmental and social impacts. We can see when the model selects developed countries to reduce environmental and social impacts, it includes developed countries such as the USA and Netherland in the configuration. Whereas, China is still the main country selected for the lowest cost option. 
Table 5. 7 Supply Chain Configuration - Four Objectives

\begin{tabular}{|l|c|c|c|c|c|c|c|c|}
\hline \hline & Option & $\mathbf{O p t i o n}$ & $\mathbf{O p t i o n}$ & Option & Option & Option & Option & Option \\
$\mathbf{1}$ & $\mathbf{2}$ & $\mathbf{3}$ & $\mathbf{4}$ & $\mathbf{5}$ & $\mathbf{6}$ & $\mathbf{7}$ & $\mathbf{8}$ \\
\hline TIER1.p & USA & USA & USA & USA & USA & USA & USA & USA \\
\hline TIER2.c1 & CHN & CHN & CHN & USA & USA & USA & USA & TUR \\
\hline TIER2.c2 & USA & USA & USA & USA & USA & USA & USA & USA \\
\hline TIER3.rm1 & CHN & USA & USA & USA & USA & USA & USA & USA \\
\hline TIER3.rm2 & CHN & CHN & CHN & CHN & CHN & JPN & NLD & JPN \\
\hline TIER3.rm3 & CHN & CHN & USA & CHN & USA & USA & USA & USA \\
\hline \hline
\end{tabular}

3. Five Dimensions: Cost, $\mathrm{CO} 2$ Emissions, Vulnerable Hours, Number of Nonfatal and Fatal Incidents

For the five-dimension analysis, we also addressed the tradeoff between the three sustainable dimensions with the addition of a number of fatal incidents as one of the social indicators. We again used the $\varepsilon$-constraint method to solve the multi-criteria optimization problem and generate the Pareto curve given in Figure 5.5. The time required to obtain solutions was a total of 32 minutes 6 second using CPLEX run in GAMS 27.3 software. This curve is consistent with the observation that the countries with strict health and safety standards for workers tend to have fewer incidents in the workplace (Martinez-Gomez et al. 2014).

The trend for the Pareto curve reveals that the tradeoffs between economic environmental and social factors. We can identify that as the cost increases, the environmental and social factors decrease. Table 5.8 shows that for the higher cost (option 8) of $\$ 7,428 \mathrm{M} / \mathrm{year}$, the number of fatalities is equal to one incident. This result is a consequence of the fact that the production units are installed in countries in which the percentage of fatal incidents is low (one or less). This solution, in particular, is the best if 
safety is considered as the most important criterion; however, usually decisions are made based on a balance between cost and environmental and social risk.

Table 5. 8 The Five Objectives Results

\begin{tabular}{|r|r|r|r|r|r|}
\hline NO & COST (M\$) & \multicolumn{1}{c|}{$\begin{array}{c}\text { CO2 Emission } \\
\text { (MT) }\end{array}$} & $\begin{array}{c}\text { Vulnerable } \\
\text { Hour (M Hr) }\end{array}$ & $\begin{array}{c}\text { Non-Fatal } \\
\text { Incidents (Cases) }\end{array}$ & $\begin{array}{c}\text { Fatal Incidents } \\
\text { (Cases) }\end{array}$ \\
\hline 1 & $4,876.43$ & 6.4 & 74.76 & 145.19 & 9.15 \\
\hline 2 & $5,423.45$ & 6.0 & 25.99 & 72.26 & 3.82 \\
\hline 3 & $5,705.58$ & 5.97 & 24.47 & 70.19 & 3.62 \\
\hline 4 & $5,974.86$ & 4.67 & 26.45 & 37.83 & 3.05 \\
\hline 5 & $6,232.11$ & 3.11 & 10.57 & 21.9 & 1.44 \\
\hline 6 & $6,467.06$ & 2.65 & 7.89 & 18.42 & 1.06 \\
\hline 7 & $6,647.82$ & 1.49 & 8.78 & 15.47 & 1.08 \\
\hline 8 & $7,428.82$ & 1.48 & 7.43 & 14.69 & 1.04 \\
\hline
\end{tabular}

Based on balancing decision criteria, option 6 might be more attractive because this option presents a considerable reduction in the cost, representing savings for $\$ 961 \mathrm{M} /$ year with respect to option 8 . This solution yields a total annual cost of $\$ 6,467 \mathrm{M} / \mathrm{year}$ and 1 fatality. Moreover, option 6 also shows goods results in other social factors, where the non-fatal incidents are 18 incidents (additional 4 cases with respect to option 8) and the total vulnerable hours are $7.89 \mathrm{M}$ hours. Regarding the $\mathrm{CO} 2$ emission, option 6 also will generate 2.65 MT emission, which is $1.17 \mathrm{MT}$ emission higher than compared with the result of option 8 . 


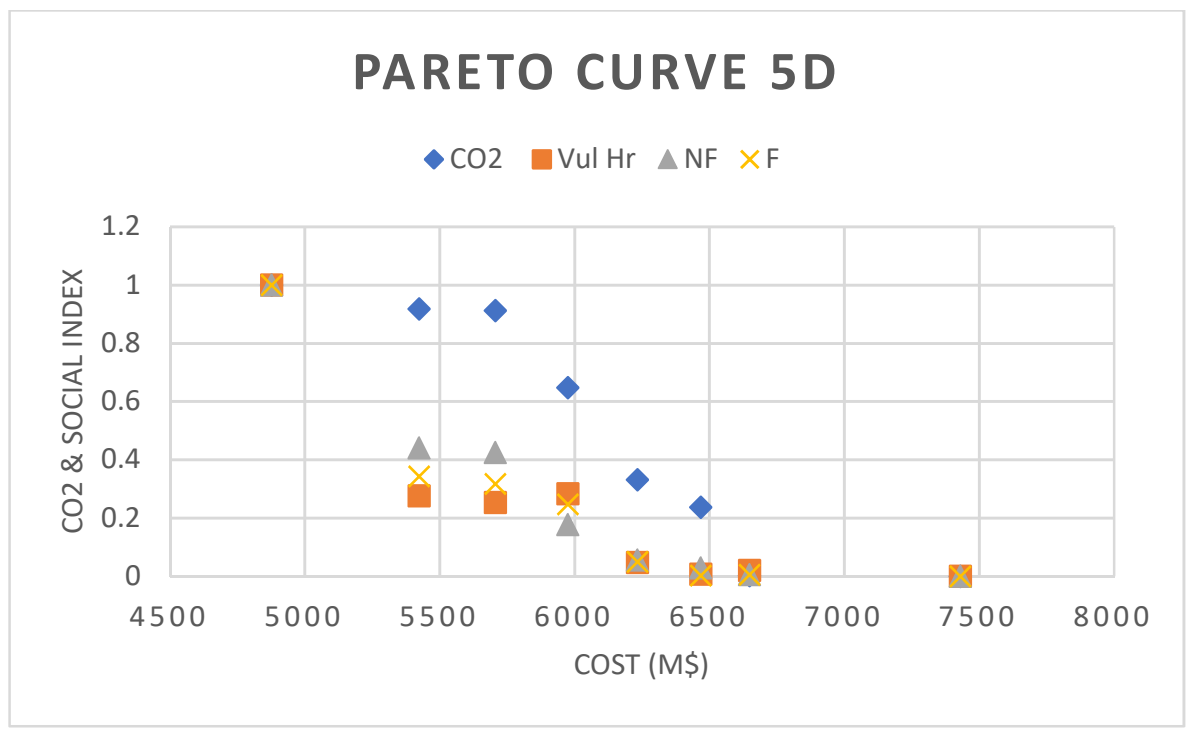

Figure 5. 5 Normalized Pareto Curve Showing Tradeoff between the Five Dimension

The results of multi-objective optimization show that considering sustainability issues in the integrated problem of supply chain configuration can lead to a better value of sustainable supply chain configuration. Although the results of the multi-objective model show a higher cost than the single-objective model, decision-makers are assured that they can improve their sustainability profile and consequently can make competitive advantages and long-term profit.

This research shows that there are a number of reasons for decision-makers to adopt sustainable supply chain design. However, global supply chain decision is not as simple as just dictating that a particular network should be selected. More research is required to assess the social issues that arise due to a global supply chain design decision.

The result of the model developed shows that simply reducing the supply of goods from developing regions could lead to positive global social impacts. But it could lead to more negative impacts on low-income households due to price increases. It could also slow 
down the economy in developing regions. This indicates that one cannot simply eliminate countries with low social responsibility practice from a supply chain network, due to resource limitations and/or interdependency between countries. The industry could identify sectors with a significant proportion of vulnerable hours, number of non-fatal and fatal incidents in the developing countries and find alternative solutions to address them, without eliminating the countries from the supply chain.

In the case of the Transport and Equipment sector, indirect economic activities contribute significantly to the total social impact in the global supply chain design. As a result, incentives to encourage social responsibility improvement with the upstream sectors could be a new priority. This calls for a commitment between local and regional development policies and global supply chain sustainability policies to guarantee fair working conditions throughout the production processes worldwide (Simas et al., 2014). Thus, improvement efforts related to supplier social responsibility can be leveraged opportunistically with modest changes to reduce vulnerable workers and increase safety in the workplace. However, the nature of these efforts might vary with the focus on supplier social improvement, such as developing monitoring capabilities and then collaborative capabilities.

In conclusion, capturing and dealing with the social impact associated with supply chain design has proven difficult. It involves understanding public expectations, regional and global social policies, and relationships between practices, cost, and innovation. Decision-makers need to improve their awareness and execution of each, and further research is needed to identify the social side effects of supply chain design in sequential 
waves. Moreover, exploring collaboration with significant sectors and countries should provide fruitful direction for improving the social impact of supply chain.

\section{Sensitivity Analysis}

The results of the GSSC model show the importance of country selection in the supply chain design. In particular, the country of China is dominant in international trade due to its low production and labor costs. This section examines the sensitivity of prices toward China's dominance in the global supply chain. The goal of this sensitivity analysis is to take into consideration what happens to the supply chain configuration when the operational cost in China gradually increases.

In order to explore the impact of an increase in operational cost in China on supply chain configuration, only a single objective that minimizes the economic objective is considered. Table 5.9 shows the results for the optimal configuration due to increasing the production price in China. Option 2 shows the current total annual cost when production price in China increases by $20 \%$. However, the model keeps selecting a similar configuration supply chain with China dominating until option 6, where the production cost increases more than $45 \%$ from its base price. The option 6 configuration consists of the USA, Japan, and Germany and has significantly better environmental and social performance. 
Table 5. 9 Sensitivity Analysis Results

\begin{tabular}{|c|c|c|c|c|c|c|c|c|c|}
\hline \hline & $\begin{array}{c}\text { Option } \\
\mathbf{1}\end{array}$ & $\begin{array}{c}\text { Option } \\
\mathbf{2}\end{array}$ & $\begin{array}{c}\text { Option } \\
\mathbf{3}\end{array}$ & $\begin{array}{c}\text { Option } \\
\mathbf{4}\end{array}$ & $\begin{array}{c}\text { Option } \\
\mathbf{5}\end{array}$ & $\begin{array}{c}\text { Option } \\
\mathbf{6}\end{array}$ & $\begin{array}{c}\text { Option } \\
\mathbf{7}\end{array}$ & $\begin{array}{c}\text { Option } \\
\mathbf{8}\end{array}$ & $\begin{array}{c}\text { Option } \\
\mathbf{9}\end{array}$ \\
\hline \hline $\begin{array}{c}\text { Cost } \\
\text { Increase }\end{array}$ & $\begin{array}{c}\text { Base } \\
\text { price }\end{array}$ & $\mathbf{2 0} \%$ & $\mathbf{2 5 \%}$ & $\mathbf{3 5 \%}$ & $\mathbf{4 5 \%}$ & $\mathbf{4 6 \%}$ & $\mathbf{5 0} \%$ & $\mathbf{5 5 \%}$ & $\mathbf{6 0} \%$ \\
\hline TIER1.p & USA & USA & USA & USA & USA & USA & USA & USA & USA \\
\hline TIER2.c1 & CHN & CHN & CHN & CHN & CHN & USA & USA & USA & USA \\
\hline TIER2.c2 & USA & USA & USA & USA & USA & USA & USA & USA & USA \\
\hline TIER3.rm1 & CHN & CHN & CHN & CHN & CHN & USA & USA & USA & USA \\
\hline TIER3.rm2 & CHN & CHN & CHN & CHN & CHN & JPN & JPN & JPN & JPN \\
\hline TIER3.rm3 & CHN & CHN & CHN & CHN & CHN & DEU & DEU & DEU & DEU \\
\hline \hline COST & $5,754.9$ & $6,185.8$ & $6,293.6$ & $6,509.1$ & $6,724.5$ & $6,728.2$ & $6,728.1$ & $6,728.2$ & $6,728.2$ \\
\hline ENV & 6.39 & 6.39 & 6.39 & 6.39 & 6.39 & 2.65 & 2.65 & 2.65 & 2.65 \\
\hline SOCIO & 94.12 & 94.12 & 94.12 & 94.12 & 94.12 & 7.9 & 7.9 & 7.9 & 7.9 \\
\hline \hline
\end{tabular}

\subsection{Conclusion}

In this research, a new Integrated Supply Chain and Input-Output model is presented to solve the GSSC problem. The model allows the inclusion of economic, environmental and social objectives in the decision-making process. It has been implemented using the MRIO database of WIOD and publicly available country indicators. Based on its application to the Transport and Equipment sector, various analysis options are explored. Finally, a sensitivity analysis has been conducted to check the robustness of the supply chain configuration results.

The practical application shows how the Integrated Supply Chain and Input-Output model approach can be used for the assessment of direct and indirect impacts on the supply chain. In the considered case study, it became obvious that the selection of the basic metal and non-fabricated metal sector, mining sector, and electricity, gas and water sector have a significant influence on the total environmental and social impact. This clearly shows that activities to reduce the environmental impact should be focused on those sectors. One 
alternative to improve SC environmental impacts may be to look for countries whose production processes are more environmentally friendly. It is also important to notice that social impacts decrease significantly in those supply chain configurations.

Given that when the model selects advanced manufacturing countries, such as the USA, Japan, and Germany, the social impact decreases considerably. One can notice that best SC configurations in terms of overall social impact match up with the ones with minimum environmental impacts. This is in contrast with the economic impact, where the trade-off shows they are less favorable due to higher costs. Although there is risk of additional cost when selecting a better supply chain configuration, decision-makers are assured that they can improve their sustainability profile and consequently can make competitive advantages and long-term profit. 


\section{CHAPTER 6 SUMMARY, CONTRIBUTION, AND FUTURE WORK}

\subsection{Summary}

Past and current research efforts in the development of sustainable supply chains have mainly focused on the economic and environmental dimensions. Addressing social impacts is becoming crucial in the move towards sustainability, so there is the need for an assessment method to measure the impact of the three dimensions of the sustainable supply chain that are grounded in the same data underpinnings which represent current complex economic systems. In this research, we introduce the concept of a sustainable supply chain design that analyzes the sustainable impacts within an extended system boundary. To make this possible, the approach employs data standards that apply to most developed countries and uses the extended MRIO analysis to quantify the indicators for the triple bottom line performance developed at an economic sector level. Moreover, the economic factors were quantified using trading cost, transportation cost, carbon price, and labor cost.

The motivation for this study was to highlight the SC-IO approach as a method for analyzing the impact of three sustainability dimensions simultaneously in order to support supply chain decision making. In general, the model is able to answer the following questions:

- Which countries should be chosen as suppliers for each tier in the supply chain?

- What are the associated economic, environmental and social impacts due to a supply chain configuration? 
- What are the sectors (direct or indirect) contribute the most toward the environemantal and social impacts in the supply chain?

The aim of this research is to provide an overall approach to optimize the supply chain performance of a commodity or industrial sector due to additional demand. To evaluate the performance of such a sustainable system one needs to look at the design issues, as well as both the direct impact and the indirect impact, in a supply chain. The supply chain also needs to be evaluated with respect to economic activities that are beyond company and country borders, thus a strategic decision-making method that addresses this complexity needs to be developed.

This research shows that including different criteria can lead to changes in decision making choices. Moreover, including the indirect impact that may come from outside the supply chain boundary affects decision making. Considering the pressure from the environment, society, and possible new governmental regulations, corporations and industry sectors should change from a focus solely on economic optimization and utilize a multi-objective model like the one introduced in this research that can provide guidance to decision/policymakers in a time when circumstances are changing.

\subsection{Contribution}

The existing research that addresses integration model of the three sustainable dimensions for supply chain design only focus on the number of jobs created as the social indicator and have been limited to the firm level (Alsamawi et al., 2017; Arampantzi and Minis, 2017; Boukherroub et al., 2015; Chen et al., 2014; Mota et al., 2015; Santibañez- 
Aguilar et al., 2014; You et al., 2012a). This research provides supply chain managers with a tool for decision making that is not only based on reducing costs or maximizing profit but also focuses on environmental protection and social responsibility. The research result shows that this approach is both feasible and valuable.

In this research, the mathematical model developed considers a supply chain with a set of predefined station nodes and possible edges connecting each node. With knowledge of the amount of final demand, the three objectives of the model are to minimize the fixed and operational costs, carbon cost, and labor cost. Besides the economic factors, the global environmental impact and social impact are also included in the model. $\mathrm{CO}_{2}$ emissions are used as the indicator of global environmental impact. Meanwhile, the social indicators are vulnerable hours, number of fatal accidents and the number of non-fatal accidents.

The model is unique among existing models in the sustainable supply chain design. It uses the concept of a global supply chain, thus global environmental impact and global social impact, which comes from economic activities at the upstream supply chain become important parameters for decision making. The model is able to optimize economic objectives, as well as minimize negative impacts on the environment and community worldwide, which makes this model unique compared to the existing research.

This model suggests that including the indirect environmental and social impact is a crucial part of the decision making at a strategic level. The proposed GSSC model can be used by decision-makers for designing a supply chain network at a global level. This will enable companies and countries that have not addressed environmental or social issues to increase their operational standards to consider better environment and social performance. 


\subsection{Future Work}

The topic of the integration of sustainability in the global supply chain has great potential for further development and extension. The concept is still open for researchers to explore using different concepts and frameworks. However, the concept of sustainability is complex, thus the integration is not straightforward. Modeling sustainability in the supply chain still needs more conceptual mathematical models to make it applicable. Although the model developed in this research has been carefully developed, some limitations and subsequently some future research opportunities exist. Several possible future extensions are discussed in the following.

1. Incorporate different types of uncertainty, such as demand fluctuation, supply disruption, etc.: The majority of the current research assumes that the demand or supply is fixed. Although uncertainty increases the complexity of the model, it would allow the problem to become closer to reality. The modeling of uncertainty can be addressed in several different ways, such as expanding the concept to dynamic network, robust optimization, stochastic approach, simulation, etc.

2. Work on larger size networks: The more complete the system, the more the results become close to reality. However, this will require using an efficient optimization algorithm and/or decomposition method to pull out data, run the model and analyze the results.

3. Imbalance of environmental and social impact between countries: Extension of the model by considering sharing responsibility due to imbalance environmental and social impact would be a promising field. 
4. Apply the SC-IO model to different supply chains: This would allow for testing if the model can be consistently applied to the various supply chain. In order to do this, data availability will be the most time-consuming process. Thus, work on updating data is important part of continuing research in this field of study.

5. Address the limitation of Input-Output analysis: One area that could be addressed is research on a flexible Input-Output model. A flexible input-output model to accommodate changes would make estimation of the impact of large changes in an area's economy, thus, researchers would not be limited by assumptions that the new spending patterns are the same as past spending patterns. 


\section{Reference}

Acquaye, A., Feng, K., Oppon, E., Salhi, S., Ibn-Mohammed, T., Genovese, A., Hubacek, K., 2017. Measuring the environmental sustainability performance of global supply chains: A multi-regional input-output analysis for carbon, sulphur oxide and water footprints. J. Environ. Manage. 187, 571-585. https://doi.org/10.1016/j.jenvman.2016.10.059

Acquaye, A.A., Wiedmann, T., Feng, K., Crawford, R.H., Barrett, J., Kuylenstierna, J., Duffy, A.P., Koh, S.C.L., McQueen-Mason, S., 2011. Identification of 'Carbon Hot-Spots' and Quantification of GHG Intensities in the Biodiesel Supply Chain Using Hybrid LCA and Structural Path Analysis. Environ. Sci. Technol. 45, 24712478. https://doi.org/10.1021/es103410q

Agbonkhese, S.E., 2010. Measuring environmental and social sustainability in the apparel supply chain. Massachusetts Institute of Technology.

Ahi, P., Searcy, C., 2015. An analysis of metrics used to measure performance in green and sustainable supply chains. J. Clean. Prod. 86, 360-377. https://doi.org/10.1016/j.jclepro.2014.08.005

Ahluwalia, P.K., Nema, A.K., 2007. A Goal Programming Based Multi-Time Step Optimal Material Flow Analysis Model for Integrated Computer Waste Management. J. Environ. Inform. 10, 82-98.

Alsamawi, A., Murray, J., Lenzen, M., Reyes, R.C., 2017. Trade in occupational safety and health: Tracing the embodied human and economic harm in labour along the global supply chain. J. Clean. Prod. 147, 187-196. https://doi.org/10.1016/j.jclepro.2016.12.110

Andrew, R., Peters, G.P., Lennox, J., 2009. Approximation and Regional Aggregation in Multi-Regional Input-Output Analysis for National Carbon Footprint Accounting. Econ. Syst. Res. 21, 311-335. https://doi.org/10.1080/09535310903541751

Arampantzi, C., Minis, I., 2017. A new model for designing sustainable supply chain networks and its application to a global manufacturer. J. Clean. Prod. 156, 276 292. https://doi.org/10.1016/j.jclepro.2017.03.164

Bamufleh, H.S., Ponce-Ortega, J.M., El-Halwagi, M.M., 2013. Multi-objective optimization of process cogeneration systems with economic, environmental, and social tradeoffs. Clean Technol. Environ. Policy 15, 185-197. https://doi.org/10.1007/s10098-012-0497-y

Bassiouny, K., 2007. create sound, efficient, and responsive financial institutions that are environmentally and socially sustainable can help achieve substantial business benefits. Int. Finance Corp. 92.

Benjaafar, S., Li, Y., Daskin, M., 2013. Carbon Footprint and the Management of Supply Chains: Insights From Simple Models. IEEE Trans. Autom. Sci. Eng. 10, 99-116. https://doi.org/10.1109/TASE.2012.2203304 
Benoît, C., Mazijn, B., Andrews, E.S., United Nations Environment Programme, Sustainable Consumption and Production Branch, 2009. Guidelines for social life cycle assessment of products: social and socio-economic LCA guidelines complementing environmental LCA and Life Cycle Costing, contributing to the full assessment of goods and services within the context of sustainable development. United Nations Environment Programme, Paris, France.

Benoit-Norris, C., Cavan, D.A., Norris, G., 2012. Identifying Social Impacts in Product Supply Chains:Overview and Application of the Social Hotspot Database. Sustainability 4, 1946-1965. https://doi.org/10.3390/su4091946

Benoît-Norris, C., Vickery-Niederman, G., Valdivia, S., Franze, J., Traverso, M., Ciroth, A., Mazijn, B., 2011. Introducing the UNEP/SETAC methodological sheets for subcategories of social LCA. Int. J. Life Cycle Assess. 16, 682-690. https://doi.org/10.1007/s11367-011-0301-y

Bojarski, A.D., Laínez, J.M., Espuña, A., Puigjaner, L., 2009. Incorporating environmental impacts and regulations in a holistic supply chains modeling: An LCA approach. Comput. Chem. Eng. 33, 1747-1759. https://doi.org/10.1016/j.compchemeng.2009.04.009

Boukherroub, T., Ruiz, A., Guinet, A., Fondrevelle, J., 2015. An integrated approach for sustainable supply chain planning. Comput. Oper. Res. 54, 180-194. https://doi.org/10.1016/j.cor.2014.09.002

Brandenburg, M., Govindan, K., Sarkis, J., Seuring, S., 2014. Quantitative models for sustainable supply chain management: Developments and directions. Eur. J. Oper. Res., Eco-Efficient Green Supply Chain Management 233, 299-312. https://doi.org/10.1016/j.ejor.2013.09.032

Brent, A., Labuschagne, C., 2006. Social Indicators for Sustainable Project and Technology Life Cycle Management in the Process Industry (13 pp + 4). Int. J. Life Cycle Assess. 11, 3-15. https://doi.org/10.1065/lca2006.01.233

Burchart-Korol, D., 2013. Life cycle assessment of steel production in Poland: a case study. J. Clean. Prod. 54, 235-243. https://doi.org/10.1016/j.jclepro.2013.04.031

Cambero, C., Sowlati, T., 2016. Incorporating social benefits in multi-objective optimization of forest-based bioenergy and biofuel supply chains. Appl. Energy 178, 721-735. https://doi.org/10.1016/j.apenergy.2016.06.079

Cambero, C., Sowlati, T., 2014. Assessment and optimization of forest biomass supply chains from economic, social and environmental perspectives - A review of literature. Renew. Sustain. Energy Rev. 36, 62-73. https://doi.org/10.1016/j.rser.2014.04.041

Carter, C.R., Jennings, M.M., 2002. Logistics Social Responsibility: An Integrative Framework. J. Bus. Logist. 23, 145-180. https://doi.org/10.1002/j.21581592.2002.tb00020.x

Carter, C.R., Rogers, D.S., 2008. A framework of sustainable supply chain management: moving toward new theory. Int. J. Phys. Distrib. Logist. Manag. 38, 360-387. https://doi.org/10.1108/09600030810882816 
Cetinkaya, B., Cuthberston, R., Ewer, G., Klass-Wissing, T., Piotrowicz, W., Tyssen, C., 2011. Sustainable supply chain management. Springer Berlin Heidelberg.

Chaabane, A., Ramudhin, A., Paquet, M., 2012. Design of sustainable supply chains under the emission trading scheme. Int. J. Prod. Econ. 135, 37-49. https://doi.org/10.1016/j.ijpe.2010.10.025

Chen, L., Olhager, J., Tang, O., 2014. Manufacturing facility location and sustainability: A literature review and research agenda. Int. J. Prod. Econ., The Economics of Industrial Production 149, 154-163. https://doi.org/10.1016/j.ijpe.2013.05.013

Crawford, R.H., 2009. Life cycle energy and greenhouse emissions analysis of wind turbines and the effect of size on energy yield. Renew. Sustain. Energy Rev. 13, 2653-2660. https://doi.org/10.1016/j.rser.2009.07.008

Cruz, J.M., Wakolbinger, T., 2008. Multiperiod effects of corporate social responsibility on supply chain networks, transaction costs, emissions, and risk. Int. J. Prod. Econ. 116, 61-74. https://doi.org/10.1016/j.ijpe.2008.07.011

Čuček, L., Klemeš, J.J., Kravanja, Z., 2012a. A Review of Footprint analysis tools for monitoring impacts on sustainability. J. Clean. Prod., Recent Cleaner Production Advances in Process Monitoring and Optimisation 34, 9-20. https://doi.org/10.1016/j.jclepro.2012.02.036

Čuček, L., Varbanov, P.S., Klemeš, J.J., Kravanja, Z., 2012b. Total footprints-based multicriteria optimisation of regional biomass energy supply chains. Energy, Integration and Energy System Engineering, European Symposium on Computer-Aided Process $\quad 2011 \quad$ Engineering 44, 135-145. https://doi.org/10.1016/j.energy.2012.01.040

Dai, J., Blackhurst, J., 2012. A four-phase AHP-QFD approach for supplier assessment: a sustainability perspective. Int. J. Prod. Res. 50, 5474-5490. https://doi.org/10.1080/00207543.2011.639396

Diabat, A., Al-Salem, M., 2015. An integrated supply chain problem with environmental considerations. Int. J. Prod. Econ. 164, 330-338. https://doi.org/10.1016/j.ijpe.2014.12.004

Dietzenbacher, E., Los, B., Stehrer, R., Timmer, M., de Vries, G., 2013. THE CONSTRUCTION OF WORLD INPUT-OUTPUT TABLES IN THE WIOD $\begin{array}{lllll}\text { PROJECT. } & \text { Econ. } & \text { Syst. } & \text { Res. }\end{array}$ https://doi.org/10.1080/09535314.2012.761180

Dixit, M.K., 2017. Embodied energy analysis of building materials: An improved IO-based hybrid method using sectoral disaggregation. Energy 124, 46-58. https://doi.org/10.1016/j.energy.2017.02.047

Dreyer, L., Hauschild, M., Schierbeck, J., 2005. A Framework for Social Life Cycle Impact Assessment (10 pp). Int. J. Life Cycle Assess. 11, 88-97. https://doi.org/10.1065/lca2005.08.223 
Dubey, R., Gunasekaran, A., Childe, S.J., 2015. The design of a responsive sustainable supply chain network under uncertainty. Int. J. Adv. Manuf. Technol. 80, 427-445. https://doi.org/10.1007/s00170-015-6967-8

El-Halwagi, A.M., Rosas, C., Ponce-Ortega, J.M., Jiménez-Gutiérrez, A., Mannan, M.S., El-Halwagi, M.M., 2013. Multiobjective optimization of biorefineries with economic and safety objectives. AIChE J. 59, 2427-2434. https://doi.org/10.1002/aic.14030

Eskandarpour, M., Dejax, P., Miemczyk, J., Péton, O., 2015. Sustainable supply chain network design: An optimization-oriented review. Omega 54, 11-32. https://doi.org/10.1016/j.omega.2015.01.006

Ewing, B.R., Hawkins, T.R., Wiedmann, T.O., Galli, A., Ertug Ercin, A., Weinzettel, J., Steen-Olsen, K., 2012. Integrating ecological and water footprint accounting in a multi-regional input-output framework. Ecol. Indic. 23, 1-8. https://doi.org/10.1016/j.ecolind.2012.02.025

Finkbeiner, M., Inaba, A., Tan, R., Christiansen, K., Klüppel, H.-J., 2006. The New International Standards for Life Cycle Assessment: ISO 14040 and ISO 14044. Int. J. Life Cycle Assess. 11, 80-85. https://doi.org/10.1065/lca2006.02.002

Foran, B., Lenzen, M., Dey, C., Bilek, M., 2005. Integrating sustainable chain management with triple bottom line accounting. Ecol. Econ. 52, 143-157. https://doi.org/10.1016/j.ecolecon.2004.06.024

Genovese, Andrea, Lake, A., Genovese, A., Kumar, N., Koh, S.C.L., Acquaye, A., 2015. An application of hybrid life cycle assessment as a decision support framework for green supply chains. Int. J. Prod. Res. 53, 6495-6521.

Ghosh, A., 1958. Input-Output Approach in an Allocation System. Economica 25, 58-64. https://doi.org/10.2307/2550694

Gimenez, C., Sierra, V., Rodon, J., 2012. Sustainable operations: Their impact on the triple bottom line. Int. J. Prod. Econ., Sustainable Development of Manufacturing and Services 140, 149-159. https://doi.org/10.1016/j.ijpe.2012.01.035

Gladwin, T.N., Kennelly, J.J., Krause, T.-S., 1995. Shifting Paradigms for Sustainable Development: Implications for Management Theory and Research. Acad. Manage. Rev. 20, 874-907. https://doi.org/10.2307/258959

Gopalakrishnan, K., Yusuf, Y.Y., Musa, A., Abubakar, T., Ambursa, H.M., 2012. Sustainable supply chain management: A case study of British Aerospace (BAe) Systems. Int. J. Prod. Econ., Sustainable Development of Manufacturing and Services 140, 193-203. https://doi.org/10.1016/j.ijpe.2012.01.003

Gupta, S., Palsule-Desai, O.D., 2011. Sustainable supply chain management: Review and research opportunities. IIMB Manag. Rev. 23, 234-245. https://doi.org/10.1016/j.iimb.2011.09.002

Haimes, Y.Y., Jiang, P., 2001. Leontief-based model of risk in complex interconnected infrastructures. J. Infrastruct. Syst. 7, 1-12. 
Hämäläinen, P., Leena Saarela, K., Takala, J., 2009. Global trend according to estimated number of occupational accidents and fatal work-related diseases at region and country level. J. Safety Res. 40, 125-139. https://doi.org/10.1016/j.jsr.2008.12.010

Hassini, E., Surti, C., Searcy, C., 2012. A literature review and a case study of sustainable supply chains with a focus on metrics. Int. J. Prod. Econ., Sustainable Development of Manufacturing and Services 140, 69-82. https://doi.org/10.1016/j.ijpe.2012.01.042

Heijungs, R., 1994. A generic method for the identification of options for cleaner products. Ecol. Econ. 10, 69-81. https://doi.org/10.1016/0921-8009(94)90038-8

Hendrickson, C.T., Lave, L.B., Matthews, H.S., 2006. Environmental Life Cycle Assesment of Godds and Services: An Input-Otput Approach, 1st ed. RFF Press, Washington DC.

Hsu, C.-W., Kuo, T.-C., Chen, S.-H., Hu, A.H., 2013. Using DEMATEL to develop a carbon management model of supplier selection in green supply chain management. J. Clean. Prod., Sustainability management beyond corporate boundaries 56, 164-172. https://doi.org/10.1016/j.jclepro.2011.09.012

Hugo, A., Pistikopoulos, E.N., 2005. Environmentally conscious long-range planning and design of supply chain networks. J. Clean. Prod., Recent advances in industrial process optimisationRecent advances in industrial process optimisation 13, 14711491. https://doi.org/10.1016/j.jclepro.2005.04.011

Hutchins, M.J., Sutherland, J.W., 2008. An exploration of measures of social sustainability and their application to supply chain decisions. J. Clean. Prod., Sustainability and Supply Chain Management 16, 1688-1698. https://doi.org/10.1016/j.jclepro.2008.06.001

ILO Office, 2012. National Profile Report on Occupational Safety and Health in China.

Irfani, T.H., 2015. The prevalence of occupational injuries and illnesses in ASEAN: comparison between Indonesia and Thailand. Public Health Indones. 1.

Jennings, P.D., Zandbergen, P.A., 1995. Ecologically Sustainable Organizations: An Institutional Approach. Acad. Manage. Rev. 20, 1015-1052. https://doi.org/10.2307/258964

Jiang, X., Chen, Q., Yang, C., 2016. A comparison of producer, consumer and shared responsibility based on a new inter-country input-output table capturing trade heterogeneity. Singap. Econ. Rev. 63, 295-311. https://doi.org/10.1142/S0217590817400124

Kannegiesser, M., Günther, H. -o, 2014. Sustainable development of global supply chains-part 1: sustainability optimization framework. Flex. Serv. Manuf. J. 26, 24-47. http://dx.doi.org/10.1007/s10696-013-9176-5

Ke, W., Sha, J., Yan, J., Zhang, G., Wu, R., 2016. A Multi-Objective Input-Output Linear Model for Water Supply, Economic Growth and Environmental Planning in Resource-Based Cities. Sustainability 8, 160. https://doi.org/10.3390/su8020160 
Klassen, R.D., Vereecke, A., 2012. Social issues in supply chains: Capabilities link responsibility, risk (opportunity), and performance. Int. J. Prod. Econ., Sustainable Development of Manufacturing and Services 140, 103-115. https://doi.org/10.1016/j.ijpe.2012.01.021

Lechón, Y., de la Rúa, C., Rodríguez, I., Caldés, N., 2019. Socioeconomic implications of biofuels deployment through an Input-Output approach. A case study in Uruguay. Renew. Sustain. Energy Rev. 104, 178-191. https://doi.org/10.1016/j.rser.2019.01.029

Lenzen, M., Moran, D., Kanemoto, K., Geschke, A., 2013. Building Eora: A Global MultiRegion Input-Output Database at High Country and Sector Resolution. Econ. Syst. Res. 25, 20-49. https://doi.org/10.1080/09535314.2013.769938

Lenzen, M., Murray, J., Sack, F., Wiedmann, T., 2007. Shared producer and consumer responsibility - Theory and practice. Ecol. Econ. 61, 27-42. https://doi.org/10.1016/j.ecolecon.2006.05.018

Leontief, W., 1949. Structural Matrices of National Economies. Econometrica 17, 273282. https://doi.org/10.2307/1907314

Löschel, A., Rexhäuser, S., Schymura, M., 2013. Trade and the environment: An application of the WIOD database. Chin. J. Popul. Resour. Environ. 11, 51-61. https://doi.org/10.1080/10042857.2013.777213

Lüthje, B., 2014. Labour relations, production regimes and labour conflicts in the Chinese automotive industry. Int. Labour Rev. 153, 535-560. https://doi.org/10.1111/j.1564-913X.2014.00215.x

Maloni, M.J., Brown, M.E., 2006. Corporate Social Responsibility in the Supply Chain: An Application in the Food Industry. J. Bus. Ethics 68, 35-52. https://doi.org/10.1007/s10551-006-9038-0

Matos, S., Hall, J., 2007. Integrating sustainable development in the supply chain: The case of life cycle assessment in oil and gas and agricultural biotechnology. J. Oper. Manag., Supply Chain Management in a Sustainable EnvironmentSpecial Issue on Frontiers of Empirical Supply Chain Research 25, 1083-1102. https://doi.org/10.1016/j.jom.2007.01.013

Matthews, H.S., Hendrickson, C.T., Weber, C.L., 2008. The Importance of Carbon Footprint Estimation Boundaries. Environ. Sci. Technol. 42, 5839-5842. https://doi.org/10.1021/es703112w

Miller, R.E., Blair, P.D., 2009. Input-Output Analysis Foundation and Extension, 2nd ed. Cambridge University Press.

Mota, B., Gomes, M.I., Carvalho, A., Barbosa-Povoa, A.P., 2015. Towards supply chain sustainability: economic, environmental and social design and planning. J. Clean. Prod., Decision-support models and tools for helping to make real progress to more sustainable societies 105, 14-27. https://doi.org/10.1016/j.jclepro.2014.07.052 
Mueller, M., dos Santos, V.G., Seuring, S., 2009. The Contribution of Environmental and Social Standards Towards Ensuring Legitimacy in Supply Chain Governance. J. Bus. Ethics 89, 509-523. https://doi.org/10.1007/s10551-008-0013-9

National Bureau of Statistics of China [WWW Document], 2008. URL http://www.stats.gov.cn/english/ (accessed 11.22.19).

Onat, N., Kucukvar, M., Tatari, O., 2014. Towards Life Cycle Sustainability Assessment of Alternative Passenger Vehicles. Sustainability 6, 9305-9342. https://doi.org/10.3390/su6129305

Onat, N.C., Kucukvar, M., Tatari, O., 2014. Integrating triple bottom line input-output analysis into life cycle sustainability assessment framework: the case for US buildings. Int. J. Life Cycle Assess. 19, 1488-1505. https://doi.org/10.1007/s11367-014-0753-y

Osmani, A., Zhang, J., 2017. Multi-period stochastic optimization of a sustainable multifeedstock second generation bioethanol supply chain - A logistic case study in Midwestern United States. Land Use Policy 61, 420-450. https://doi.org/10.1016/j.landusepol.2016.10.028

Pagell, M., Wu, Z., 2009. Building a More Complete Theory of Sustainable Supply Chain Management Using Case Studies of 10 Exemplars. J. Supply Chain Manag. 45, 3756. https://doi.org/10.1111/j.1745-493X.2009.03162.x

Papong, S., Itsubo, N., Ono, Y., Malakul, P., 2016a. Development of Social Intensity Database Using Asian International Input-Output Table for Social Life Cycle Assessment. Sustainability 8, 1135. https://doi.org/10.3390/su8111135

Papong, S., Itsubo, N., Ono, Y., Malakul, P., 2016b. Development of Social Intensity Database Using Asian International Input-Output Table for Social Life Cycle Assessment. Sustainability 8, 1135. https://doi.org/10.3390/su8111135

Pishvaee, M.S., Razmi, J., Torabi, S.A., 2012. Robust possibilistic programming for socially responsible supply chain network design: A new approach. Fuzzy Sets Syst., Theme: Operational Research 206, 1-20. https://doi.org/10.1016/j.fss.2012.04.010

Puri, P., Compston, P., Pantano, V., 2009. Life cycle assessment of Australian automotive door skins. Int. J. Life Cycle Assess. 14, 420-428. https://doi.org/10.1007/s11367009-0103-7

Resosudarmo, B.P., Thorbecke, E., 1996. The impact of environmental policies on household incomes for different socio-economic classes: The case of air pollutants in Indonesia. Ecol. Econ. 17, 83-94. https://doi.org/10.1016/0921-8009(95)001131

Rodríguez-Serrano, I., Caldés, N., Rúa, C. de la, Lechón, Y., 2017. Assessing the three sustainability pillars through the Framework for Integrated Sustainability Assessment (FISA): Case study of a Solar Thermal Electricity project in Mexico. J. Clean. Prod. 149, 1127-1143. https://doi.org/10.1016/j.jclepro.2017.02.179 
Rowley, H.V., Lundie, S., Peters, G.M., 2009. A hybrid life cycle assessment model for comparison with conventional methodologies in Australia. Int. J. Life Cycle Assess. 14, 508-516. https://doi.org/10.1007/s11367-009-0093-5

Santamaría, M., Azqueta, D., 2015. Promoting biofuels use in Spain: A cost-benefit analysis. Renew. Sustain. Energy Rev. 50, 1415-1424. https://doi.org/10.1016/j.rser.2015.04.192

Santibañez-Aguilar, J.E., González-Campos, J.B., Ponce-Ortega, J.M., Serna-González, M., El-Halwagi, M.M., 2014. Optimal planning and site selection for distributed multiproduct biorefineries involving economic, environmental and social objectives. J. Clean. Prod. 65, 270-294. https://doi.org/10.1016/j.jclepro.2013.08.004

Sardy, M., Fetscherin, M., 2009. A Double Diamond Comparison of the Automotive Industry of China, India, and South Korea 15.

Savitz, A.W., Weber, K., 2006. The Triple Bottom Line: How Today's Best-run Companies Are Achieving Economic, Social, and Environmental Success-and How You Can Too [WWW Document]. URL http://eds.a.ebscohost.com/ehost/ebookviewer/ebook/ZTkwMHh3d19fMTY4MT U4X19BTg2? sid=60b2e6fa-f149-4310-b1d9af5fc9f81602@sessionmgr4001\&vid=0\&format=EB\&rid=1 (accessed 2.1.16).

Seuring, S., 2013. A review of modeling approaches for sustainable supply chain management. Decis. Support Syst., Rapid Modeling for Sustainability 54, 15131520. https://doi.org/10.1016/j.dss.2012.05.053

Seuring, S., 2004. Industrial ecology, life cycles, supply chains: differences and interrelations. Bus. Strategy Environ. 13, 306.

Seuring, S., Müller, M., 2008a. From a literature review to a conceptual framework for sustainable supply chain management. J. Clean. Prod., Sustainability and Supply Chain Management 16, 1699-1710. https://doi.org/10.1016/j.jclepro.2008.04.020

Seuring, S., Müller, M., 2008b. From a literature review to a conceptual framework for sustainable supply chain management. J. Clean. Prod., Sustainability and Supply Chain Management 16, 1699-1710. https://doi.org/10.1016/j.jclepro.2008.04.020

Seuring, S., Müller, M., 2008c. Core issues in sustainable supply chain management - a Delphi study. Bus. Strategy Environ. 17, 455-466. https://doi.org/10.1002/bse.607

Simas, M., Golsteijn, L., Huijbregts, M., Wood, R., Hertwich, E., 2014. The "Bad Labor" Footprint: Quantifying the Social Impacts of Globalization. Sustainability 6, 75147540. https://doi.org/10.3390/su6117514

Suh, S., 2004. Functions, commodities and environmental impacts in an ecologicaleconomic model. Ecol. Econ. 48, 451-467. https://doi.org/10.1016/j.ecolecon.2003.10.013

Suh, S., Huppes, G., 2002. Missing inventory estimation tool using extended input-output analysis. Int. J. Life Cycle Assess. 7, 134-140. https://doi.org/10.1007/BF02994047 
Sundarakani, B., de Souza, R., Goh, M., Wagner, S.M., Manikandan, S., 2010. Modeling carbon footprints across the supply chain. Int. J. Prod. Econ. 128, 43-50. https://doi.org/10.1016/j.ijpe.2010.01.018

Székely, F., Knirsch, M., 2005. Responsible Leadership and Corporate Social Responsibility:: Metrics for Sustainable Performance. Eur. Manag. J. 23, 628-647. https://doi.org/10.1016/j.emj.2005.10.009

Timmer, M.P., Dietzenbacher, E., Los, B., Stehrer, R., de Vries, G.J., 2015. An Illustrated User Guide to the World Input-Output Database: the Case of Global Automotive Production. Rev. Int. Econ. 23, 575-605. https://doi.org/10.1111/roie.12178

Tukker, A., de Koning, A., Wood, R., Hawkins, T., Lutter, S., Acosta, J., Rueda Cantuche, J.M., Bouwmeester, M., Oosterhaven, J., Drosdowski, T., Kuenen, J., 2013. Exiopol - Development and Illustrative Analyses of a Detailed Global Mr Ee Sut/Iot. Econ. $\quad$ Syst. $\quad$ Res. 25, 50-70. https://doi.org/10.1080/09535314.2012.761952

Vachon, S., Mao, Z., 2008. Linking supply chain strength to sustainable development: a country-level analysis. J. Clean. Prod., Sustainability and Supply Chain Management 16, 1552-1560. https://doi.org/10.1016/j.jclepro.2008.04.012

Vidal, C.J., Goetschalckx, M., 1997. Strategic production-distribution models: A critical review with emphasis on global supply chain models. Eur. J. Oper. Res. 98, 1-18. https://doi.org/10.1016/S0377-2217(97)80080-X

Wang, F., Lai, X., Shi, N., 2011. A multi-objective optimization for green supply chain network design. Decis. Support Syst., Multiple Criteria Decision Making and Decision Support Systems 51, 262-269. https://doi.org/10.1016/j.dss.2010.11.020

Weidema, B.P., 2016. The social footprint-a practical approach to comprehensive and consistent social LCA. Int. J. Life Cycle Assess. 1-10. https://doi.org/10.1007/s11367-016-1172-z

Wiedmann, T.O., Suh, S., Feng, K., Lenzen, M., Acquaye, A., Scott, K., Barrett, J.R., 2011. Application of Hybrid Life Cycle Approaches to Emerging Energy Technologies The Case of Wind Power in the UK. Environ. Sci. Technol. 45, 5900-5907. https://doi.org/10.1021/es2007287

Wood, R., Stadler, K., Bulavskaya, T., Lutter, S., Giljum, S., de Koning, A., Kuenen, J., Schütz, H., Acosta-Fernández, J., Usubiaga, A., Simas, M., Ivanova, O., Weinzettel, J., Schmidt, J.H., Merciai, S., Tukker, A., 2014. Global Sustainability Accounting-Developing EXIOBASE for Multi-Regional Footprint Analysis. Sustainability 7, 138-163. https://doi.org/10.3390/su7010138

Woolley, T.D., 2010. Sustainable supply chains: Multicriteria decision-making and policy analysis for the environment.

Xiao, Y., Norris, C.B., Lenzen, M., Norris, G., Murray, J., 2017. How Social Footprints of Nations Can Assist in Achieving the Sustainable Development Goals. Ecol. Econ. 135, 55-65. https://doi.org/10.1016/j.ecolecon.2016.12.003 
Yawar, S.A., Seuring, S., 2015. Management of Social Issues in Supply Chains: A Literature Review Exploring Social Issues, Actions and Performance Outcomes. J. Bus. Ethics 1-23. https://doi.org/10.1007/s10551-015-2719-9

You, F., Tao, L., Graziano, D.J., Snyder, S.W., 2012a. Optimal design of sustainable cellulosic biofuel supply chains: Multiobjective optimization coupled with life cycle assessment and input-output analysis. AIChE J. 58, 1157-1180. https://doi.org/10.1002/aic.12637

You, F., Tao, L., Graziano, D.J., Snyder, S.W., 2012b. Optimal design of sustainable cellulosic biofuel supply chains: Multiobjective optimization coupled with life cycle assessment and input-output analysis. AIChE J. 58, 1157-1180. https://doi.org/10.1002/aic.12637

Yue, D., Pandya, S., You, F., 2016. Integrating Hybrid Life Cycle Assessment with Multiobjective Optimization: A Modeling Framework. Environ. Sci. Technol. 50, 1501-1509. https://doi.org/10.1021/acs.est.5b04279

Zaks, D.P.M., Barford, C.C., Ramankutty, N., Foley, J.A., 2009. Producer and consumer responsibility for greenhouse gas emissions from agricultural production-a perspective from the Brazilian Amazon. Environ. Res. Lett. 4, 044010. https://doi.org/10.1088/1748-9326/4/4/044010

Zhixiang Chen, Andresen, S., 2014. A Multiobjective Optimization Model of ProductionSourcing for Sustainable Supply Chain with Consideration of Social, Environmental, and Economic Factors. Math. Probl. Eng. 1-11. https://doi.org/10.1155/2014/616107

Zimmer, K., Fröhling, M., Breun, P., Schultmann, F., 2017a. Assessing social risks of global supply chains: A quantitative analytical approach and its application to supplier selection in the German automotive industry. J. Clean. Prod. 149, 96-109. https://doi.org/10.1016/j.jclepro.2017.02.041

Zimmer, K., Fröhling, M., Breun, P., Schultmann, F., 2017b. Assessing social risks of global supply chains: A quantitative analytical approach and its application to supplier selection in the German automotive industry. J. Clean. Prod. 149, 96-109. https://doi.org/10.1016/j.jclepro.2017.02.041 


\section{VITA}

Dian Trihastuti holds a bachelor's degree in Industrial Engineering at the Surabaya University, Indonesia. She worked for the Ministry of Education and Culture, serving as a lecturer in the Engineering School. In 2008 she received her master's degree in Engineering (Integrated Logistics Management) from the Royal Melbourne Institute of Technology University, Australia. She is back to work in academia for several years and decided to get her Doctoral degree. Dian has received her Ph.D. in Industrial and Manufacturing Systems Engineering at the University of Missouri.

She has worked for several years as a researcher at the Center for Excellence in Logistics and Distribution (CELDi) and a teaching fellow at MU. Her research interests include Sustainability, Supply Chain and Logistics Management and Risk Analysis. Within this interdisciplinary study, she has integrated the areas of Operations Research, Data Analytics, and Production Economics. Upon completion of her doctoral degree, Dian returns to Indonesia to work as a professor and researcher. 